\title{
Clinical Impact of Bloodstream Infections - Characterization, Risk factors and Outcome
}

MDR healthcare antibiotic-resistance risk-factors incidence treatment sweden HCA-BSI multidrug-resistance blood-culture infections UPEC CA-BSI strategies $\sim^{\text {strategies }}$ surveillance enterobacteriaceae sT131 UPEC DDDsescherichia-coli o risk-factors community-acquired outcome prehospital-care $\$$ Tblood-culture bloodstream outcome surveillance bacteraemiaantibiotic enterobacteriaceae limpact septic-shock

SOFA classification community-acquired impactinfections society ${ }^{m}$ guidelines gram-negative MDR clinica multiresistance 5

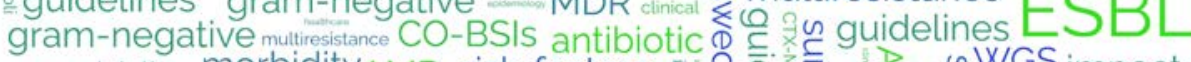

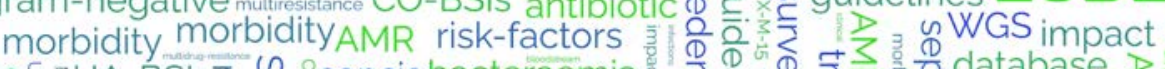

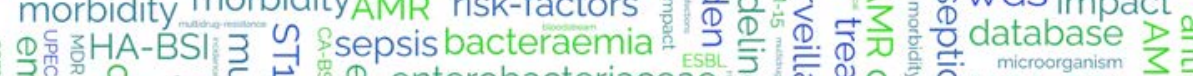

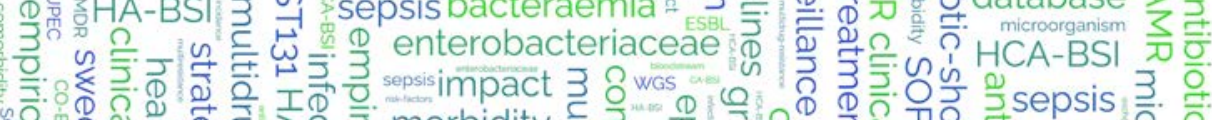
กกิ

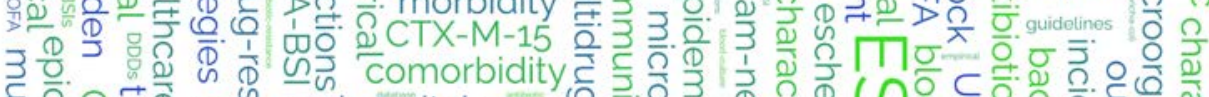

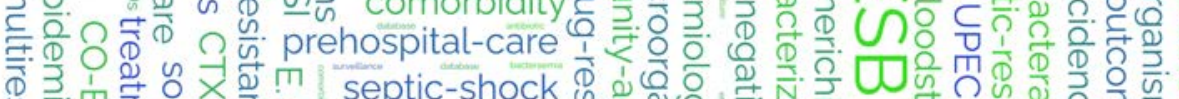

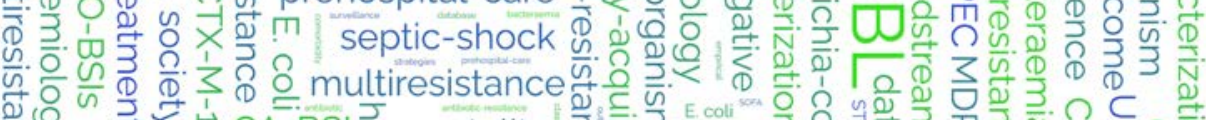

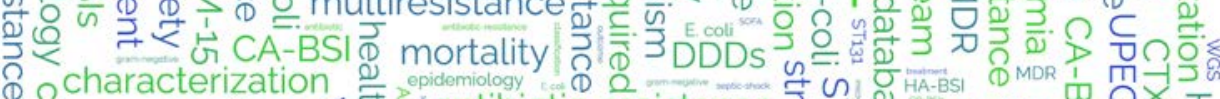

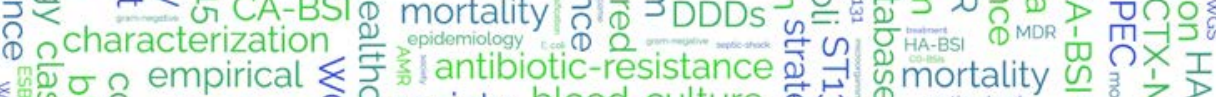

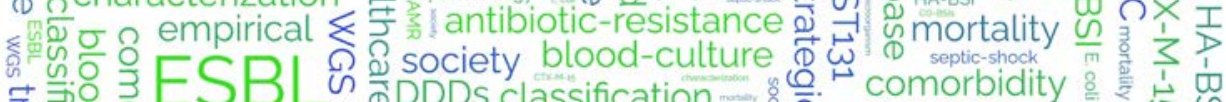

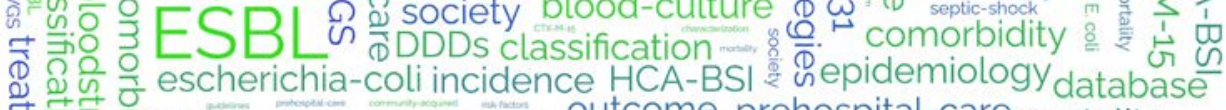

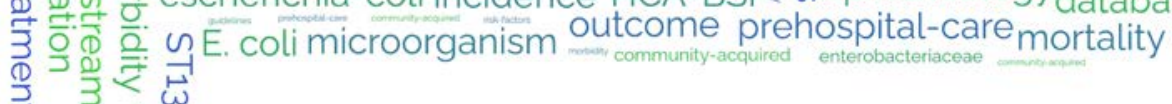

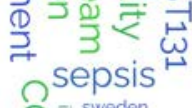

Martin Holmbom 

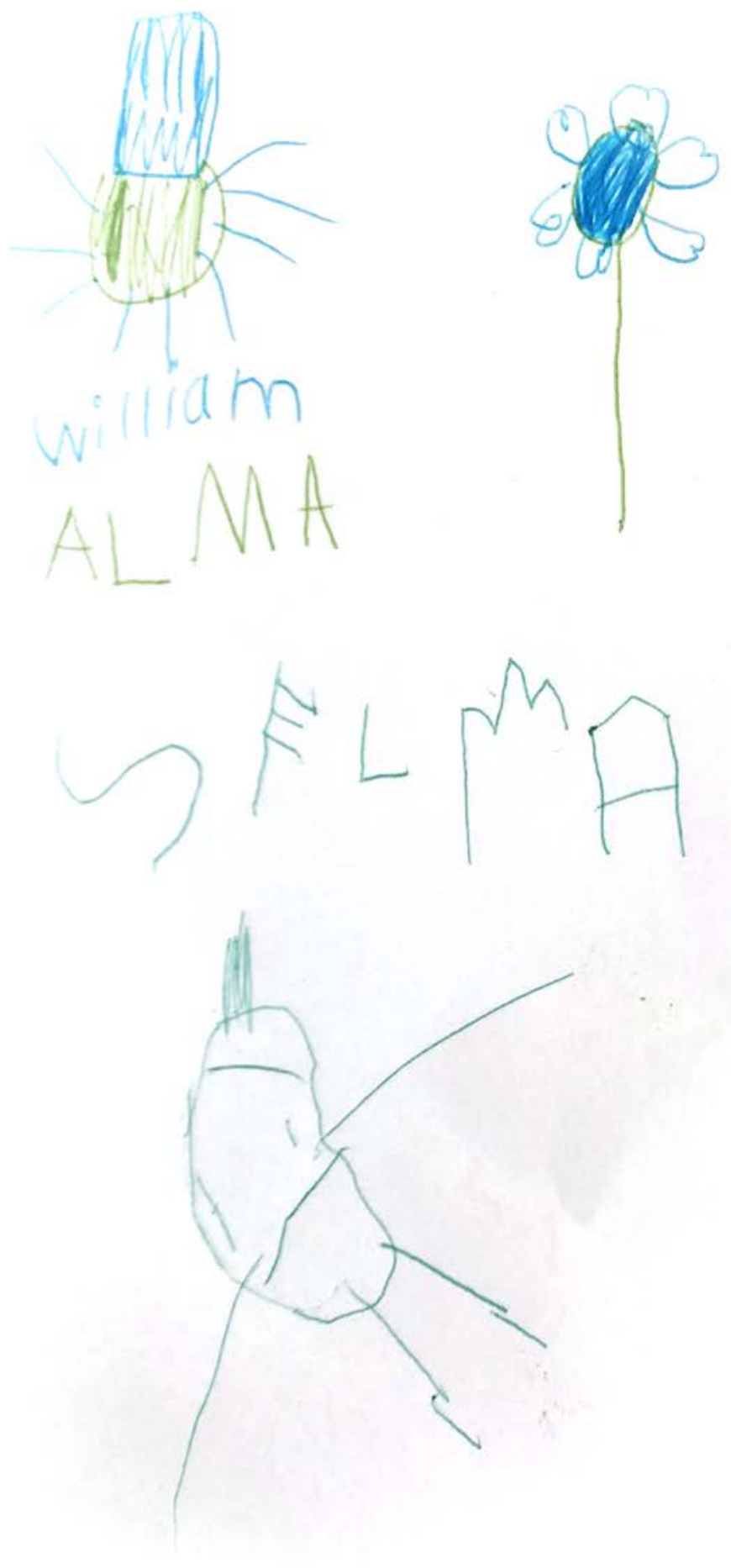
From the DEPARTMENT OF UROLOGY

Linköping University Medical Dissertation No. 1794

\title{
Clinical Impact of Bloodstream Infections - Characterization, Risk factors and Outcome
}

\author{
Martin Holmbom
}

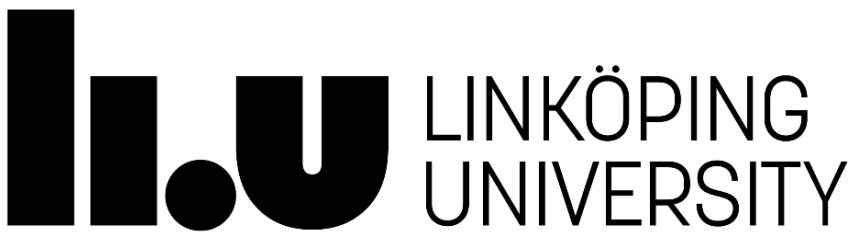

Linköping 2021 
(oc) $\mathbf{E Y}$ This work is licensed under a Creative Commons Attribution 4.0 International License.

https://creativecommons.org/licenses/by/4.0/

(C) Martin Holmbom 2021

All previously published papers were reproduced with permission of the publisher.

Printed by LiU-tryck, Linköping 2021.

ISBN: 978-91-7929-054-2

ISSN: 0345-0082 


\section{Clinical Impact of Bloodstream Infections - Characterization, Risk factors and Outcome}

\section{THESIS FOR DOCTORAL DEGREE (Ph.D.)}

By

\section{Martin Holmbom}

Principal Supervisor:

Håkan Hanberger, MD, Professor

Department of Biomedical and Clinical

Sciences, Faculty of Medicine and Health

Sciences, Linköping University

Division of Infectious Diseases

Co-supervisors:

Christian G. Giske, MD, Professor

Department of Laboratory Medicine,

Karolinska Institute, Stockholm

Division of Clinical Microbiology

Lennart E Nilsson, Professor

Department of Biomedical and Clinical

Sciences, Linköping University, Linköping

Division of Clinical Microbiology

Mats Fredrikson, Statistician, Associate

Professor

Department of Biomedical and Clinical

Sciences and Forum Östergötland, Faculty of

Medicine and Health Sciences

Åse Östholm Balkhed, MD, PhD

Department of Biomedical and Clinical

Sciences, Faculty of Medicine and Health

Sciences, Linköping University

Division of Infectious Diseases
Opponent:

Ralph Peeker, MD, Professor

Department of Urology, Institute of Clinical

Sciences at the Sahlgrenska Academy,

University of Gothenburg, Göteborg

\section{Examination Board:}

Åsa Nilsdotter, MD, Associate Professor

Department of Biomedical and Clinical

Sciences, Faculty of Medicine and Health

Sciences, Linköping University

Division of Infectious Diseases

Malin Inghammar, MD, Associate Professor Department of Clinical Sciences Lund Division of Infectious Medicine, Skåne University Hospital, Lund University, Lund

Olle Stendahl, Professor emeritus Department of Biomedical and Clinical Sciences, Linköping University

Division of Inflammation and Infection

This Thesis will be defended in public at Linköping University, December 17, 2021, beginning 13:00. 



\section{"If you want to walk fast, walk alone. But if you want to walk far, walk together"}

"I can do all this through him who give me strength" Philippians 4:13

To my lovely family Matilda, William, Alma, Selma 



\section{LIST OF SCIENTIFIC PAPERS}

I. Holmbom, M., Christian G. Giske, Mats Fredrikson, Åse Östholm Balkhed, Carina Claesson, Lennart E. Nilsson, Mikael Hoffmann, Håkan Hanberger., 14Year Survey in a Swedish County Reveals a Pronounced Increase in Bloodstream Infections (BSI). Comorbidity - An Independent Risk Factor for Both BSI and Mortality. PLoS One, 2016. 11(11): p. e0166527.

II. Holmbom, M., Vidar Möller, Lennart E. Nilsson, Christian G. Giske, Mamun-Ur Rashid, Mats Fredrikson, Anita Hällgren, Håkan Hanberger, Åse Östholm Balkhed., Low incidence of antibiotic-resistant bacteria in south-east Sweden: An epidemiologic study on 9268 cases of bloodstream infection. PLoS One, 2020. 15(3): p. e0230501.

III. Holmbom, M., Maria Andersson, Sören Berg, Dan Eklund, Pernilla Sobczynski, Daniel Wilhelms, Anna Moberg, Mats Fredrikson, Åse Östholm Balkhed, Håkan Hanberger., Prehospital delay is an important risk factor for mortality in community-onset bloodstream infection (CO-BSI): A matched case-control study. BMJ Open, 2021. e052582.

IV. Holmbom, M., Vidar Möller, Loa Kristinsdottir, Maud Nilsson, Mamun-Ur Rashid, Mats Fredrikson, Björn Berglund, Åse Östholm Balkhed., Low risk of mortality due to extended-spectrum $\beta$-lactamase-producing uropathogenic Escherichia coli in community-onset bloodstream infections: a ten-year casecontrol study in a Swedish county. (submitted manuscript) 


\section{OTHER RELATED PUBLICATIONS}

1. Håkan Hanberger, Massimo Antonelli, Martin Holmbom, Jeffrey Lipman, Peter Pickkers, Marc Leone, Jordi Rello, Yasser Sakr, Sten Walther, Philippe Vanhems och Jean-Louis Vincent. Infections, antibiotic treatment and mortality in patients admitted to ICUs in countries considered to have high levels of antibiotic resistance compared to those with low levels. BMC Infectious Diseases, 2014 Sep 22; 14:513.

2. Maria Andersson, Åse Östholm Balkhed, Mats Fredrikson, Martin Holmbom, Anita Hällgren, Sören Berg, Håkan Hanberger. Delay of appropriate antibiotic treatment is associated with high mortality in patients with community-onset sepsis in a Swedish setting. European Journal of Clinical Microbiology and Infectious Diseases, 2019 Jul;38(7):1223-1234.

3. Vidar Möller, Åse Östholm Balkhed, Dag Berild, Mats Fredrikson, Magnus Gottfredsson, Martin Holmbom, Asko Jarvinen, Mar Kristjansson, Ulf Rydell, Ute Wolff Sonksen, Hans Joern Kolmos, Håkan Hanberger. Antibiotic resistance among major pathogens compared to hospital treatment guidelines and antibiotic use in Nordic hospitals 2010-2018. Infectious Diseases, 2021 Aug;53(8):607-618. 


\section{POPULAR SCIENCE SUMMARY}

Bloodstream infection (blood poisoning) and antibiotic resistance are increasing worldwide, and already cause the loss of millions of human lives each year. According to the World Health Organisation (WHO), bloodstream infections (BSIs) represent $20 \%$ of global mortality on a par with cardiac infarct, stroke, and major trauma. BSI may occur when bacteria from a focus of infection gain access to the circulation (bacteraemia). BSIs are usually divided into two subclasses: community- and hospital-onset infections, since disease this involves different patient groups, types of bacteria, and reasons for infection. Compared to other countries, Sweden has been fortunate in having a relatively low death rate from BSI and low antibiotic resistance. However, as our lifestyle changes, the age of the population increases with more disease as a result, and as the healthcare system responds, death from infection and antibiotic resistance are on the increase. It is important that we recognise "warning symptoms" if we are to manage BSIs correctly and initiate effective treatment. It is difficult to design individualised empirical treatment, so it is very important to be aware of risk factors for BSI and local resistance patterns, and to have an effective management programme.

Bacterial resistance to antibiotics is an increasing problem, especially in bowel organisms that can cause infections that are very difficult to treat. In short, antibiotic resistance arises as a result of evolutionary processes where bacteria protect themselves by developing resistance genes. These genes can be exchanged between similar organisms or transmitted to others that in turn cause resistant infection. The use of antibiotics leads to an evolutionary/selection process leading to resistance in bacteria, both normal and pathogenic, enabling resistant organisms to survive, thrive, and go on to cause infection. Antibiotic resistance is a threat to global health.

This thesis aims to increase our awareness of a large group of patients who suffer bloodstream infection. BSIs are increasing globally and the death toll is high. Antibiotic resistance is an increasing threat to the health of the population and we are inundated by alarming reports of resistance getting out of control. What is the situation in Sweden, and can we identify risk factors for BSI and mortality?

In Study I, our aim was to study the incidence and mortality of BSI in Östergötland. To be able to do this, a large patient population stretching over several years was required. The study design was thus population-based in the form of an observational cohort study where all 
blood culture results from 2000 to 2013 were analysed, and evaluated from clinical data. A total of 109,938 results were analysed resulting in 11,480 BSIs.

We saw that the incidence of BSI increased by $64 \%$ (mostly community-onset BSIs). We also saw that mortality increased by $45 \%$. These results illustrate the importance of nationwide cooperation to combat the increasing problem of BSI and its mortality, and the establishment of a nationwide BSI register.

The aim of Study II was to assess resistance development in Östergötland and its relationship to mortality. A total of 9,587 microorganisms were analysed between 2008 and 2016. We observed an increase in quinolone resistance (3.7-7.7\%) and cephalosporin resistance (2.5$5.2 \%$ ) amongst Enterobacteriaceae. We then looked at BSIs caused by multiresistant bacteria showing a total of 245 cases (2.6\%); an increase of $300 \%$. Despite this, we did not see an increased mortality in this group.

There are several possible explanations for the increase in BSI mortality of which antibiotic resistance is a predominant factor globally. We were unable to show this in our study, even so mortality is increasing and is currently at a high level. In Study III we therefore analysed risk factors associated with death during a community-acquired BSI, focusing on preliminary prehospital and hospital management. In a retrospective case-control study on 195 deaths matched 1:1 regarding age, gender and microorganism, with 195 survivors (controls). Results showed that many patients had contacted the primary healthcare system because of infection before they became severely ill, and that the strongest affectable risk factor for death was delay ( $>24 \mathrm{~h}$ ) between primary healthcare contact and admission to hospital. This shows the need for increased awareness in society and amongst the medical profession of those patients at risk and symptoms that should raise the alarm, leading to more rapid treatment.

In Studies I and II we found an increase in both BSIs and mortality, we also saw an increase in antibiotic resistance and multiresistant bacteria, mainly ESBL-producing E. coli. On the other hand, we did not see any coupling between multiresistance and mortality in this Swedish population. E. coli is a gram-negative bacteria that causes most BSIs. Since E. coli is predominantly a urine tract pathogen, Study IV aimed to study BSIs caused by ESBLproducing $E$. coli originating from the urinary tract (UPEC). We studied the prevalence of $E$. coli clones, resistance genes and risk factors, as well as any signs of increased mortality from ESBL-producing E. coli compared to sensitive E. coli. Our main finding was a surprisingly low mortality from ESBL-producing E. coli (3\%). Most patients in the ESBL-producing $E$. 
coli group received inadequate antibiotic treatment for at least $48 \mathrm{~h}$, but we did not see any sign of increased mortality or risk for serious sepsis with circulatory failure in this group. This finding is interesting and opens up for new studies on virulence factors and immunological factors that govern the immune response to BSI.

The implementation of cost-effective monitoring systems including clinical microbiological epidemiology and early identification of BSI, together with information campaigns aimed at the public as well as healthcare personnel regarding patients at risk and symptoms giving cause for alarm, should lead to a radical reduction in morbidity and mortality from BSI. This requires new diagnostic tools to individualise both antibiotic treatment and targeted management based on microorganism virulence factors. Modernisation of the medical journal system with algorithms aimed at early identification of risk patients and automated suggestions for empirical antibiotic treatment based on antibiotic resistance seen in previous cultures and local resistance patterns, would certainly improve management. Furthermore, new immunological tests showing the type of immunological reaction to a serious BSI will lead to individualised immunotherapy that, together with antibiotic treatment, will further improve patient care in this important group. 



\section{CONTENTS}

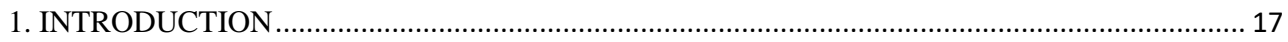

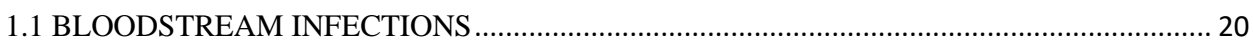

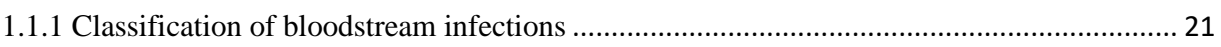

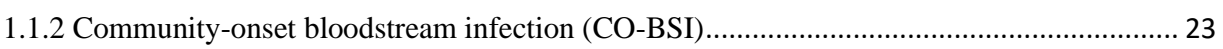

1.1.3 Community-acquired versus healthcare-associated bloodstream infection.......................... 23

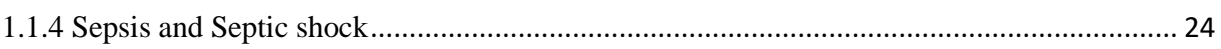

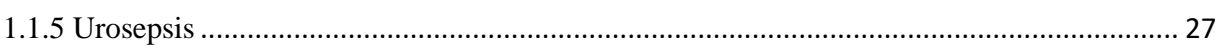

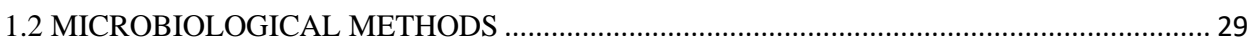

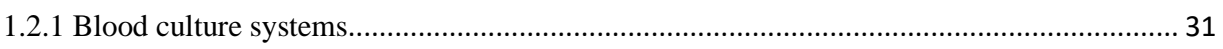

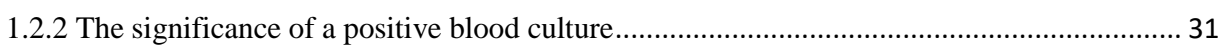

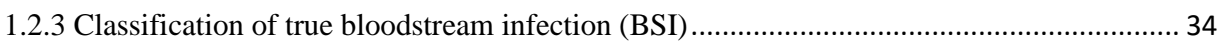

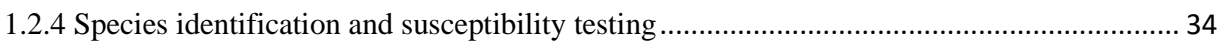

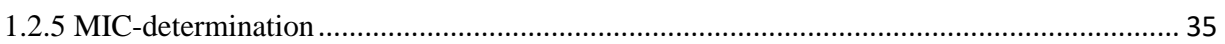

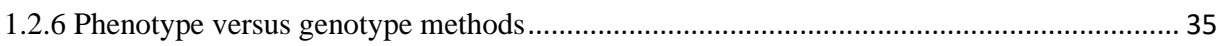

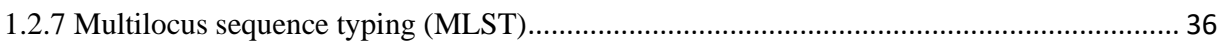

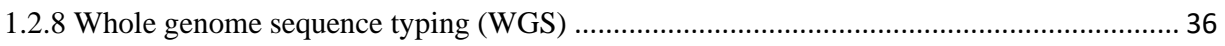

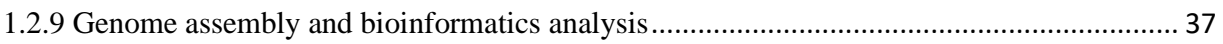

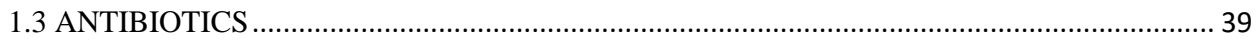

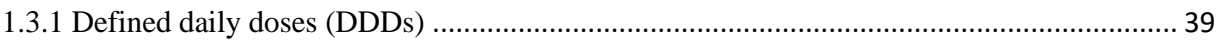

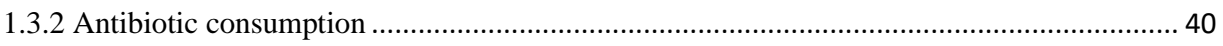

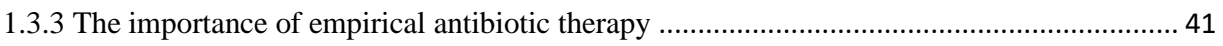

1.4 ANTIMICROBIAL RESISTANCE AND RESISTANCE MECHANISMS............................. 43

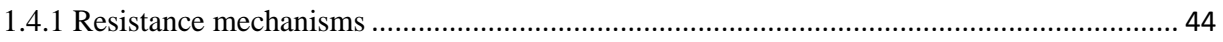

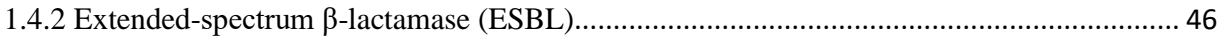

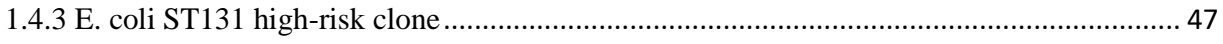

1.4.4 Increase in community-onset bloodstream infections with resistant bacteria ....................... 47

1.4.5 Risk factors for bloodstream infection with ESBL-producing pathogen ............................. 48

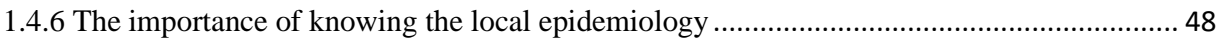

1.5 THE BURDEN OF COMMUNITY-ONSET BLOODSTREAM INFECTION .......................... 49

1.5.1 Overall burden at the population level ............................................................................... 49

1.6 RISK FACTORS FOR BLOODSTREAM INFECTION AND SEPSIS ................................. 51

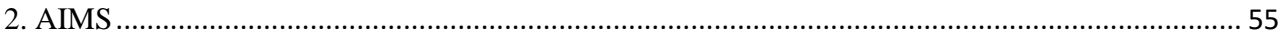

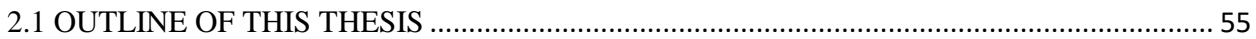




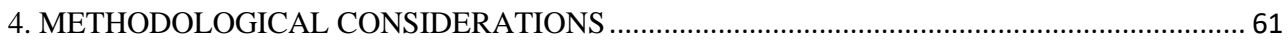

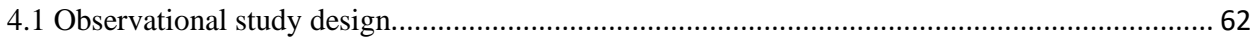

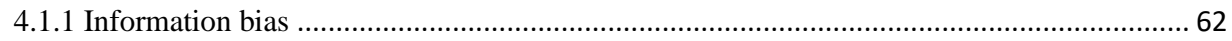

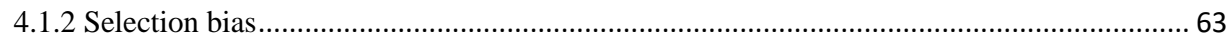

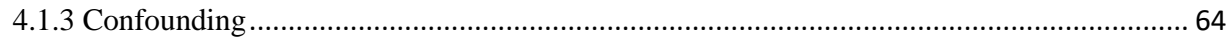

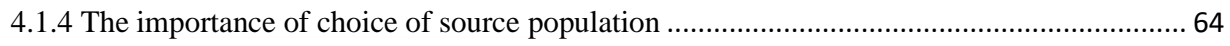

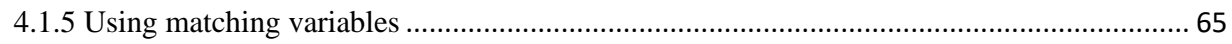

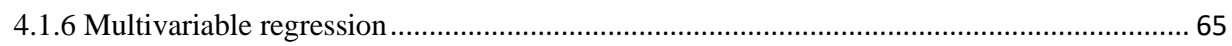

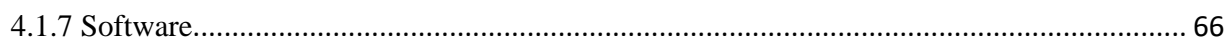

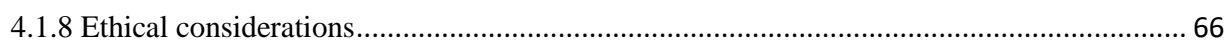

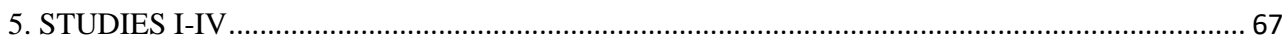

5.1 STUDY I "14-Year Survey in a Swedish County Reveals a Pronounced Increase in Bloodstream Infections (BSI). Comorbidity - An Independent Risk Factor for Both BSI and Mortality”.............. 67

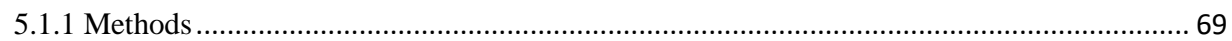

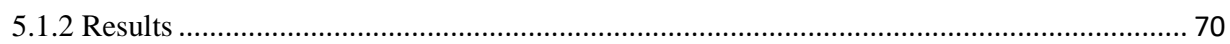

5.2 STUDY II "Low incidence of antibiotic-resistant bacteria in south-east Sweden: An

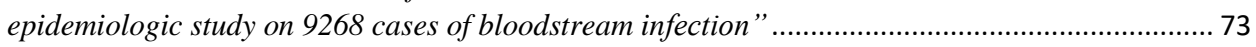

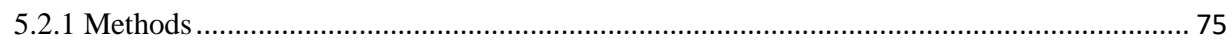

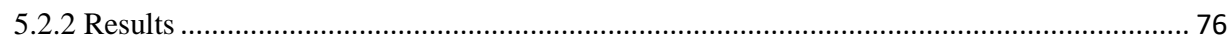

5.3 STUDY III "Prehospital delay is an important risk factor for mortality in community-acquired

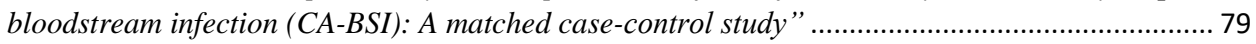

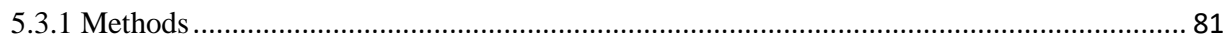

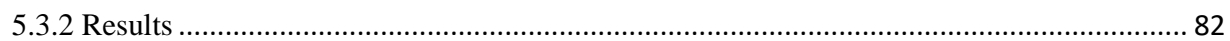

5.4 STUDY IV "Risk factors and outcome due to extended-spectrum $\beta$-lactamase-producing uropathogenic Escherichia coli in community-onset bloodstream infections: a ten-year cohort study

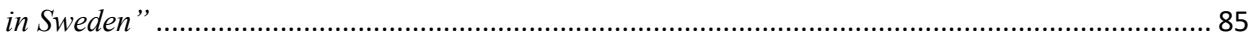

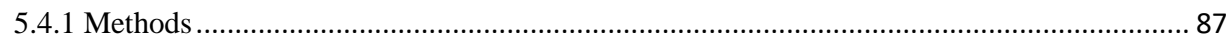

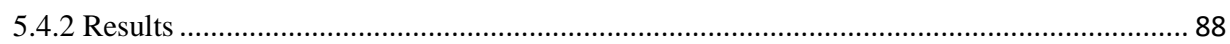

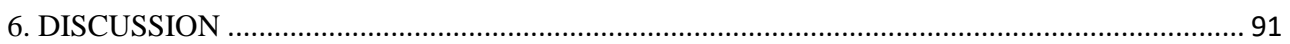

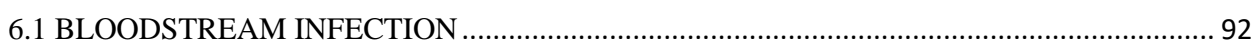

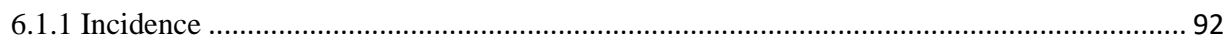

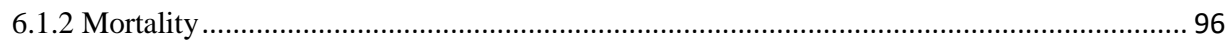

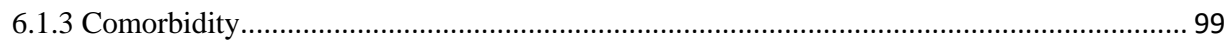

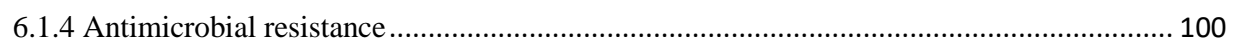

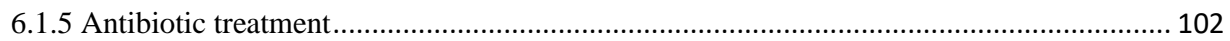

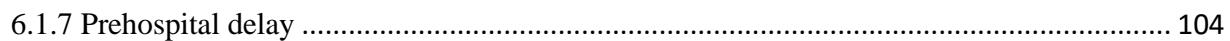


6.1.8 Risk factors for ESBL UPEC-associated mortality and development of ESBL.................. 106

6.1.9 Predicting infection with ESBL-producing E. coli on admission to hospital...................... 108

6.1.10 Empirical antibiotic therapy and differences in outcome to ESBL-producing E. coli ..... 109

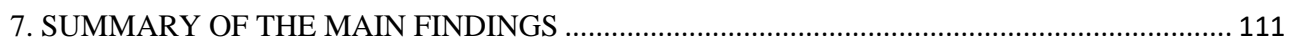

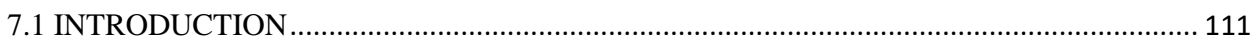

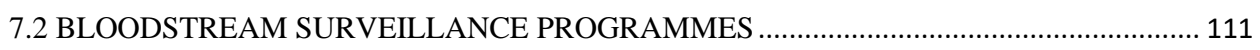

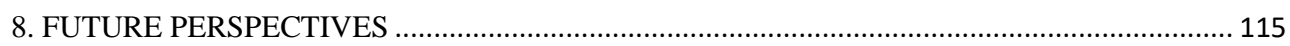

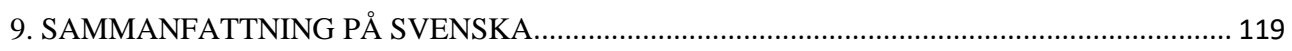

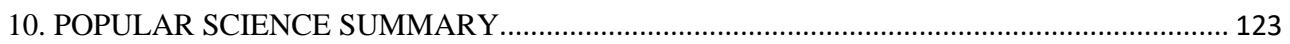

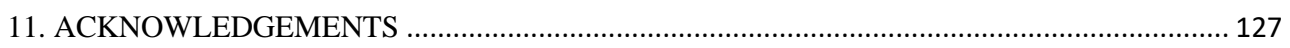

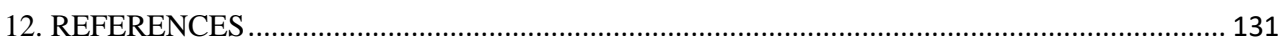




\section{LIST OF ABBREVIATIONS}

\begin{tabular}{|c|c|}
\hline AMR & Antimicrobial resistance \\
\hline BSI & Bloodstream infection \\
\hline EPE & ESBL-producing Enterobacterales \\
\hline ESBL & Extended spectrum $\beta$-lactamase \\
\hline ESBL-EC & ESBL-producing E. coli \\
\hline ICU & Intensive care unit \\
\hline MALDI-TOF MS & $\begin{array}{l}\text { Matrix-assisted laser desorption/ionisation time-of-flight mass } \\
\text { spectrometry }\end{array}$ \\
\hline MDR & Multidrug-resistant \\
\hline MLST & Multilocus sequence typing \\
\hline NGS & Next-generation sequencing \\
\hline OR & Odds ratio \\
\hline $\mathrm{RR}$ & Risk ratio \\
\hline SIR & $\begin{array}{l}\text { Susceptibility categories. EUCAST definition: } \mathrm{S}=\text { Susceptible, } \mathrm{I}= \\
\text { Susceptible, increased exposure, } \mathrm{R}=\text { Resistant }\end{array}$ \\
\hline SOFA & Sequential (sepsis-related) organ failure assessment score \\
\hline qSOFA & Quick SOFA \\
\hline ST & Sequential type (MLST-derived) \\
\hline UPEC & Uropathogenic E. coli \\
\hline UTI & Urinary tract infection \\
\hline WBCs & White blood cells \\
\hline WGS & Whole genome sequencing \\
\hline $3 \mathrm{GC}$ & Third generation cephalosporin \\
\hline $3 \mathrm{GCR}$ & $\begin{array}{l}\text { Third generation cephalosporin-resistant (mainly caused by } \\
\text { ESBLproduction) }\end{array}$ \\
\hline
\end{tabular}




\section{INTRODUCTION}

Bloodstream infection (BSI) is a major healthcare problem associated with an illness burden similar to well-known diseases such as acute stroke, major trauma, and myocardial infarction. While stroke and heart disease have gained much attention and financial support from both private and public organisations, severe bacterial infection, including community-onset BSI (CO-BSI), has remained in their shadow. In view of the magnitude of the burden of disease associated with CO-BSI it is important to monitor and document this problem and bring it to the attention of a greater public, thus increasing awareness and financial support for efforts aimed to reduce the disease and its threat to public health. Data from epidemiological studies of infectious diseases are very important to investigate the burden of disease and the aetiologies of BSI in a defined region. In general, the most common microorganisms in bloodstream infection are Staphylococcus aureus and Escherichia coli. Shedding light on the importance of these microorganisms at a nationwide level provides the basis upon which governing authorities can prioritise future preventative strategies such as immunisation, optimal management of chronic medical disease, and environmental hygiene. The importance of CO-BSI is likely to increase in coming years due to rising rates of healthcare-associated bloodstream infections related to the increasing management of older patients with frailty in the community. The increase in incidence of CO-BSI demonstrates the need for ongoing surveillance to improve clinical healthcare and prevent further emergence of antibiotic resistance. Otherwise, this will have a major impact on the epidemiology, morbidity, and mortality of bloodstream infection in our increasingly global society.

The best way to study the epidemiology of infectious disease is through population-based studies, since all cases occurring within a defined geographical area are usually registered and data are complete. In cohort studies, it may be difficult to identify an appropriate exposed cohort of bloodstream infection and comparison group, which can result in a significant risk for bias. For example, patients selected from a given clinic/hospital ward or from an emergency department, among those admitted to a hospital, or arbitrary selection of hospitals, may run a significant risk of selection bias [1,2]. Another advantage of population-based studies is that the population at risk is definable, so incidence rates may be determined and standardised against a reference population. Data may then be used to establish the burden of a disease and to compare regions and periods in time [3]. 
Increase in the incidence of BSIs, antibiotic resistance (AMR), and multidrug-resistant (MDR) microorganism present a serious threat to global public health [4-10]. Antibiotic resistance amongst both Gram-positive and Gram-negative bacteria is increasing at an alarming rate [11, 12]. Causes include increased use of antibiotics in human and veterinary medicine, antibiotics in food production, environmental contamination with antibiotics, larger healthcare facilities, and globalisation [13, 14].

The unnecessary and inappropriate use of antibiotics has led to a major public health problem and must be stopped if we are to control increasing antibiotic resistance in the community and in hospitals. Antibiotic consumption may be monitored using ATC/DDD per 1,000 inhabitants/day, which provides a rough estimate of the incidence of persons in a population being treated with antibiotics $[15,16]$. Antibiotic use in hospital may also be expressed as DDDs per 100-bed days and DDDs per 1,000 patient/hospital-days [16]. Human and veterinary use of antibiotics, and antibiotic resistance in Sweden are low compared to other European countries $[17,18]$. MRSA causes only $1.2 \%$ of all Staphylococcus aureus BSIs in Sweden and has remained so for the last 20 years. Escherichia coli resistant to third generation cephalosporins (3GC), particularly cefotaxime and ceftazidime has increased over the past year and the prevalence of Enterobacteriaceae resistant to fluroquinolones is probably the most common antibiotic resistance problem in Sweden, followed by Enterobacteriaceae resistant to $3 \mathrm{GC}$ usually producing extended-spectrum beta-lactamase (ESBL) [15, 19-21]. It is thus important to study the local epidemiology of BSI, antibiotic resistance, antibiotic consumption, and risk factors to establish the burden of a disease and to develop surveillance strategies.

The most common pathogen causing BSI is Escherichia coli, often secondary to a primary urinary tract infection (UTI). It has been estimated about 150 million people worldwide develop a UTI each year, with associated high morbidity and medical costs. Most UTIs are caused by uropathogenic Escherichia coli (UPEC), many leading to BSI and urosepsis associated with high morbidity and mortality in the community [22, 23]. The increase in Enterobacteriaceae and Escherichia coli resistant to 3GC, usually producing extendedspectrum beta-lactamase (ESBL), is the main cause of increased mortality.

Studies have shown differences between countries and regions regarding patterns of BSI and antibiotic resistance [14]. It is important to implement local surveillance programmes in hospitals to optimise infection control and follow regional trends. Local guidelines on the treatment of BSIs must be produced and implemented [14, 24-28] to meet the changing 
epidemiology of bacteraemia due to ageing populations, shifts in healthcare, and advances in medicine such as the increased use of intravascular devices, immunosuppressive therapy, and invasive procedures. The aim of this thesis is to increase our understanding of the incidence of BSI, antibiotic resistance, risk factors for BSI, and associated mortality, thereby increasing our chance of designing effective treatment programs for BSI, sepsis, and septic shock.

Optimal treatment of infection, including antibiotic therapy, depends on good cooperation between the ward and the microbiology department, and the existence of a system to continually monitor specified species and their resistance patterns. Through cost-effective surveillance strategies, we can reduce morbidity and mortality due to BSI. 


\subsection{BLOODSTREAM INFECTIONS}

Bloodstream infection is a major threat to public health worldwide, and an important cause of morbidity and mortality $[4,29,30]$. Patients with BSI present with a broad spectrum of signs and symptoms ranging from fever of unknown origin to life-threatening systemic inflammation with organ failure, sepsis and septic shock. There are several diagnostic criteria and nomenclatures for BSI that lead to inconsistency of definitions applied in studies, especially those on community-onset disease. No gold standard definition has been widely accepted, but bloodstream infection is generally considered present when a microorganism associated with infectious disease is cultured from the bloodstream of patients with suspected infection. Any definition of bloodstream infection must include a laboratory-confirmed positive blood culture for one or more microorganisms. An isolated positive blood culture, on the other hand, does not necessarily signify an ongoing BSI.

A positive blood culture may result from three different situations: 1) contamination, 2) in the absence of a clinical infection, or 3 ) in the presence of a clinical infection. Contamination defined as an organism isolated from blood culture that entered during specimen obtaining or processing and were not actually circulating in the patient's bloodstream. It can arise from inadequate sterile technique when obtaining the blood sample or when processing the blood for culture. Bacteraemia and fungaemia are defined as the presence of viable bacteria or fungi in the blood, and blood cultures are classed as positive when contamination has been excluded. For microorganisms typically belonging to the skin (that often cause contamination of blood cultures), the definition of bacteraemia or BSI is more complex. Though the terms bloodstream infection (BSI) and bacteraemia are frequently used synonymously, there are two important differences: 1) BSI is a wider concept in that both bacterial and fungal aetiologies are included; and 2) BSI implies that the positive blood culture is associated with clinical features of infection. Most cases of bacteraemia are associated with an infection, but transient bacteraemia does occur after manipulations of non-sterile body surfaces/sites (e.g., upper and lower gastrointestinal tract, upper respiratory tract), without associated infection [31-41]. Infections of the bloodstream usually originate from an infection located in some part of the body such as the urogenital tract, respiratory system, skin and soft tissue, or the gastrointestinal tract. Depending on the adequacy of the patient's immune response, serious infection can lead to sepsis. Despite intense research, the pathophysiology of sepsis remains complex and obscure. 


\subsubsection{Classification of bloodstream infections}

BSIs are traditionally divided into community-acquired (CA) and nosocomial infections [42]. Increase in outpatient alternatives to inpatient care, changes in population demographics, and globalisation have radically altered the epidemiology of CO-BSI. Furthermore, antibioticresistant organisms, particularly methicillin-resistant Staphylococcus aureus (MRSA) and extended spectrum beta-lactamase-producing (ESBL) Enterobacteriaceae, have emerged as important causes of CO-BSI. Hospital-acquired (HA) and healthcare-associated (HCA) BSIs are also on the rise. These infections lead to prolonged hospital stay, increased healthcare costs, and treatment failure with increased mortality [43-46]. Several BSI definitions may be found in clinical studies; this causes confusion and makes comparisons difficult or even impossible and interobserver variation (the amount observers vary from one another when reporting on the same material) in application of these definitions make it very difficult to objectively state the true source of infecting isolates. This major problem causes confusion [47] and does not help our understanding of microbiological resistance patterns and what empirical antibiotic treatment should be recommended in local guidelines. It is important not to use hospital-onset (HO), HA, CO, CA and HCA synonymously, nor bacteraemia and sepsis, because microbial aetiology, empirical antibiotic treatment, and outcome all differ [4850]. Another important challenge is the dramatic shift in healthcare delivery in recent years, with complex medical treatments such as home haemodialysis and parenteral antibiotics now given in the community setting. As a result, community-onset infections may, by definition, in fact be hospital associated. 
Figure 1. Classification of bloodstream infections (BSI)

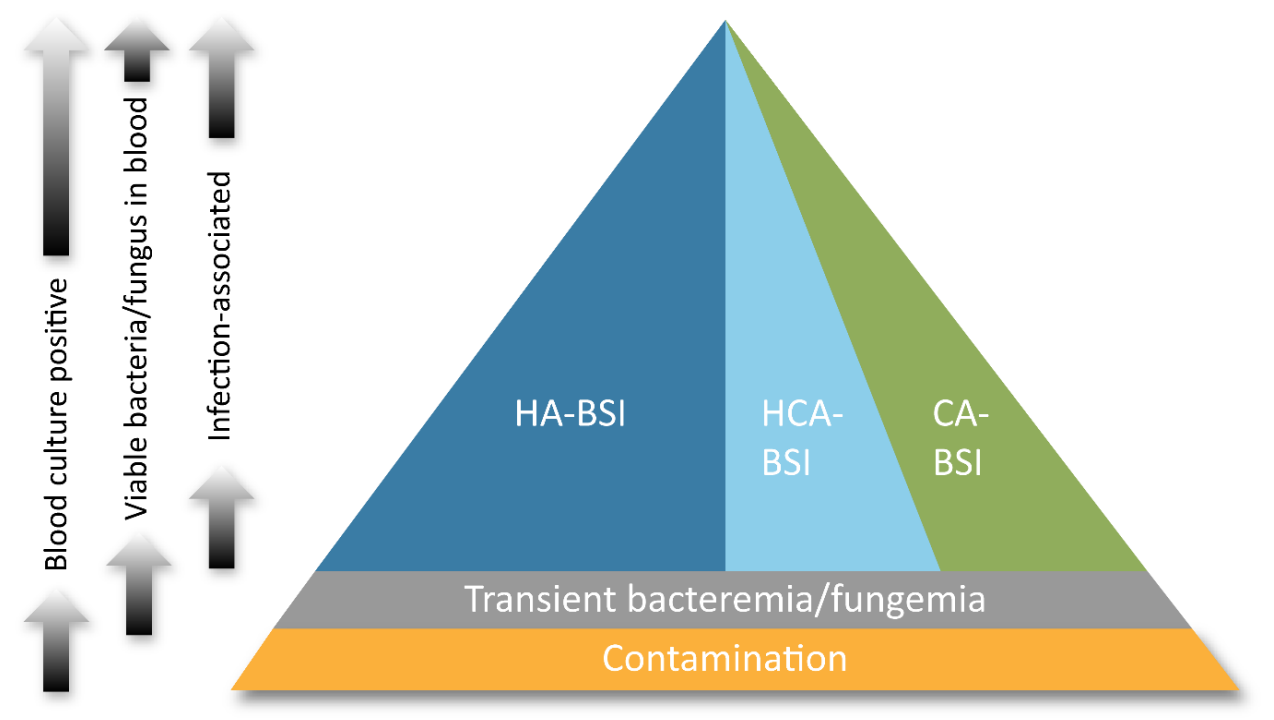

Fig 1. Diagnostic pyramid from positive blood culture in hospital-onset (HO) or community-onset (CO): The triangular area indicates all positive blood culture. First level (represent contamination), second level (transient bacteraemialfungemia) or third level ("true" BSI). BSIs are further classified into hospital-acquired (HA-BSI), Health care associated (HCA) and community-acquired (CA). Adapted and modified from AMS journals, Clinical Microbiology Reviews. Laupland et al [51].

Attempts have been made to address discrepancies in the traditional definitions $[52,53]$. The classification of infections into hospital-acquired (HA) or community-onset $(\mathrm{CO})$ provides a convenient watershed. Community-onset infection is now defined as one occurring in the outpatient setting or first identified (cultures drawn) within 2 days $(<48 \mathrm{~h})$ after hospital admission. Hospital-acquired is defined as an infection where a positive culture is first identified 2 or more days ( $\geq 48 \mathrm{~h})$ after hospital admission or within 2 days $(<48 \mathrm{~h})$ after hospital discharge [52]. Specialised care outside the hospital has increased, and the definition of community-onset BSI has been further subclassified into healthcare-associated (HCA) i.e., patients with ongoing or significant prior healthcare contact, and community-acquired (CA) i.e., all others $[30,49]$. 


\subsubsection{Community-onset bloodstream infection (CO-BSI)}

Population-based studies conducted in "high income countries" have reported communityonset BSI incidence rates of approximately $100-150$ per 100,000 population per year, with higher rates observed in recent years [54-59]. Despite extensive research into BSI, the burden of community-onset BSI on society remains due to inconsistent use of terminology, definitions, and reliance on hospital-based studies that are highly subject to potential bias. A greater understanding of the epidemiology and microbiology of CO-BSI is necessary. Only then, can we assess its impact on community health and thereby develop intervention strategies. Unlike hospital-acquired/nosocomial infections where widely accepted definitions exist and patients are, by definition, restricted to the hospital setting, assessment of CO-BSI is methodologically more challenging and complex. Research on CO-BSI must therefore include the following: 1. how CO-BSI should be detected and assessed; 2 . the roles played by different organisms; 3) study designs with minimal bias; 4) the use of definitions that are concise, unambiguous and clinically relevant; and 5) subclassification of CO-BSI into community-acquired (CA) and healthcare-associated (HCA).

\subsubsection{Community-acquired versus healthcare-associated bloodstream infection}

Morin and Hadler first came up with the subclassification of CO-BSI into two categories: recently hospitalised patients (healthcare-associated BSI) and patients not recently admitted (community-associated BSI) [52]. Friedman et al later proposed that CO-BSI be subclassified as healthcare-associated and community-acquired infection, and these have subsequently been widely accepted [49]. Their definition of healthcare-associated CO-BSI includes at least one of the following: a) patient recently hospitalised; b) patient recently received specialised medical care at home; c) patient recently attended a hospital-based clinic or haemodialysis unit; and d) patient is a nursing home resident. Patients not having any these criteria are deemed community-acquired BSI. In Östergötland we cannot with certainty classify the cohort as CA-BSI according to the criteria above because of care received in the community where data were unavailable. Several investigations that have attempted to validate the criteria for healthcare-associated, community-acquired, community-onset, and hospital-acquired BSIs [49, 50, 60-64]. Study cohorts and definitions have varied to some degree over the years, but healthcare-associated bloodstream infections are more likely in older patients with 
comorbidities, have a different spectrum of pathogens; higher rates of "Staphylococcus aureus and Pseudomonas aeruginosa and lower rates of Streptococcus pneumoniae and Escherichia coli", have higher antibiotic resistance rates, and higher morbidity compared to communityacquired bloodstream infections [49, 51]. Healthcare-associated and hospital-acquired BSIs are easily definable using objective criteria and are thus readily applicable in surveillance systems [65]. It is not that easy to set up electronic surveillance system for community-onset or community-acquired BSI, since not all patients are admitted to hospital and therefore subject to selection bias. [51].

\subsubsection{Sepsis and Septic shock}

The overall incidence of sepsis worldwide is 31.5 million cases per year, of which 5.3 million die. Urinary tract infection has been identified as the source of sepsis in 10-30\% of cases, with high morbidity and mortality [66-68]. In 2016, sepsis was redefined (Sepsis-3) and described as a dysregulated host response to infection that leads to life-threatening organ dysfunction, characterised by a 2-point increase or more in the Sequential Organ Failure Assessment (SOFA) score [68]. SOFA-score grades the level of organ failure based on clinical interventions and a set of laboratory variables.

The Sepsis-3 definition attempts to standardise the nomenclature and discourage conflation and misapplication of terminologies. The new definitions read:

"Sepsis is defined as life-threatening organ dysfunction caused by a dysregulated host response to infection".

"Septic shock is a subset of sepsis in which underlying circulatory and cellular/metabolic abnormalities are profound enough to substantially increase mortality”. 
Figure 2. The Third International Consensus Definitions for Sepsis and Septic Shock (Sepsis3)

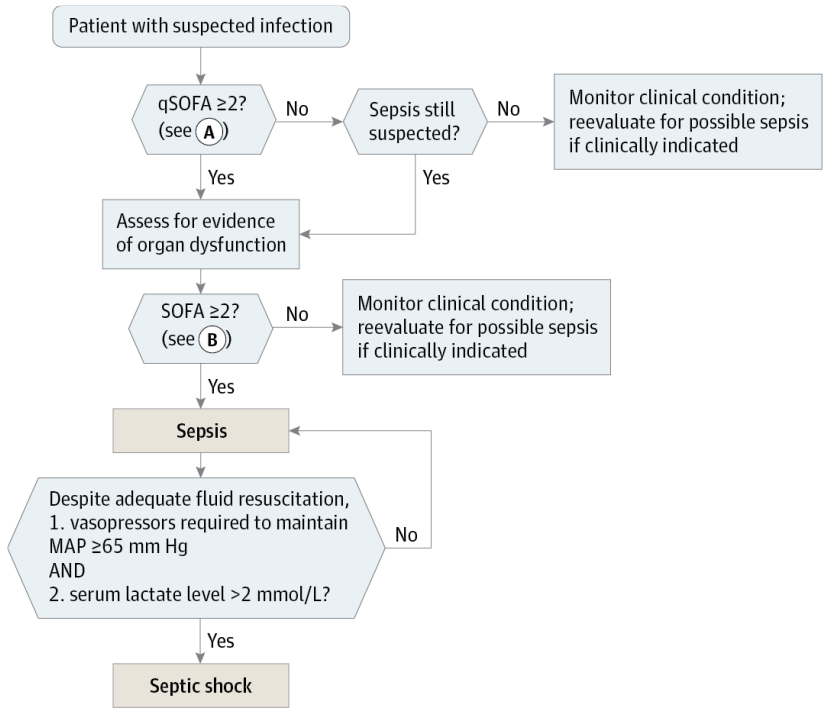

A qSOFA Variables
Respiratory rate
Mental status
Systolic blood pressure
B. SOFA Variables
$\mathrm{PaO}_{2} / \mathrm{FiO}_{2}$ ratio
$\mathrm{Glasgow}$ Coma Scale score $^{\text {Mean arterial pressure }}$
Administration of vasopressors
with type and dose rate of infusion
Serum creatinine or urine output
Bilirubin
Platelet count

Fig 2. Criteria also include the Sequential (sepsis-related) Organ Failure Assessment (SOFA) score where sepsis implies suspected or document infection and an acute increase of 2 or more SOFA points or a qSOFA (quick SOFA) of 2 or more points. Septic shock implies sepsis that requires vasopressor therapy to maintain a MAP $\geq 65 \mathrm{mmHg}$ and lactate $>2 \mathrm{mmol} / \mathrm{L}$ after adequate hydration. Baseline SOFA-score should be assumed to be zero unless the patient is known to have pre-existing (acute or chronic) organ dysfunction before the onset of infection (reprinted with permission). [69].

Despite these sepsis criteria, it is a challenge to make an accurate diagnosis and to verify the presence of infection and occurrence of organ dysfunction secondary to the immune response (dysregulated host response), due to the lack of rapid and reliable sepsis tests.

The following is a brief summary of the inflammatory system:

The inflammatory system has developed to combat pathogenic bacteria and foreign material that has made its way into the body. Inflammation occurs locally and systemically, the latter giving rise to sepsis and septic shock if it gets out of control.

The pro-inflammatory phase begins with the release of endotoxins, or exotoxins that stimulate macrophages to produce interleukin-1 (IL-1) and tumour necrosis factor- $\alpha$ (TNF- $\alpha$ ) that initiate the coagulation-, fibrinolytic-, kallikrein/kinin-, and complement systems. This in turn leads to general activation of neutrophilic granulocytes that adhere to the endothelium of 
blood vessels in many organs causing increased permeability. In more serious cases, the fibrinolytic system is inactivated leading to an increased risk for thrombosis.

To prevent the damaging effects of inflammation, the reaction is downregulated by the antiinflammatory system via e.g., receptor antagonists. Anti-inflammatory agents such as cortisone and several cytokines are also released. Treg (regulatory T-cells) are not affected which leads to immunosuppression.

In some individuals, however, activation of the pro-inflammatory system is so great that activation of the delayed anti-inflammatory response is unable to slow down the process. The degree of activation is not only the result of the type of pathogen, its virulence, the focus of infection, or number of organisms (bacterial load), but also patient-specific factors (genetic predisposition, medication, comorbidity, and age). The degree of inflammation also depends on the presence of infection and/or trauma.

In septic shock, bradykinin, prostaglandin, TNF, platelet activating factor (PAF), and nitric oxide etc. are released and lead to vasodilatation of both arteries and veins. This, together with micro thrombosis and tissue oedema, leads to a fall in both oxygen delivery and consumption. On top of this, hypovolaemia due to increased vessel permeability, vasodilatation, and dehydration develop causing poor tissue perfusion. Cellular hypoxia leads to anaerobic metabolism and anabolic acidosis due to high lactate levels. The combination of severe inflammation and tissue hypoxia leads to organ failure and finally MODS (Multiple Organ Dysfunction Syndrome).

Hyperdynamic circulation and high cardiac output with low peripheral resistance develop early on in sepsis. If hypovolaemia is not corrected, or if the patient's heart is unable to cope with the stress, the hyperdynamic phase goes over to a hypodynamic situation where the sympathetic system is activated. In this stage there is a great risk that the situation develops into irreversible shock, and 50\% dying of septic shock have a picture of treatment-refractory shock. Others die within a month of multiple organ failure and, in many cases, disseminated intravascular coagulation (DIC) with consumption of coagulation factors and their inhibitors, often resulting in spontaneous haemorrhage $[70,71]$.

These factors cause dysregulation of the immune response leading to organ failure, septic shock, and mortality. If the patient survives, continued dysregulation of the immune response and immunosuppression can lead to secondary infection and increased morbidity and mortality in the long run. Our understanding of immune dysregulation is hampered by the fact 
that there is pronounced heterogenicity in the host response of patients, thus complicating our ability to develop immunotherapy treatment for sepsis.

In a recent study, leukocytes from blood in patients with sepsis admitted to the ICU were analysed. Genome-wide analysis of gene expression in the leukocytes was performed [72], and based on the transcription-profiles, 4 endotypes with different expression of genes involved in adaptive and innate immune functions were identified. These 4 profiles were associated with differences in the proportion of patients with sepsis, septic shock and associated mortality.

Sepsis is a life-threatening organ dysfunction with an uncontrolled immunologically complex condition characterised by a dysregulated immune response followed by immunosuppression, which in some patients leads to sepsis, septic shock, and death. No specific treatment modality or drugs with high efficacy are available for sepsis. Furthermore, since dysregulation and immune expression vary between individuals, individualised treatment forms and related diagnostic tests will be necessary if we are to succeed in conquering sepsis with novel immunomodulatory treatments. Survival from bloodstream infection depends not only on the host immune response but also on the virulence of the infecting microbe and the adequacy of antimicrobial treatment provided.

\subsubsection{Urosepsis}

Bacteraemia associated with infection but is not synonymous with sepsis. A common example is urosepsis, which is often used synonymously with febrile urinary tract infection (UTI) [73]. Urosepsis is a life-threating sequel of an infection originating in the urinary tract [74]. There is no generally accepted definition of urosepsis, and several definitions have been used. The European Association of Urology (EAU) guidelines state the following definition:

"Urosepsis is defined as life threatening organ dysfunction caused by a dysregulated host response to infection originating from the urinary tract and/or male genital organs" [69].

The main cause of urosepsis is urinary tract obstruction [75], and it is therefore imperative that patients with suspected urosepsis are immediately x-rayed (or ultrasound) to rule out any urinary tract disorder leading to obstruction. Conditions predisposing to urine tract infection include any structural malformation with functional abnormality that impedes the flow of 
urine [76-80]. It is essential to reach the diagnosis of urosepsis as soon as possible and to provide time-sensitive empirical antibiotic treatment, supportive therapy, and source control [81]. Most pathogens reach the urinary tract by way of the intraluminal-ascending route. For urosepsis to develop, the pathogen must first reach the bloodstream [80]. The risk for urosepsis is increased in severe urogenital infections such as pyelonephritis and is further increased when there is obstruction of the urinary tract. Therefore, assessment of renal function is essential in the management of urosepsis $[82,83]$. 


\subsection{MICROBIOLOGICAL METHODS}

\section{Generally}

The diagnosis of bloodstream infections requires a positive blood culture. Blood samples are taken under aseptic conditions, preferably by venepuncture, and immediately thereafter a fixed volume is injected into each bottle. Blood for culture may be drawn through an indwelling intravascular catheter, but at least one set of blood cultures should be obtained via venepuncture [84-86]. The most guidelines recommend collecting $40 \mathrm{ml}$ of blood, divided to two set of blood cultures (one aerobic and one anaerobic bottle) i.e., by two venepuncture sites, multi-sampling strategy. In a study from 2020 single-sampling strategy (single puncture site) were compare to multi-sampling strategy and no significant difference in detecting pathogenic microorganisms were observed between these two strategies [87]. A separate needle for drawing blood and for bottle injection is recommended [88, 89].

Matrix-assisted laser-desorption ionisation time-of-flight (MALDI TOF) mass spectroscopy, is commonly used to identify bacteria at the species level. It is now possible to identify pathogens in blood cultures within hours of them turning positive. This means that specific pathogen-directed antibiotic therapy can be given soon after diagnosis. Susceptibility testing has a major impact on the prescription of antibiotics, providing the clinician with information on whether the infection being treated is likely to respond to a specific antibiotic or not. In the past (25-30 years ago), susceptibility testing was crude using somewhat arbitrary thresholds, and test results were reported as simply sensitive or resistant. But as knowledge of antimicrobial resistance and its detection have become more sophisticated, the results provided have become more reliable. However, the cut-off or breakpoint between susceptible, susceptible increased exposure, and resistant, is a complex, multifactorial process and it may be difficult to interpret. Where different techniques and methods could produce different results. The two major scientific bodies in this field, the Committee for Laboratory Science and Investigation (CLSI) and the European Committee on Antimicrobial Susceptibility Testing (EUCAST), have strived hard to achieve internationally accepted cut-off points/breakpoints to ensure that laboratory susceptibility testing is more informative and consistent than ever. From 2019, antimicrobial susceptibility is classed as Susceptible (S), Susceptible, Increased exposure (I) ("there is a high likelihood of therapeutic success 
because exposure to the agent is increased by adjusting the dosing regimen or by its concentration at the site of infection") or Resistant (R) according to EUCAST.

Practice related to blood culture sampling of patients with suspected bloodstream infection (BSI) influences detection. Obviously, if a blood culture is not sent for analysis, then a diagnosis of BSI cannot be made. In contrast, liberal blood culture sampling could result in higher rates of detection [90]. Population-level studies have been conducted to determine association to number of blood culture samples and incidence of bloodstream infection. This study found a correlation between the frequency of blood cultures and the rate of detection of BSI [91], but we have yet to find a threshold at which this correlation breaks down. The probability of detecting bacteraemia also depends on the frequency of blood sampling over time. Certain disorders such as septic thrombophlebitis and endocarditis are associated with continual bacteraemia and high numbers of the microorganisms present in the bloodstream. In these cases, cultures are positive regardless of when taken, even if the volume of blood cultured is small. With most other infections, however, microorganism counts are lower and larger volumes of blood are required to increase the probability of culture detection. Blood culture bottles should be inoculated with $\geq 8 \mathrm{~mL}$ of blood. When blood culture bottles are underfilled by $\leq 5 \mathrm{~mL}$ of blood/bottle, false-negative results or delay in microbial growth may occur [92]. It is also important that blood culture bottles not are overfilled (>10 mL) because there is an increased risk of being falsely positive due to high production of $\mathrm{CO}_{2}$ by WBCs $[93,94]$. Cumulative results from repeated $20-\mathrm{ml}$ blood sampling over a 24 -h period indicate that approximately $70 \%$ of patients with bacteraemia will have a positive result at the $1^{\text {st }}$ draw, $85 \%$ after the $2^{\text {nd }}, 97 \%$ after the $3^{\text {rd }}$, and over $99 \%$ after the $4^{\text {th }}[95,96]$. The ability to identify a pathogen in intermittent bacteraemia increases with the sampling rate, and is more likely to reflect the larger total volume of blood drawn [97]. The addition of an anaerobic blood culture bottle increases the chance of detecting facultative anaerobic organisms, enables the detection of anaerobes, and reduces the time to detection of some fastidious microorganisms $[98,99]$. BSIs could be classified into three main groups: 1. Infection of unknown origin i.e. primary infection with no identifiable source of infection; 2. Hospitalacquired bloodstream infection mostly due to infected intravascular catheters; and 3. Community-associated bloodstream infections, mainly secondary infection related to a focal infection at a defined locus, usually the respiratory, gastrointestinal, or urogenital tracts [51, 93, 100]. 
Figure 3. Two sets of blood cultures (4 bottles)

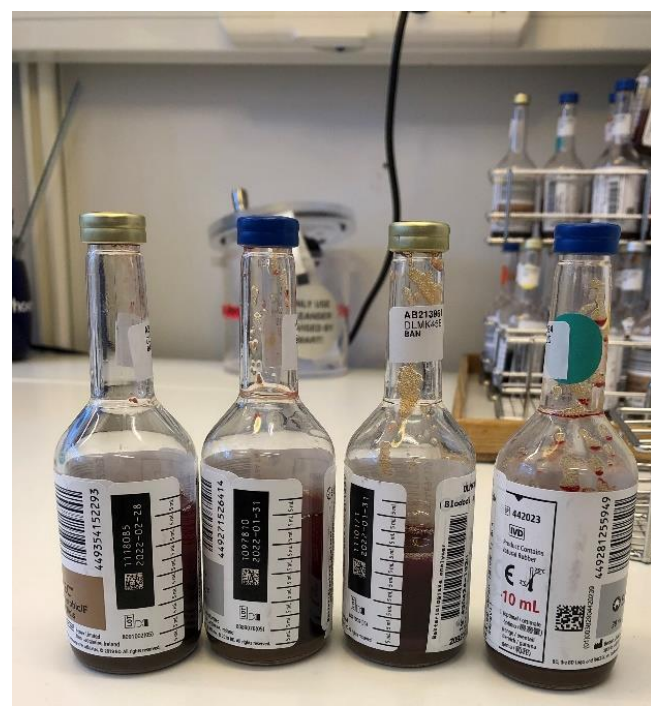

Fig 3. Blood cultures: Blood cultures were taken on clinical indications. One set of blood cultures comprised one aerobic (blue topped bottle) and one anaerobic (gold topped bottle) blood culture bottle using aseptic technique. It is recommended that at least two sets of blood cultures are taken simultaneously. For each episode of bacteraemia, blood should be collected from two separate sites (i.e., blood culture $\times 2$ ). Thus, a total of 2 cultures or 4 bottles (2 sets) should be collected per episode of bacteraemia.

\subsubsection{Blood culture systems}

There are several different procedures and laboratory protocols for analysing blood cultures. Automated incubation and detection systems are now being used because of their high efficiency, low risk for contamination, and short incubation time compared to the manual approach [95, 101-105]. Commercially available automated systems vary regarding the media and detection technique used. However, provided similar volumes of blood are cultured, their performances are overall comparable. If there are residual antimicrobials in the blood, media containing charcoal or resins improve pathogen recovery, and there are specialised media to enhance the recovery of anaerobes, mycobacteria, and fungi [93, 106, 107].

\subsubsection{The significance of a positive blood culture}

Commensal organisms on the skin typically contaminate the system when the blood sampling technique is poor. In many cases this gives rise to false-positive blood cultures with microorganisms such as “coagulase-negative staphylococci (CoNS), Bacillus spp. (not 
Bacillus anthracis), Micrococcus spp., Corynebacterium spp., and Cutibacterium acnes" [108]. Aspergillus species is the most common mould infection, and in the absence of advanced immunosuppression this usually represents environmental contamination. It is vital, therefore, that contamination is first excluded. Thereafter, it is important to ensure whether bacteraemia/fungaemia is associated with an infection (i.e., bloodstream infection) or not. Widely accepted definitions of bacteraemia/fungaemia and BSI would be ideal, but unfortunately this is not the case. Instead a combination of laboratory, clinical and microbiological factors is required [108]. When evaluating a positive blood culture, the following must be considered:

(a) The organism(s) identified. Detection of an organism(s) in an aseptically obtained and handled blood culture sample indicates bloodstream infection in most cases. As mentioned above, several skin commensal organisms can give rise to falsely positive blood culture. Among immunocompetent patients without the use of indwelling medical device such as intravascular catheters, bacteraemia with these organisms is uncommon, but on occasions, they do cause community-onset BSI [109]. Isolation of a yeast or fungus in blood culture, on the other hand, invariably indicates fungaemia and bloodstream infection.

(b) Timing and number of positive cultures. Adequate blood sample volume is the most important factor in the laboratory detection of microorganisms in the bloodstream. The Clinical and Laboratory Standards Institute (CLSI) guidelines recommend "that four bottles, $10 \mathrm{ml}$ blood per bottle (e.g., two sets of blood cultures, each consisting of an aerobic and an anaerobic bottle, equivalent to $40 \mathrm{ml}$ blood) be taken" if the $1^{\text {st }}$ blood culture is to detect 90 $95 \%$ of bacteraemias. A $3^{\text {rd }}$ blood culture set increases the detection rate to $95-99 \%[63,110]$. In a study by Collazos-Blanco et al 2019, with 4,000 episodes of bloodstream infections, demonstrated that without a $3^{\text {rd }}$ blood culture set, $8 \%$ of the bloodstream infections would have been missed [111]. Studies have suggested that even larger blood volumes may needed [96, 112]. In a study by Lee et al, Pseudomonas aeruginosa and Candida albicans bacteraemia was detected in the $1^{\text {st }}$ blood culture in $60 \%$ of cases. [96]. Similar results were seen for episodes of polymicrobial infection, where only $67 \%$ of the microorganisms were detected in the $1^{\text {st }}$ blood culture, but on the whole, $99 \%$ were detected by the $3^{\text {rd }}$ blood culture [96]. Studies have shown that the number of positive blood cultures may be used to classify the isolate as representing a true bacteraemia or as a common skin contaminant. However, most of these studies have focused on hospital-acquired coagulase-negative staphylococcal infections [108, 109, 113-116]. According to these findings, if only one blood culture is returned positive, the risk for contamination is $75-95 \%$. In cases of true 
bacteraemia, the likelihood is greater than $75 \%$ that a second blood culture shows the same microorganism as that isolated from the first culture set, which is not the case if the initial isolate is a contaminant [100]. If it takes a long time for a positive culture to appear, it is more likely to be contamination, whereas an early positive culture suggests bacteraemia $[51,108$, 117].

(c) Transient bacteraemia. Transient bacteraemia (low-grade bacteraemia) is where viable microorganisms are present in the bloodstream but do not represent a BSI because there is no associated infection. The cause of transient bacteraemia generally involves the manipulation of contaminated or colonised mucosal surfaces including dental manipulation or even brushing of teeth [33, 37, 38, 41], endoscopic gastrointestinal procedures [31, 32, 34, 36], and invasive respiratory procedures $[35,39]$. Approximately $20 \%$ of transrectal needle prostate biopsy procedures are associated with transient bacteraemia , some of which lead to BSI [40]. (d) Clinical criteria. Bloodstream infection is defined as a positive blood culture in the presence of an evident focus of infection. The focus may be detected clinically and/or microbiologically by isolation of the same species from deep tissue aspirates or samples obtained from a normally sterile site. In some cases, determination of the focus of infection is difficult and other parameters are required to classify a positive blood culture as being contamination or not. The occurrence of an elevated WBCs with fever is often cited as an important criterium, but alone this is a poor indicator of BSI. If, however, this is accompanied by several positive blood cultures, an indwelling catheter, hypotension, and criteria indicating a "systemic inflammatory response" (SIRS), the probability of a bloodstream infection increases considerably $[113,114]$. Some BSI criteria include whether or not the patient is on antibiotics. However, ongoing antibiotic therapy may simply indicate inadequate treatment rather than a BSI per se $[51,118]$. 


\subsubsection{Classification of true bloodstream infection (BSI)}

In individual cases, the clinician bases a diagnosis of bloodstream infection on an aggregate of the microbiological, clinical, and radiological information available. This is fully acceptable in clinical practice but for research purposes and surveillance, this has its limitations. To improve consistency for research purposes, standard definitions and algorithms have been developed [113]. The subjective component, however, continues to cause substantial interobserver variability [47]. Electronic surveillance systems have been developed to overcome this problem and improve efficiency. Reports based on these have increased in recent years [119-121].

\subsubsection{Species identification and susceptibility testing}

Identification of species and susceptibility testing are essential for optimal antibiotic treatment. Usually is this done by pathogen culture in different culture media, followed by species identification with matrix-assisted laser desorption/ionisation time-of-flight mass spectrometry (MALDI-TOF MS). A positive blood culture is usually obtained within 4-48 hours, and then pathogen identification within 4 hours. Once a positive culture and pathogen identification are established, the next stage is susceptibility testing. The disk diffusion method, classified as an agar diffusion method, is a manual technique that requires trained personnel [122]. Apart from the cost of personal, this method is validated, cheap and flexible for local needs.[122]. The method is recommended by the "European Committee of Antibiotic Susceptibility Testing” (EUCAST) [123]. A brief summary of the method: "In general, bacterial colonies are suspended in saline solution to a density of 0.5 McFarland. The suspension is inoculated on Mueller-Hinton agar plates, and standardised antibiotic disks are placed on the inoculated plates. After 16-20 hours incubation, the inhibition zones are measured with a pair of callipers and interpreted as: a) susceptible, b) susceptible, increased exposure, or c) resistant according to cut-offs provided in EUCAST breakpoint tables" [123]. 
Figure 4. Automated incubator/cabinet and disk diffusion test
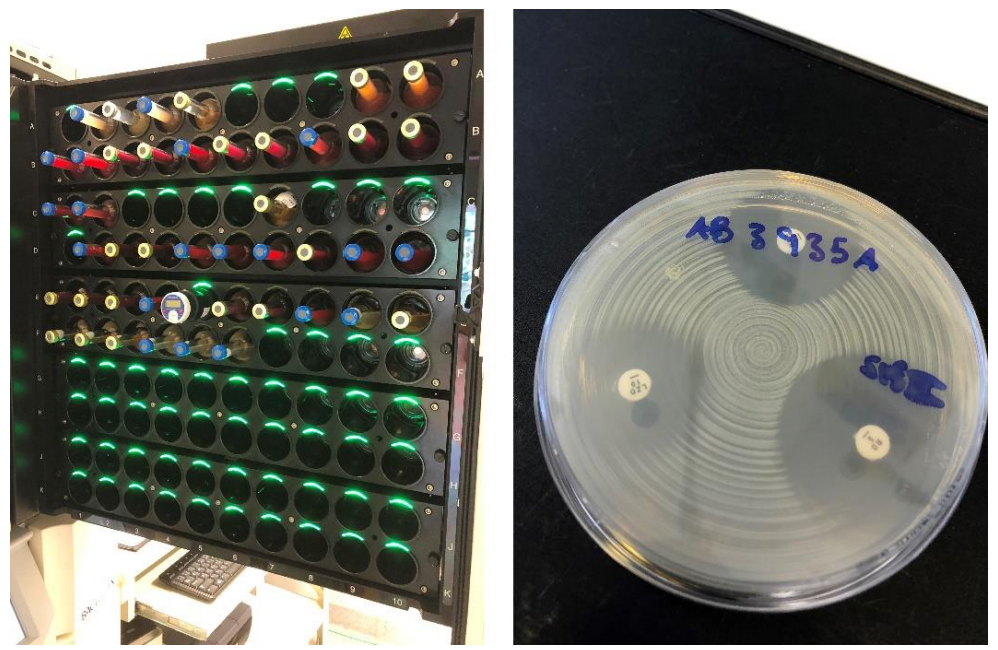

Fig 4. The bottles in the automated system (incubator/cabinet) incubated until flagged positive or for at least 5 days (to the left). Disk diffusion test photographed at 18 hours of incubation (to the right).

\subsubsection{MIC-determination}

Minimum inhibitory concentration (MIC) can be determined by culturing organisms. The MIC is defined as the lowest concentration of an antimicrobial agent that inhibits the growth of an organism. Gradient-test is a common method for routine MIC determination. A paper/plastic strip are coated with a known concentration of an antimicrobial compound and placed on a Mueller-Hinton agar (MHA) agar plate inoculated with a suspension of the pathogen[124]. The reference method for AST according to ISO20776-1 is "Minimal Inhibitory Concentration" (MIC) determination by broth dilution [125].

\subsubsection{Phenotype versus genotype methods}

Bacteria can have many resistance mechanisms that together confer higher levels of resistance. [126]. Disk diffusion described above is a phenotypic method and can demonstrate both resistance and susceptibility. However, PCR-based methods demonstrate the presence of a resistance gene [127] and in some case the gene can predict phenotypic resistance, but other 
resistance genes may be present without clinical relevance, due to for instance defective gene expression. Whole genome sequencing techniques have the potential to be used for prediction of resistance and possibly susceptibility. This presupposes advanced bioinformatic power and continuous validation against phenotypic methods. This is important to ensure an updated database where previously unknown resistance mechanisms are added continuously [126].

\subsubsection{Multilocus sequence typing (MLST)}

Multilocus sequence typing (MLST) is the most suitable and widely used method for global surveillance typing of common bacterial pathogens [128]. However, the discriminating power is too weak to be used for local surveillance and in outbreak situations. In 1998 the first MLST type was introduced and [129, 130] seven or eight housekeeping genes were identified. These genes are present in all strains of the microorganism. [131]. With the aid of a basic local alignment search tool (BLAST), the DNA sequence of each housekeeping gene is compared to previously sequenced isolates in a database and assigned a currently known or new sequence type (ST).

\subsubsection{Whole genome sequence typing (WGS)}

The classic Sanger sequencing method was introduced in 1977. It is a target sequencing technique based on primers to seek out specific DNA regions. [132]. The technique is useful for single genes (limited to sequences $<1,000$ bases in length) but not for entire genomes. An E. coli genome, for instance, consists of about 4-5 million base pairs. In Linköping, total DNA was extracted using the "EZ1 DNA Tissue Kit (Qiagen)". A sequencing library for whole-genome sequencing was constructed using 20 ng DNA. The QIAseq FX DNA Library Kit (Qiagen) was applied for library preparation. The quantity and quality of DNA was assessed with a Qubit 2.0 fluorometer and a QIAxcel instrument (Qiagen), and then paired ends sequenced on a MiSeq instrument (Illumina, San Diego, CA). Sequencing was carried out by a MiSeq instrument (Illumina) producing a mean sequencing depth of 30x. Over the last 15 years, sequencing methods have been expanded and improved, and in 2007 the cost of sequencing dropped rapidly, and powerful high-throughput sequencing methods were 
introduced [133]. Whole genome sequencing (WGS) is a next-generation sequencing (NGS) application that is used for sequencing entire genomes. [132].

Figure 5. The main steps of WGS

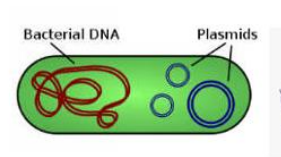

(EZ1, Qiagen)

DNA extraction

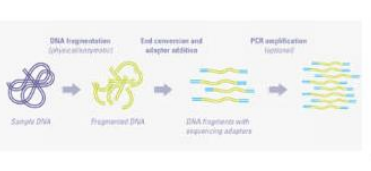

(QlAseg, Qiagen)

Library preparation

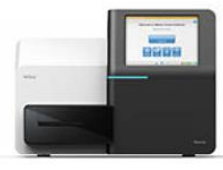

(2×300 bp, Miseq, Illumina)

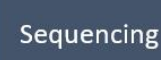

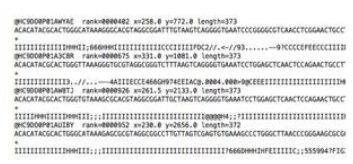

Pipeline created in CLC, Qiagen

Bioinformatics

Clinical

interpretation

Fig 5. The main steps of WGS are: 1. DNA extraction; 2. DNA Library preparation; 3. DNA library sequencing; and 4. Bioinformatics (DNA sequence analysis).

\subsubsection{Genome assembly and bioinformatics analysis}

The CLC Genomics Workbench v.9.5.1 (Qiagen) was used to assemble the genome of the reads obtained from the whole genome sequenced isolates. The Center for Genomic Epidemiology online database (http://www.genomicepidemiology.org) was used for identification of chromosomal fluoroquinolone resistance. The CLC Genomics Workbench v.9.5.1 (Qiagen) was used for MLST and identification of antibiotic resistance genes, using a pubMLST database. 


\subsection{ANTIBIOTICS}

Antibiotics are important in the initial management of patients with severe infection [134]. Inappropriate use of antibiotics may not only cause therapeutic failure but also lead to the emergence of resistant pathogens. Adequate antibiotic therapy within the first hour of admission improves the outcome of septic shock. In most cases, initial antibiotic treatment is empirically based on individual patient's requirements, expected bacterial species, and local antibiotic resistance rates. Empirical antibiotic treatments are generally broad-spectrum (broad coverage) and should later be adapted according to sensitivity results [135].

Monitoring of antibiotic usage is an important part of our efforts to control antibiotic resistance (AMR). Such surveillance identifies areas where rates of consumption are high and the potential for development of resistance is greatest. Information provided may also be used as a measure of the effectiveness of actions taken to reduce antibiotic consumption and thereby preserve their effect.

\subsubsection{Defined daily doses (DDDs)}

The ratio of the number of DDDs over time as numerator and the size of the population as denominator is used as a quantitative measurement of antibiotic consumption. This enables meaningful comparisons over time that consider differences in population characteristics and geographical differences such as hospitals, regions or countries. In the community setting the simplest denominator is the number of inhabitants. The most common measure is DDD per 1000 inhabitants per day.

The most common unit of antibiotic consumption is the World Health Organisation's (WHO) defined daily dose (DDD) defined as "the assumed average maintenance dose per day for a drug used for its main indication in adults".

The concept of DDD allows meaningful comparison between drugs and can be used in both community and hospital settings. Community consumption is measured as DDDs per 1,000 inhabitants, or prescriptions or packs dispensed per 1,000 inhabitants, while Hospital consumption is measured as DDDs per 100 or 1,000 bed days, or DDDs per 1000 admissions or discharges. 


\subsubsection{Antibiotic consumption}

Global antibiotic consumption increased by 65\% (21.1-34.8 billion DDDs) between 2000 and 2015, and consumption rate increased by 39\% (11.3-15.7 DDDs per 1,000 inhabitants per day). The WHO AWaRe antibiotic categorisation has three categories.

Access: Antibiotics with activity against a wide range of commonly susceptible microorganisms while also showing lower resistance potential.

Watch: Antibiotics with higher resistance potential. These include most of the important antimicrobials used in high priority situations.

Reserve: Antibiotics reserved for therapy of confirmed or suspected infections due to multidrug resistant microorganisms [136, 137].

Watch antibiotic use has been estimated to have increased by $90 \%$ (from 3.3 to 6.3 defined daily doses (DDDs) per 1,000 inhabitants per day (DIDs), 2000-2015, compared to Access antibiotic use with an increase of $26.2 \%$ (from 8.4 to 10.6 DIDs). This increase was greatest in "low- and middle-income countries" and driven by factors such as economic growth and increased access to antibiotics. However, high-income countries have also increased their use of antibiotics on a per capita basis [138, 139].

Reducing the inappropriate and unnecessary use of antibiotics has become a public health priority to control increasing antibiotic resistance in community and hospital settings. Our main measure of antibiotic consumption is the ATC/DDD per 1,000 inhabitants/day classification, which is a global standard for drug consumption research. This provides a rough estimate of the overall incidence in the population of individuals treated with antibiotics $[15,16]$. We also express antibiotic use in hospital as and DDDs per 100 bed days or DDDs per 1,000 patient/hospital days [16]. Veterinary and human antibiotic consumption and antibiotic resistance in Sweden are low compared to other European countries [17, 18]. MRSA causes only $1.2 \%$ of all Staphylococcus aureus BSIs in Sweden and has not increased significantly over the last 20 years. However, Escherichia coli resistant to $3 \mathrm{GC}$ increased from 5.6\% in 2014 to $7.4 \%$ in 2017 in Sweden. The prevalence of Enterobacteriaceae resistant to quinolones is probably the most common antibiotic resistance problem in Sweden, followed by Enterobacteriaceae resistant to $3^{\text {rd }}$ generation cephalosporins, usually producing extended-spectrum beta-lactamase (ESBL) [15, 19-21]. 


\subsubsection{The importance of empirical antibiotic therapy}

Early appropriate antibiotic treatment is crucial to reducing mortality and morbidity in patients with a severe infection $[81,140]$. When deciding on antimicrobial treatment, we do not have the help of rapid diagnostic methods (tests) for identification of organisms and associated resistance markers. As a result, empirical antibiotic treatment must be initiated before detection and identification of the microorganism causing the infection. Empirical antibiotic therapy is based on the severity of illness, comorbidities, clinical presentation, suspected source of an infection, patient-specific factors and is usually governed by local guidelines.

BSIs caused by ESBL-producing E. coli are associated with a high risk of inadequate empirical antibiotic therapy, and these patients seem to have a higher mortality risk [141]. In a study from Netherlands, inappropriate antibiotic therapy during the first 24 hours was not associated with a higher 30-day mortality [142]. However, in an Italian study 50\% of the patients (in total 186 patients with bloodstream infection caused by EPE) received inadequate antibiotic treatment, and of those sixty percent died within 21 days, compared to eighteen percent of patients with adequate antibiotic treatment [141]. According to a review by Trecarichi et al, several studies have been published showing somewhat conflicting mortality results, mostly due to low sample sizes [143]. A meta-analysis by Schwaber and Carmeli showed an increased mortality rate associated with ESBL-production [144, 145].

Furthermore, it is generally accepted that inappropriate antibiotic therapy increases both cost of care and length of hospital stay.[145, 146]. 


\subsection{ANTIMICROBIAL RESISTANCE AND RESISTANCE MECHANISMS}

Overview

Antimicrobial resistance (AMR) occurs when microorganisms develop resistance mechanisms and become resistant to an antimicrobial agent that was originally effective in the therapy of infections caused by the same pathogen. Continual overuse of antibiotics in healthcare, veterinary care, and agricultural sectors creates a strong selection pressure leading to resistance. Excessive use and misuse of antimicrobial agent increases the emergence of drugresistant strains in combination with factors such as poor infection control, inadequate sanitary conditions, inappropriate food handling, lack of or inadequate diagnostic tests, lack of knowledge, cultural beliefs and traditions, fear of poor clinical outcome, patient demand, use and misuse of antibiotics in agriculture and the environment, travel, and many others. A better understanding of these driving factors is critical when developing and implementing stewardship interventions.

Gut microbiota refers to all organisms that colonise the gastrointestinal tract. It is well-known that antibiotics, even when taken appropriately, can shift the gut microbiota to a state termed dysbiosis characterised by loss of diversity, changes in metabolic capacity, and reduced colonisation resistance against invading pathogens. Excessive and inappropriate use of broadspectrum agents causes greater dysbiosis, which in turn promotes: 1) horizontal transfer of resistance genes, 2) evolution of drug-resistant microorganisms, and 3) spreads antibiotic resistance. Resistant bacteria can continue to exist in our microbiota for many months, and the risk of prolonged carriage is increased by further use of antibiotics.

Two mechanisms drives the global increase in AMR amongst Enterobacterales: 1) horizontal plasmid transfer and 2) successful high-risk clones [147].

1. The first mechanism involves horizontal transfer of genes and plasmids. The potential for success depends on 4 different properties necessary for transfer of a plasmid or transposon (a gene) from one organism to another: "penetration (ability to reproduce and spread), promiscuity (ability to exchange information), plasticity (variability), and persistence (construction of durable links with its environment)” [148].

2. The second mechanism involves high-risk clones. The term high risk clone has been used to describe bacterial clones that enhance the dissemination of antibiotic resistance 
worldwide, have increased pathogenicity and virulence, are able to colonise and persist in the host more than six months, and perform effective transmission and carriage of multiple antimicrobial characteristics [149]. A clone refers to a very closely related strain (not identical genomes) that has a recent common ancestor with small differences caused by horizontal gene transfer, mutations, and recombination events [150]. It is the combination of acquired genetic properties and the selective pressure of antimicrobial treatment that causes spread of these high-risk clones [147]

\subsubsection{Resistance mechanisms}

The effect of antibiotics largely depends on the components of the bacterial cell wall. The differences between Gram-negative and Gram-positive bacteria are primarily related to their cell wall structure, and the effect of an antimicrobial agent is therefore often limited to either Gram-negative or Gram-positive bacteria. This dissertation has focused on Gram-negative bacteria and the four most important resistance mechanisms (four main categories) that inactivate antibiotics are: a) An impermeable barrier that limits drug uptake. In gram negative bacteria the structure and function of the lipopolysaccharide (LPS) layer provide a barrier; $b$ ) Efflux pumps that actively transport antibiotics out of the cell, c) Resistance mutation with modification of drug targets in the bacterial cell such as penicillin binding proteins (PBPs); d) Drug inactivation, bacteria inactivate the drugs by transfer of a chemical group or actual degradation of the drug [151-153]. 
Figure 6. Important resistance mechanisms in gram-negative bacteria

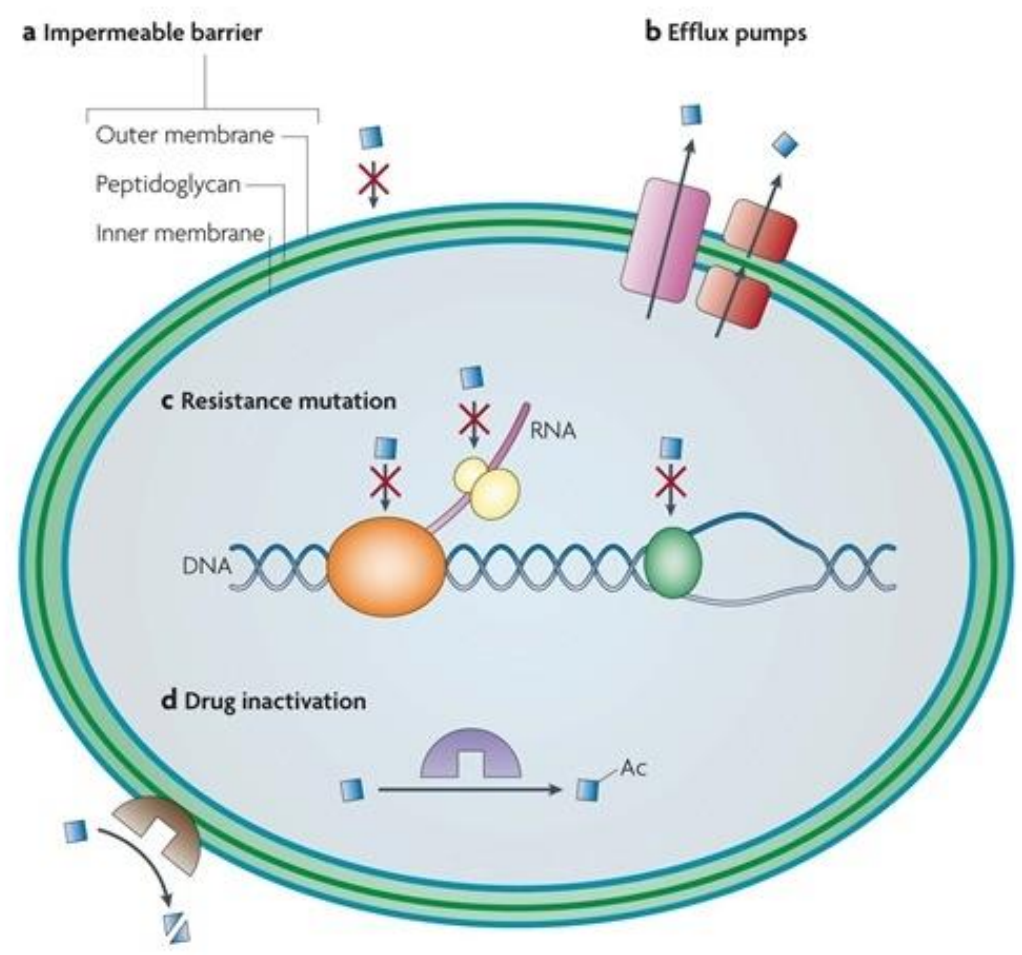

Fig 6. Principal resistance mechanisms in Gram-negative bacteria. (reprinted with permission) [152].

\section{$\beta$-lactam antibiotics and $\beta$-lactamases}

$\beta$-lactams are the most widely used antibiotics [12], the main advantages being their low toxicity, high efficacy, and the variety of $\beta$-lactams available. $\beta$-lactam have a specific core structure, $\beta$-lactam ring. The $\beta$-lactam antibiotics bind covalently to and inhibit penicillin binding proteins (PBPs). PBPs are essential to catalyse cross-linking of the peptidoglycan layer of the bacterial cell wall. Further this breaks down the cell wall causing bacterial rupture. There are several PBPs, and each bacterial species has its own set of PBPs, often 3-8 types. Usually 1-2 of these are essential (PBP1a-b, PBP2, and PBP3 in gram-negative bacteria) [154]. The two most important resistance mechanisms against $\beta$-lactam agents are: “1) target modification of PBPs (often due to expression of an alternative PBP); and 2) $\beta$ - 
lactamases (enzymes) in the periplasmic space of the cell wall (between the outer and inner membrane) hydrolyse the $\beta$-lactam ring of the antibiotic, thus inactivating the agent. Over 2,800 $\beta$-lactamases had been described by Bush et al in 2018 [155].

\subsubsection{Extended-spectrum $\beta$-lactamase (ESBL)}

Extended-spectrum $\beta$-lactamases (ESBLs) are enzymes produced by certain types of bacteria. The enzymes hydrolyse/degrade $\beta$-lactam antibiotics with extended spectrum such as $3 \mathrm{GC}$ [156]. $\beta$-lactams are one of the most commonly used antibacterial agents and are frequently used for several common infections such as urinary tract infections and pneumonia, but also more severe infections such as bloodstream infections. Several definitions and nomenclatures are used to describe ESBL. In this dissertation, Giske's ESBL definition is used[157]. This divides ESBL into three main groups; " $E S B L_{A}, E S B L_{M}$, and $E S B L_{C A R B A}$. In $E S B L_{A}$ group, the most frequently found enzymes are: $C T X-M$ as well as SHV and TEM enzymes that are degraded by clavulanic acid and horizontally transferrable". ESBLs are increasing worldwide, and ESBL-producing E. coli producing CTX-M are the most commonly type encountered clinically. The majority of ESBL-producing $E$. coli infections are in the urinary tract, but these can also cause bloodstream infections. E. coli is a common bacteria in the gastrointestinal tract and part of the normal gut microbiota; therefore, increasing prevalence of ESBL-producing strains is worrying. 


\subsubsection{E. coli ST131 high-risk clone}

E. coli range from harmless gut colonisers to multidrug- resistant potentially life-threatening pathogens. There are many strains of E. coli with differing resistance- and virulenceassociated factors. Since plasmids carry the gene encoding ESBL-enzymes, these enzymes can be present in any strain. The ST131 is a "highly successful high-risk clone" that is largely responsible for the increase in ESBL-producing bacteria worldwide [158, 159]. In bloodstream infections, ST131 is the dominant ESBL-producing E. coli strain, with reported rates of $20-60 \%[158,160]$. However, ST10, ST59, ST23 and ST405 are other E. coli strains associated with ESBL production. [161].

\subsubsection{Increase in community-onset bloodstream infections with resistant bacteria}

Bloodstream infections due to antibiotic-resistant microorganisms have previously been associated with patients admitted to intensive care units (ICUs) or high-acuity units that provide closer monitoring $[162,163]$. However, the number of multidrug- resistant microorganism arising in the community-setting over the last decade has risen throughout the world, notable examples being community-onset MRSA [164, 165] and ESBL-producing $E$. coli $[166,167]$.

E. coli is an important cause of CO-BSI and is the most common uropathogen. Several multidrug-resistant Enterobacteriaceae, notably Klebsiella pneumonia and E. coli, have emerged worldwide and are now a significant cause of community-onset BSI. In the 90s, ESBL-producing Enterobacteriaceae were largely a problem in the hospital environment and rarely caused community-onset disease. However, over the last two decades a variety of ESBL-producing Enterobacteriaceae have been observed and have emerged as major community-onset microorganisms around the globe [166-168] [169-174]. In Sweden, ESBLproducing Enterobacteriaceae increased from 50 to 104 cases per 100,000 inhabitants between 2010 and 2019. Enterobacteriaceae resistant to fluoroquinolones, followed by Enterobacteriaceae resistant to $3^{\text {rd }}$ generation cephalosporins are probably the most frequently encountered and clinically important antibiotic-resistant pathogens in Sweden today $[19-21,175]$. 


\subsubsection{Risk factors for bloodstream infection with ESBL-producing pathogen}

It is obviously important that we identify patients at increased risk of having a BSI caused by ESBL-producing pathogen when initiating empirical antibiotic therapy, especially in patients with severe infection and/or septic shock. Numerous studies have investigated the risk factors for bloodstream infection with ESBL-producing Enterobacteriaceae, including one from Sweden [176]. Thirty of these were reviewed by Trecharichi et al [143]. The following risk factors for ESBL BSI were detected: "history of antibiotic treatment, especially fluoroquinolones and 3GC; previous hospitalisation; residency in long-term care facility with healthcare contacts; presence of an indwelling device, especially urinary catheter; and presence of comorbidity”. In studies from Sweden the only significant risk factor for BSI with an ESBL-producing pathogen was a previous culture showing ESBL-production [176, 177]. In this study, it was not clearly specified if "previous culture" included both screening and clinically specific cultures.

\subsubsection{The importance of knowing the local epidemiology}

The importance of local epidemiology, risk factors, and bacterial resistance is essential for prevention and management of infections. The risk factors for ESBL-producing bacterial infections vary between different parts of the world. In a Chinese study by Quan et al from 2017, risk factors for bloodstream infection with ESBL E. coli were studied In that study, $55 \%$ of E. coli from blood cultures were ESBL-positive [178] while the resistance level was still below 8\% in Sweden (2019) [179]. In most parts of USA, Australia, Canada and northwest Europe the rate is less than 25\%. The majority are caused by CTX-M type enzymes, especially CTX-M-15 that is carried by the successful clone ST131 [180]. This stresses the importance of risk-scoring systems being developed in the same epidemiological setting as their application i.e., that risk- scoring systems from other countries must undergo local validation and adaptation [177]. Due to differences in practice when obtaining samples for blood culture, it is difficult to compare antibiotic resistance rates between countries. Indications for blood culture sampling differ; in some countries, blood cultures are only taken in cases of therapy failure or hospital infection, resulting in a higher proportion of resistant isolates. 


\subsection{THE BURDEN OF COMMUNITY-ONSET BLOODSTREAM INFECTION}

Generally unknown to politicians, medical communities, and citizens, the burden of CO-BSI is comparable to those of major trauma, stroke, and acute myocardial infarction [57]. Several studies have investigated the adverse impact of bloodstream infection on the community, but most of these studies have been performed on selected cohorts such as patients admitted to an emergency department or hospital. Such studies have limitations such as lack of adequate denominator data and risk for selection bias[1]. Population-based studies are best when estimating the burden of bloodstream infection [181], since all BSI-episodes occurring in the population of a defined region are accounted for and non-residents can be excluded [182]. This minimises selection bias [183], enables calculation of incidence and mortality rates, and helps define the population at risk.

\subsubsection{Overall burden at the population level}

Only a few studies have reported data estimating the overall burden of CO-BSI at the population level $[55-58,184]$. Others have studied the impact of BSI at the population level but with inadequate case data, analyses limited to subgroups, and no clear differentiation between community-onset and hospital-onset BSI [5, 7, 8, 91, 172, 185-189]. Accurate assessment of the overall burden of CO-BSI over the last 20 years presents certain problems: 1) only a few studies have been conducted; 2) the incidence of BSI has increased over the past 4 decades [5, 7, 8, 55, 187, 190]; and 3) the demographic profiles of the populations studied have varied. Adjustment for gender and age alone has been shown to result in differences of between 20 and $30 \%$ in reported incidences between populations [181]. This also applies to different geographic regions within the same country [58]; and 4) these studies were all performed in high-income countries, and it is most likely that burden of community-onset disease may differ substantially in other parts of the world [172, 185, 189]. 


\subsection{RISK FACTORS FOR BLOODSTREAM INFECTION AND SEPSIS}

Studies on selected subgroups, populations or aetiologies have identified several comorbidities with increased risk for BSI [191-195]. Increasing knowledge and awareness of risk factors for developing bloodstream infections is essential to guide preventive measures and identify target groups at an early stage. Comorbidity is classified according to Charlson et al [196].

Table 1. Charlson Comorbidity Index

\begin{tabular}{|c|c|c|c|c|}
\hline Comorbid Condition & $\begin{array}{l}\text { ICD-9-CM Diagnosis } \\
\text { Codes }\end{array}$ & $\begin{array}{l}\text { ICD-10-CA Diagnosis } \\
\text { Codes }\end{array}$ & Weight & $\begin{array}{l}\text { Updated } \\
\text { Weight }\end{array}$ \\
\hline Myocardial Infarction & 410,412 & $\mathrm{I} 21, \mathrm{I} 22, \mathrm{I} 25.2$ & 1 & 0 \\
\hline $\begin{array}{l}\text { Congestive Heart } \\
\text { Failure }\end{array}$ & $\begin{array}{l}398.91,402.01,402.11, \\
402.91,404.01,404.03, \\
404.11,404.13,404.91, \\
404.93,425.4-425.9,428 \\
\text { (hosp), 398, 402, 425, } 428 \\
\text { (med) }\end{array}$ & $\begin{array}{l}\text { I09.9, I11.0, I13.0, I13.2, } \\
\text { I25.5, I42.0, } \\
\text { I42.5-I42.9,I43, I50, P29.0 }\end{array}$ & 1 & 2 \\
\hline $\begin{array}{l}\text { Peripheral Vascular } \\
\text { Disease }\end{array}$ & $\begin{array}{l}093.0,437.3,440,441, \\
443.1-443.9, \\
447.1,557.1,557.9, \mathrm{~V} 43.3 \\
\text { (hosp) } \\
440,441,443,447,557 \\
\text { (med) }\end{array}$ & $\begin{array}{l}\text { I70, I71, I73.1, I73.8, } \\
\text { I73.9, I77.1, I79.0, } \\
\text { I79.2, K55.1, K55.8, } \\
\text { K55.9, Z95.8, Z95.9 }\end{array}$ & 1 & 0 \\
\hline $\begin{array}{l}\text { Cerebrovascular } \\
\text { Disease }\end{array}$ & $\begin{array}{l}362.34,430-438 \text { (hosp) } \\
430-438 \text { (med) }\end{array}$ & G45, G46, H34.0, I60-I69 & 1 & 0 \\
\hline Dementia & $\begin{array}{l}290,294.1,331.2 \text { (hosp) } \\
290,294,331 \text { (med) }\end{array}$ & $\begin{array}{l}\text { F00-F03, F05.1, G30, } \\
\text { G31.1 }\end{array}$ & 1 & 2 \\
\hline $\begin{array}{l}\text { Chronic Pulmonary } \\
\text { Disease }\end{array}$ & $\begin{array}{l}416.8,416.9,490-505 \\
506.4,508.1, \\
508.8 \text { (hosp), 416, 490- } \\
496,500-505 \text { (med) }\end{array}$ & $\begin{array}{l}\text { I27.8, I27.9,J40-J47, J60- } \\
\text { J67 J68.4, J70.1, } \\
\text { J70.3 }\end{array}$ & 1 & 1 \\
\hline $\begin{array}{l}\text { Connective Tissue } \\
\text { Disease- } \\
\text { Rheumatic Disease }\end{array}$ & $\begin{array}{l}446.5,710.0-710.4, \\
714.0-714.2,714.8, \\
725 \text { (hosp), 446, 710, 714, } \\
725 \text { (med) }\end{array}$ & $\begin{array}{l}\text { M05, M06, M31.5, M32- } \\
\text { M34, M35.1, } \\
\text { M35.3, M36.0 }\end{array}$ & 1 & 1 \\
\hline Peptic Ulcer & $531-534$ & $\mathrm{~K} 25-\mathrm{K} 28$ & 1 & 0 \\
\hline Mild Liver Disease & $\begin{array}{l}070.22,070.23,070.32, \\
070.33,070.44, \\
070.54,070.6,070.9,570, \\
571,573.3, \\
573.4,573.8,573.9, \mathrm{~V} 42.7 \\
\text { (hosp) } \\
070,570,571,573 \text { (med) }\end{array}$ & $\begin{array}{l}\text { B18, K70.0-K70.3, K70.9, } \\
\text { K71.3-K71.5, } \\
\text { K71.7, K73, K74, K76.0, } \\
\text { K76.2-K76.4, } \\
\text { K76.8, K76.9, Z94.4 }\end{array}$ & 1 & 2 \\
\hline
\end{tabular}




\begin{tabular}{|c|c|c|c|c|}
\hline $\begin{array}{l}\text { Diabetes without } \\
\text { Chronic } \\
\text { Complications }\end{array}$ & $\begin{array}{l}250.0-250.3,250.8,250.9 \\
\text { (hosp) } \\
250 \text { (med) }\end{array}$ & $\begin{array}{l}\text { E10.0, E10.1, E10.6, } \\
\text { E10.8, E10.9, E11.0, } \\
\text { E11.1, E11.6, E11.8, } \\
\text { E11.9, E12.0, E12.1, } \\
\text { E12.6, E12.8, E12.9, } \\
\text { E13.0, E13.1, E13.6, } \\
\text { E13.8, E13.9, E14.0, } \\
\text { E14.1, E14.6, E14.8, } \\
\text { E14.9 }\end{array}$ & 1 & 0 \\
\hline $\begin{array}{l}\text { Diabetes with Chronic } \\
\text { Complications }\end{array}$ & $\begin{array}{l}250.4-250.7 \\
(\text { med n/a) }\end{array}$ & $\begin{array}{l}\text { E10.2-E10.5, E10.7, } \\
\text { E11.2-E11.5, E11.7, } \\
\text { E12.2-E12.5, E12.7, } \\
\text { E13.2-E13.5, E13.7, } \\
\text { E14.2-E14.5, E14.7 }\end{array}$ & 2 & 1 \\
\hline $\begin{array}{l}\text { Paraplegia or } \\
\text { Hemiplegia }\end{array}$ & $\begin{array}{l}334.1,342,343,344.0- \\
344.6,344.9 \\
\text { (hosp), 334, 342-344 } \\
\text { (med) }\end{array}$ & $\begin{array}{l}\text { G04.1, G11.4, G80.1, } \\
\text { G80.2, G81, G82, } \\
\text { G83.0-G83.4, G83.9 }\end{array}$ & 2 & 2 \\
\hline Renal Disease & $\begin{array}{l}403.01,403.11,403.91, \\
404.02,404.03, \\
404.12,404.13,404.92, \\
404.93,582, \\
583.0-583.7,585,586, \\
588.0 . \text { V42.0, } \\
\text { V45.1, V56 (hosp), 403, } \\
582,583,585, \\
586,588, \text { V56 (med) }\end{array}$ & $\begin{array}{l}\text { I12.0, I13.1, N03.2-N03.7, } \\
\text { N052-N05.7, } \\
\text { N18, N19, N25.0, Z49.0- } \\
\text { Z49.2, Z94.0, } \\
\text { Z99.2 }\end{array}$ & 2 & 1 \\
\hline Cancer * & $\begin{array}{l}140-172,174-195.8,200- \\
208,238.6 \\
\text { (hosp), 140-172, 174-195, } \\
200-208, \\
238 \text { (med) }\end{array}$ & $\begin{array}{l}\mathrm{C} 00-\mathrm{C} 26, \mathrm{C} 30-\mathrm{C} 34, \mathrm{C} 37- \\
\mathrm{C} 41, \mathrm{C} 43, \\
\mathrm{C} 45-\mathrm{C} 58, \mathrm{C} 60-\mathrm{C} 76, \mathrm{C} 81- \\
\mathrm{C} 85, \mathrm{C} 88, \\
\mathrm{C} 90-\mathrm{C} 97\end{array}$ & 2 & 2 \\
\hline $\begin{array}{l}\text { Moderate or Severe } \\
\text { Liver } \\
\text { Disease }\end{array}$ & $\begin{array}{l}456.0-456.2,572.2-572.4 \text {, } \\
572.8 \\
\text { (hosp), 456, } 572 \text { (med) }\end{array}$ & $\begin{array}{l}\text { I85.0, I85.9, I86.4, I98.2, } \\
\text { K70.4, K71.1, } \\
\text { K72.1, K72.9, K76.5- } \\
\text { K76.7, }\end{array}$ & 3 & 4 \\
\hline $\begin{array}{l}\text { Metastatic } \\
\text { Carcinoma** }\end{array}$ & 196-199 & C77-C80 & 6 & 6 \\
\hline HIV/AIDS & $042-044$ & B20-B22, B24 & 6 & 4 \\
\hline
\end{tabular}

Table 1. Abbreviations: AIDS, acquired immunodeficiency syndrome; HIV, human immunodeficiency virus. * Including lymphoma and leukemia, except malignant neoplasm of skin ** or Metastatic solid tumour.

Few clinical studies have investigated an array of potential aetiological factors that increase the risk for CO-BSI in a population-based cohort. Two Norwegian studies identified "smoking, iron deficiency, sedentary lifestyle, obesity, and alcohol consumption as risk factors for bloodstream infection" [193, 197]. Two Danish studies reported "liver disease, renal failure, and diabetes as significant risk factors for BSI” [195, 198]. Another Danish study by Sogaard et al analysed each of the Charlson Score variables in a large populationbased cohort of patients with CA bloodstream infections in northern Denmark [199]. 
Unfortunately, they had a cohort with negative blood cultures as control group and did not report the degree of risk at the population level. Diabetes is a well-known risk factor for BSI, the reason being multifactorial [200, 201]. COPD is also a risk factor for BSI. [202, 203]. 


\section{AIMS}

\subsection{OUTLINE OF THIS THESIS}

The purpose of this thesis was to conduct a detailed analysis of the clinical epidemiology and impact of bloodstream infections in south-east Sweden, focusing on risk factors for BSIassociated mortality.

In Study 1 (Section 5.1) trends in incidence and mortality of BSI, CO-BSI, and HA-BSI in Sweden between 2000 and 2013 were examined. Results revealed that the incidence and mortality of BSI are increasing, particularly CO-BSI. While the use of antibiotics in primary healthcare decreased, that in hospital care increased. We also saw an association between an increase in the number of patients with comorbidity and an increase in BSI.

In Study 2 (Section 5.2) we further evaluated the increase in incidence and mortality of BSIs caused by the antibiotic-resistant pathogens. Trends in all-cause bacteraemia, and the influence of AMR on all-cause mortality from BSI were followed. The most common species found in cases of AMR BSI was E. coli. An interesting finding was that the burden of AMR in Östergötland is low and not associated with increased mortality.

The incidence and mortality of CO-BSI are increasing. Paper 3 (Section 5.3) presents the results of a study investigating factors likely to increase survival in CA-BSI, focusing on prehospital care. In previous studies, we have noted an increased incidence of CO-BSI and a primary increase in gram-negative microorganisms. In Paper 4 (Section 5.4) we present the results of a study focusing on risk factors, initial management, and outcome of patients with ESBL-UPEC BSI.

Finally, in Section 6 the results are discussed, and Section 7 summarises the results of the studies in this thesis as well as the challenges that remain regarding research into communityonset bloodstream infection. 


\section{DATABASE MANAGEMENT AND SURVEILLANCE OF INFECTION AND DATA COLLECTION}

Database handling for infection controls, hospital epidemiology, surveillance of infection, and data collection

In today's medicine, huge amounts of data are generated such as prescriptions, laboratory and imaging results, vital signs, hospital admission notes, diagnoses, comorbidities etc. This provides researchers with a mine of information enabling them to recognise trends, as well as providing clinicians with a basis upon which decisions in real time are made. Much of the work in this dissertation focuses on the design and creation of a register database to facilitate follow-up of clinical outcome. This register has now been linked to an antibiotic stewardship database and contains all relevant laboratory, microbiology, clinical, and mortality data.

Figure 7. Bacteraemia "BaCt-X" database overview

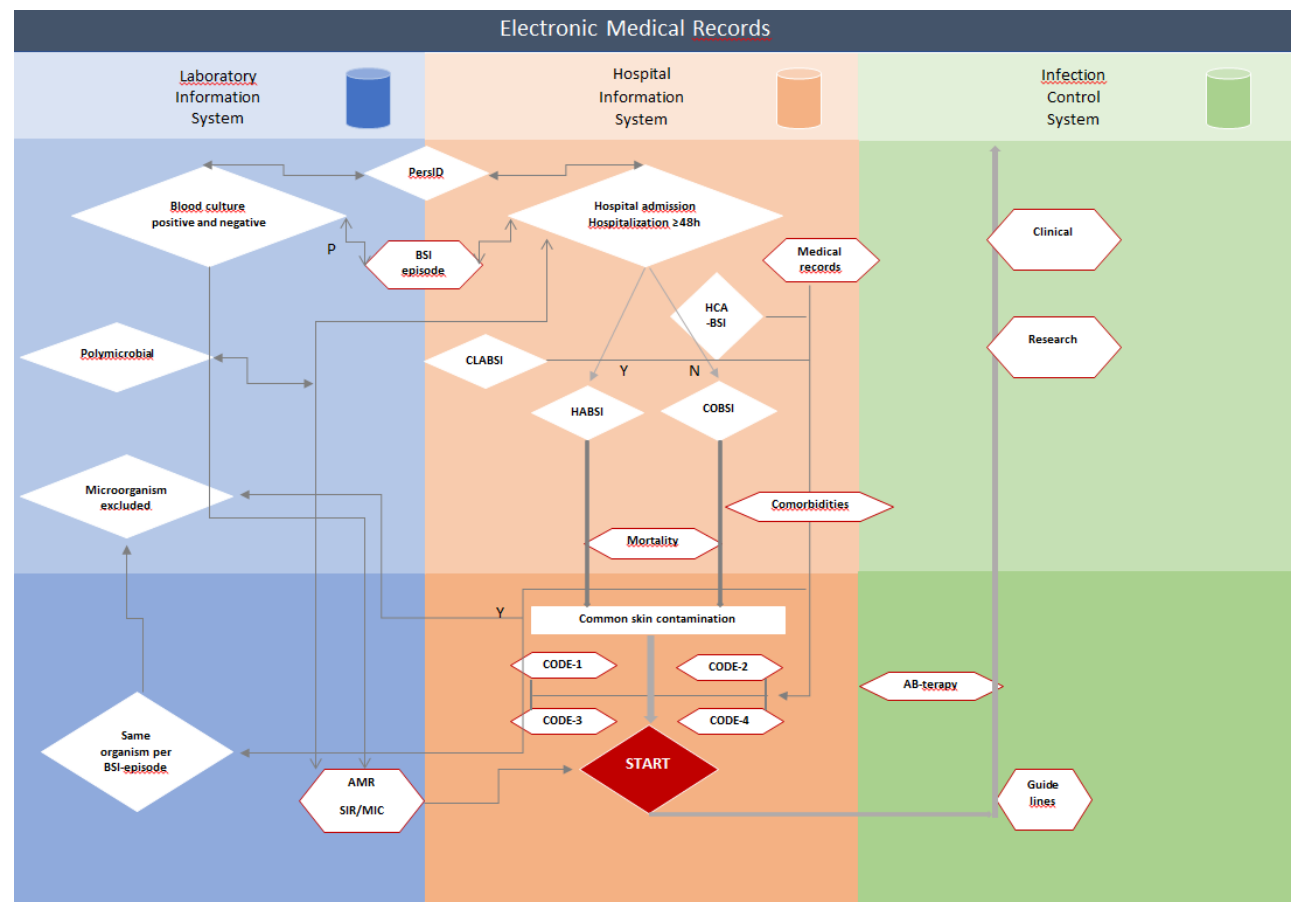

Fig 7. General architecture of the semi-automated surveillance and classification system. 
The database may be used to identify patients admitted to hospital with a predetermined combination of criteria including date of admission, location, hospital stay, culture results, susceptibility results, ICD-diagnosis, comorbidity, and various other laboratory results. Data from the microbiology laboratory and patient-specific data are collected twice a year. The database can be used to create tables with unique ID-tags where related data are grouped in rows and columns specifying primary keys and analysing relationships. This enables information from several tables to be compared at the same time, providing answers to specific research enquiries using SQL commands and keywords.

Figure 8. Bacteraemia "BaCt- $\mathrm{X}$ " database overview

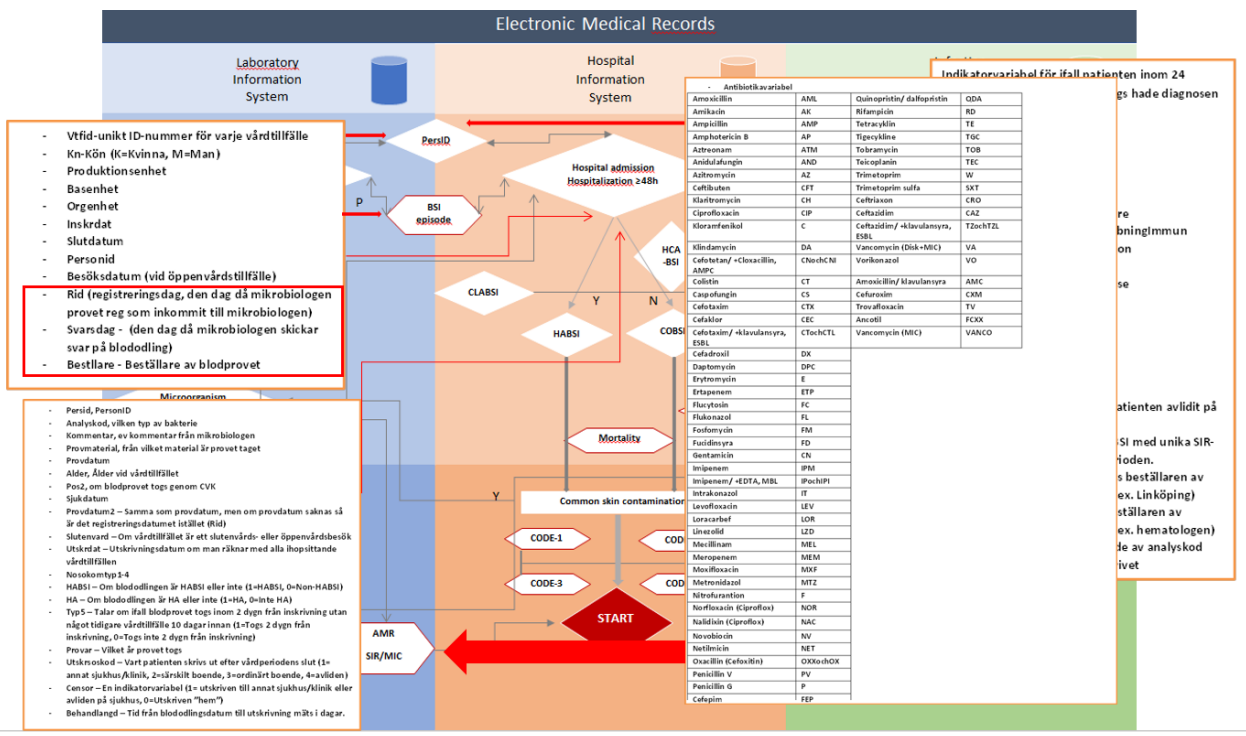

Fig 8. Computer algorithms (variables) for screening of data from laboratory information system, hospital information system, antibiotic information system, guidelines and death-register. 
Figure 9. An overview of the database structure (data model)

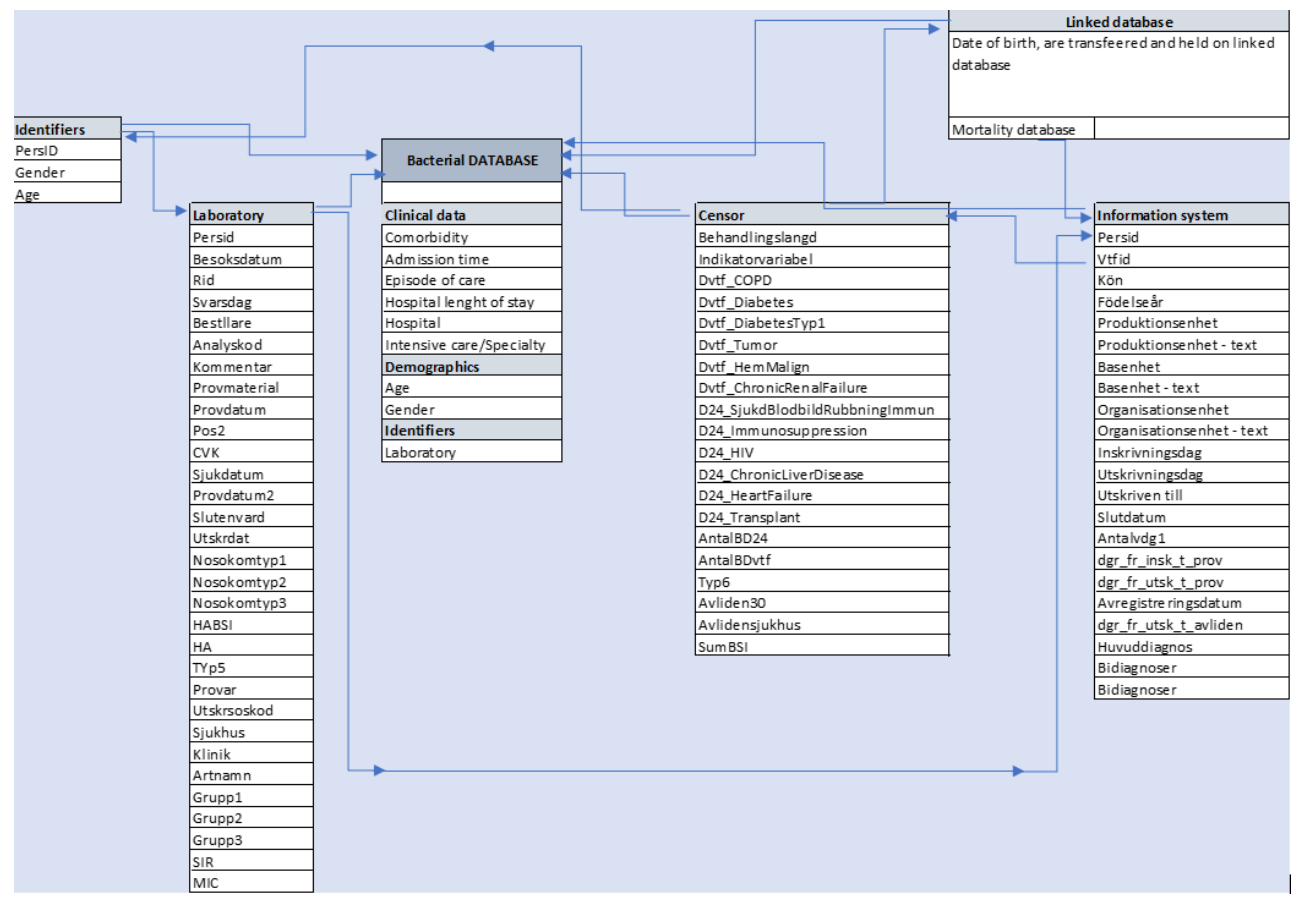

Fig 9. An overview of processes for an semi-automatic database generation

This unique infectious disease database includes data on patient care and microbiology data in south-east Sweden from 2000 onwards. It enables us to monitor and follow resistance patterns as well as burden of bloodstream infections in the county of Östergötland. Since 2000, all data on positive cultures have been assembled and matched with data from the patient care administration system, pharmacy database, and the Swedish Death Register. We have extracted data relevant to the research issues in this dissertation. 


\section{METHODOLOGICAL CONSIDERATIONS}

Several methodological issues are important when quantifying associations between antibiotic resistance, treatment, comorbidity, severity of illness, and outcome. In several studies evaluating the association between bacteraemia and patient outcome, sepsis and septic shock were incorporated as potential confounders. Yet sepsis and septic shock develop from bacteraemia and are the main cause of death, and should therefore not be adjusted for when assessing the association between antibiotic resistance and outcome [204]. However, if the goal is to determine the effect of adequate therapy on mortality, the presence of sepsis and septic shock before onset of therapy should be considered since these are associated with mortality. Choice of therapy is usually based on severity of disease at the onset of bacteraemia, and septic shock before onset of treatment is not part of the causal pathway of adequacy of treatment and mortality. The definition of comorbidity and the method used to obtain data are most important. Diagnoses are often based on clinical assessment, and this is difficult to validate in epidemiological studies. Hence, interpretation of comorbidity must be made with some caution. There are also financial incentives when diagnosing a patient. It is therefore important to study data over time to minimise sources of error. Severity of illness is an important confounding factor that should be accounted for when investigating the impact of antibiotic resistance or treatment on outcome. Severity of illness is best evaluated immediately before the onset of bacteraemia. When assessment is made at the time of hospital admission or ICU admission, two patients with an apparently similar prognosis at that time may have disease that evolved differently with different prognoses at the onset of bacteraemia. If severity of illness is measured after onset of bacteraemia, this could result in inappropriate adjustment for variables in the causal pathway rather than adjusting for the patient's mortality risk, thus underestimating the true effect. 


\subsection{Observational study design}

\subsubsection{Information bias}

A population-based observational study design was used in this dissertation, partly cohortstudies (Studies I, II and IV) and a case-control study (Study III). All inhabitants in the county of Östergötland, Sweden, were under constant surveillance for bacteraemia due to the observational study design and availability of all blood culture results within the county. Bacteraemia and BSI may be misclassified in several ways, the consequence of which would be underestimation or overestimation of the true rates of bacteraemia and BSI.

Sources of bias:

1. It cannot be ruled out that a few patients with bacteraemia will have either mild or no symptoms while others a have a rapidly fatal infection. In that case medical attention may not have been sought.

2. It is quite likely that some individuals were effectively treated by their general practitioner without hospitalisation. In support of this, we recently showed (Study IV) that patients with community-onset bacteraemia is a heterogenic group, and do not necessarily appear seriously ill.

3. Some patients may not have had their blood cultured and therefore some bacteraemia cases remain undetected and do not appear in the database.

4. Patients admitted critically ill with severe infection may have died before blood cultures were taken.

5. False-negative blood cultures may result due to prior use of appropriate antibiotics (prior to blood culture) either at the hospital or by the general practitioner.

6. We did not include patients with bacteraemia who were transferred or admitted to a hospital outside Östergötland County.

7. Using our inclusion criteria for true bloodstream infection (with associated computer algorithm), contaminations may have been misclassified as true bacteraemias or vice versa, which would lead to underestimation or overestimation of the true incidence rate of bacteraemia and BSI.

The above-mentioned sources of bias could of course affect our trend estimates if some of these biases changed significantly during the study period. Furthermore, it is difficult to 
analyse community-onset bloodstream infection because it is impossible to assess non-blood cultured individuals with our study design.

The Surviving Sepsis Campaign began in 2002-2003, prompting protocol-guided management of severely ill patients with suspected sepsis and septic shock, including taking blood cultures prior to administration of antibiotics [29]. We did not observe a significantly larger number of positive blood cultures per total number of blood cultures drawn at the end of the study period (Study I), which probably means few undetected bacteraemias. The cohort in this study was open and dynamic i.e., individuals may have entered the cohort one or several times (even with well-defined inclusion criteria). This could have affected incidence rate calculations.,

\subsubsection{Selection bias}

Two extremely large cohorts of patients admitted with bacteraemia were included in Studies I and II where we investigated incidence, mortality, and risk factors. Selection bias can arise from initial selection of the study-population if exposure (bacteraemia) and outcome (30-day mortality) differed between participants included in the study and those not included. To avoid bias, all patients in Studies I and II with a positive blood culture were included using well-defined selection criteria. But we may overestimate the impact of bacteraemia on 30-day mortality, because we only considered individuals with bacteraemia who were hospitalised. Some studies have shown that most patients included in bacteraemia databases have sepsis or septic shock $[205,206]$, whereas patients with bacteraemia treated in the community without the need for hospitalisation are probably less severely ill and have a better prognosis. On the other hand, we probably underestimated the impact of bacteraemia on 30-day mortality in cases where bacteraemia remained undetected in those patients who died before the blood culture was taken.

Furthermore, patients admitted to hospital with severe symptoms are more likely to have blood cultures taken after start of empirical antibiotic treatment than less ill patients, which could result in a false-negative blood culture, and underestimation of 30-day mortality associated with bacteraemia (by misclassification). [207]. 


\subsubsection{Confounding}

We accounted for several confounding factors by adjusting for them in our analyses. In Studies III and IV, gender, year of birth, microorganism, and year of blood sample were adjusted for in the matched design and the statistical models. Even when all confounding factors are known and controlled for, mortality in bacteraemia patients may explained by unmeasured, inappropriately measured, or by residual confounding factors. Residual confounding results from incorrect categorisation or misclassification of confounding factors. Unmeasured confounders include: "obesity, smoking, low income, and low educational level, all of which have been identified as predictors of short-term mortality among bacteraemia patients” [208, 209]. Other likely confounders include: 1) level of physical activity, 2) functional status, 3) nutritional status, 4) as well as use of medication, though this is somewhat inferred in the Charlson comorbidity index.

\subsubsection{The importance of choice of source population}

In this dissertation the criteria for those included in the source population were patients $\geq 18$ years-old, admitted to hospital in Östergötland, and a blood culture taken.

An appropriate source population is important to implement local surveillance programmes in hospitals, to optimise infection control, to monitor regional changes over time, to follow trends, and to develop local guidelines for the treatment of bloodstream infections (BSIs). Identification of appropriate participants (source population) is one of the most important tasks in the study to ensure generalisability of results and possibility of their application. Results are only valid for the population studied, and this is especially important in studies on antimicrobial resistant bacteria (AMR), risk factors for BSI, and mortality. Special study design considerations are necessary when the subject is prediction of infections with AMR bacteria (Study II). In Study IV, risk factors for BSI with ESBL-producing E. coli were compared to those with non-ESBL E. coli. This design could lead to bias by overestimating the significance of previous antibiotic treatment $[210,211]$ since individuals who have previously received effective antibiotic therapy are less likely to have a new infection (BSIepisode) with a susceptible bacterial pathogen. This implies that exposure to previous antibiotic therapy will be less probable in cases with non-ESBL-producing E. coli (control group). 


\subsubsection{Using matching variables}

Controls should be representative of the source population and randomly selected. Matching of confounders can improve efficiency and this is a method frequently used. A study without matching risks overlapping between cases and controls, and the only solution is to have a very large control group. For example, if a study on prostate cancer is not matched for age, there will be too few controls in the relevant age group. It is important with correction of matching variables in some statistical analyses, and the impact of a matching variable cannot be studied [212].

\subsubsection{Multivariable regression}

Multivariate regression analyses (models) are used to establish the relationship between a dependent variable and more than one independent variables. In this dissertation multivariate regression was used to measure the association between the variables examined and outcome of interest.

Studies I and II were based on all patients in the cohort and there were no selected controls and therefore no matching variables were considered. In Studies III and IV, the controls were randomly selected and matched for: gender, age, microorganism, and year of blood culture samples, and the multivariable regression was adjusted for these variables. The variables were purposefully selected for inclusion in the multivariable analyses. The selection was performed according to a modification of Hosmer, Lemshaw, and Sturdivant [213]. This process includes: “1. Careful univariate analysis; 2. Selection of variables to include considering a) clinical relevance b) a univariateladjusted p-value <0.20; and c) Avoidance of intermediate variables between exposure and the outcome variables; 3. Adaption of the model to all variables selected - variables with the highest p-value are removed and a new model designed; 4. The new model is compared to the old one by post estimation using the likelihood ratio test. If the new model differs significantly, the last-removed variable is reintroduced; and 5. This process continues until no variable can be removed without causing a significant difference between the new and previous model". 


\subsubsection{Software}

A relational database was used (Studies I-IV) to store, match, report, and analyse data (see Section 3). In Study IV, graphical illustrations and analysis of genomic sequences was done by web resources (see Section 1.2.9). Microsoft Excel, SPSS v24 and STATA v19 were used for data storage and statistical calculations.

\subsubsection{Ethical considerations}

Clinical data in Studies III and IV were extracted from the medical records of patients included, theoretically violating patient privacy. We chose, however, not to seek patient consent. The Regional Ethics Review Board in Linköping (replaced by Swedish Ethical Review Authority) approved the studies. (Dnr 2010/160-31).

The ethical dilemma or conflict in this case is between the individual's right to provide informed consent and the value of medical research for society, advancing medical knowledge to improve patient care in the future. However, uniform informed consent was not possible since many of the patients included were dead at the time of the study. Furthermore, we considered the value of the knowledge gained from the study would be significant. Indeed, this was the case. By identifying risk factors for mortality from bloodstream infection, particularly community-onset bloodstream infections, our research has expanded our medical knowledge, and this will improve the care of patients with BSIs in the future. Furthermore, we have increased our understanding of the epidemiology of BSI and antibiotic resistance patterns. All data were pseudonymised, handled strictly confidentially, and were password protected. 


\section{STUDIES I-IV}

5.1 STUDY I “14-Year Survey in a Swedish County Reveals a Pronounced Increase in Bloodstream Infections (BSI). Comorbidity - An Independent Risk Factor for Both BSI and Mortality"

Martin Holmbom, ${ }^{1,2}$ Christian G Giske, ${ }^{3.4}$ Mats Fredrikson, ${ }^{5.6}$ Åse Östholm Balkhed, ${ }^{1}$ Carina Claesson, ${ }^{7}$ Lennart E Nilsson, ${ }^{7}$ Mikael Hoffmann, ${ }^{8}$ Håkan Hanberger ${ }^{1}$

PLoS ONE 11(11): e0166527. doi:10.1371/journal.pone.0166527

Published: November 11, 2016. https://doi.org/10.1371/journal.pone.0166527.

Copyright: () 2016 Holmbom et al.

${ }^{1}$ Division of Infectious Diseases, Department of Clinical and Experimental Medicine, Faculty of Medicine and Health Sciences, Linköping University, Linköping, Sweden.

${ }^{2}$ Division of Urology, Department of Clinical and Experimental Medicine, Faculty of Medicine and Health Sciences, Linköping University, Linköping, Sweden.

${ }^{3}$ Department of Laboratory Medicine, Karolinska Institute, Stockholm, Sweden

${ }^{4}$ Clinical Microbiology, Karolinska University Hospital, Stockholm, Sweden

${ }^{5}$ Occupational and Environmental Medicine, Department of Clinical and Experimental Medicine, Faculty of Medicine and Health Sciences, Linköping University, Linköping, Sweden

${ }^{6}$ Forum Östergötland, Faculty of Medicine and Health Sciences, Linköping University, Linköping, Sweden.

${ }^{7}$ Division of Clinical Microbiology, Department of Clinical and Experimental Medicine, Faculty of Medicine and Health Sciences, Linköping University, Linköping, Sweden.

${ }^{8}$ The NEPI foundation, Division of Health Care Analysis, Department of Medical and Health Sciences, Faculty of Medicine and Health Sciences, Linköping university, Linköping, Sweden 


\section{Abstract}

Objectives we assessed the incidence, risk factors and outcome of BSI over a 14-year period (20002013) in a Swedish county.

Methods retrospective cohort study on culture confirmed BSI among patients in the county of Östergötland, Sweden, with approximately 440,000 inhabitants. A BSI was defined as either community-onset BSI (CO-BSI) or hospital-acquired BSI (HA-BSI).

Results of a total of 11,480 BSIs, 67\% were CO-BSI and 33\% HA-BSI. The incidence of BSI increased by $64 \%$ from 945 to 1,546 per 100,000 hospital admissions per year during the study period. The most prominent increase, $83 \%$ was observed within the CO-BSI cohort whilst HA-BSI increased by $32 \%$. Prescriptions of antibiotics in outpatient care decreased with $24 \%$ from 422 to 322 prescriptions dispensed/1,000 inhabitants/year, whereas antibiotics prescribed in hospital increased by $67 \%$ (from 424 to 709 DDD per 1,000 days of care). The overall 30-day mortality for HA-BSIs was $17.2 \%$, compared to $10.6 \%$ for CO-BSIs, with an average yearly increase per 100,000 hospital admissions of 2 and 5\% respectively. The proportion of patients with one or more comorbidities, increased from 20.8 to $55.3 \%$. In multivariate analyses, risk factors for mortality within 30 days were: HA-BSI (2.22); two or more comorbidities (1.89); single comorbidity (1.56); CO-BSI (1.21); male (1.05); and high age (1.04).

Conclusion this survey revealed an alarming increase in the incidence of BSI over the 14-year study period. Interventions to decrease BSI in general should be considered together with robust antibiotic stewardship programmes to avoid both over- and underuse of antibiotics.

Keywords bloodstream infection; bacteraemia, healthcare-associated; hospital-acquired, community-onset 


\subsubsection{Methods}

Design

Multicentre observational cohort study using prospectively recorded data.

\section{Objective}

To study incidence and outcome of bloodstream infection over a 14-year period (2000-2013) in Östergötland, Sweden.

\section{Exposure}

The exposure variables in this study required a blood culture taken between 2000 and 2013 in Östergötland, Sweden. For further analyses, a significant positive blood culture and admission to hospital for the associated BSI-episode were obligatory.

\section{Outcome}

The primary outcome was to investigate the incidence of bloodstream infection in general, as well as community-onset bloodstream infection (CO-BSI) and hospital-acquired bloodstream infection (HA-BSI) in particular. Secondary outcomes were 30-day mortality and associated risk factors for incidence and mortality.

\section{Study population}

Altogether 109,983 blood cultures were taken in adults ( $\geq 18$ years), resulting in 11,480 confirmed BSIs between 2000 and 2013 in the county of Östergötland, Sweden. All patients included had a positive blood culture i.e., isolation of a microorganism (one or more bacterial or fungal isolates) from a set of blood culture samples. BSI episode required hospital admission with a significant positive blood culture. If a patient had more than one BSI episode per admission, only the first was included in the analyses involving comorbidity and mortality. HA-BSI was defined as bloodstream infections occurring two or more calendar 
days after hospital admission, and CO-BSI was define as BSI occurring less than two calendar days after admission.

\section{Statistics and data analysis}

Using Poisson regression, we assessed changes in incidence of BSI and these are presented as IR ratios with 95\% confidence interval (CI). Chi-square tests and Wilcoxon rank-sum tests were used to determine differences in clinical characteristics between HA-BSI and CO-BSI. Linear regression was used to analyse annual trends of predominating pathogens defined at genus or species level. Unadjusted variables used to determine risk factors for BSI and 30-day mortality were analysed with Chi-square and t-test. Multivariable binomial regression analysis adjusted for confounding was used to determine risk factors. A p-value $<0.05$ was considered significant.

\subsubsection{Results}

The results of Study I show that between 2000 and 2013, the incidence of bloodstream infections, with hospital admissions as denominator, increased by $64 \%$ in Östergötland; community-onset BSI increased by $83 \%$ and hospital-acquired BSI by $32 \%$. Corresponding figures with hospital days as the denominator were $111 \%, 129 \%$, and $70 \%$ respectively. The 30-day mortality rate increased approximately 3\% each year and totaled 44\% (2000-2013), with an overall 30-day mortality of $17.2 \%$ for hospital-acquired BSI and $10.6 \%$ for community-onset BSI. Antibiotic use in primary healthcare decreased by $24 \%$ while that in hospital care increased by $67 \%$. The number of patients with comorbidity increased over the study period corresponding to a significant decrease in patients with no comorbidity. There was a significant association between hospital-acquired BSI in patients with haematological malignancy, tumour, and diseases of the blood and blood-forming organs with anaemia. Diabetes mellitus was more common among patients with community-onset BSI. Risk factor analysis for 30-day mortality revealed the following risk factors: hospital-acquired BSI (RR = 1.89, 95\% CI: 1.79-2.00); comorbidity (RR = 1.56, 95\% CI: 1.48-1.65); CO-BSI, $(\mathrm{RR}=$ 1.21, 95\% CI: $1.13-1.30)$; male gender ( $\mathrm{RR}=1.05,95 \% \mathrm{CI}: 1.01-1.11)$; and age $(\mathrm{RR}=1.04$, 95\% CI: 1.04-1.05). In conclusion, between 2000 and 2013 there were surprisingly large 
increases in the incidence of BSI, crude mortality rate, and comorbidity among patients with BSI in Östergötland. Comorbidity was an independent risk factor for both bloodstream infection and mortality. 


\title{
5.2 STUDY II "Low incidence of antibiotic-resistant bacteria in south-east Sweden: An
} epidemiologic study on 9268 cases of bloodstream infection"

\author{
Martin Holmbom ${ }^{1,2}$, Vidar Möller ${ }^{1}$, Lennart E. Nilsson ${ }^{3}$, Christian G. Giske ${ }^{4,5}$, Mamun-Ur Rashid ${ }^{1,4}$, Mats \\ Fredrikson $^{6,7}$, Anita Hällgren ${ }^{1}$, Håkan Hanberger ${ }^{*}$, Åse Östholm Balkhed ${ }^{1}$
}

PLoS ONE 15(3): e0230501. doi.org/10.1371/journal.pone.0230501

Published: March 27, 2020. . https://doi.org/10.1371/journal.pone.0230501

Copyright: () 2016 Holmbom et al.

${ }^{1}$ Department of Infectious Diseases in Östergötland, and Department of Biomedical and Clinical Sciences, Linköping University, Linköping, Sweden,

2 Department of Urology in Östergötland and Department of

Biomedical and Clinical Sciences, Linköping University, Linköping, Sweden,

${ }^{3}$ Department of Clinical Microbiology, and Department of Biomedical and Clinical Sciences, Linköping University, Linköping, Sweden,

${ }^{4}$ Department of Laboratory Medicine, Karolinska Institute, Stockholm, Sweden,

${ }^{5}$ Clinical Microbiology, Karolinska University Hospital, Stockholm, Sweden,

${ }^{6}$ Occupational and Environmental Medicine, Department of Biomedical and Clinical Sciences, Faculty of Medicine and Health Sciences, Linköping University, Linköping, Sweden,

${ }^{7}$ Forum Östergötland, Faculty of Medicine and Health Sciences, Linköping University, Linköping, Sweden. 


\section{Abstract}

Objectives The aim of this study was to investigate the epidemiology of bloodstream infections (BSI) in a Swedish setting, with focus on risk factors for BSI-associated mortality.

Methods A 9-year (2008-2016) retrospective cohort study from electronic records of episodes of bacteremia amongst hospitalized patients in the county of Östergötland, Sweden was conducted. Data on episodes of BSI including microorganisms, antibiotic susceptibility, gender, age, hospital admissions, comorbidity, mortality and aggregated antimicrobial consumption (DDD /1,000 inhabitants/day) were collected and analyzed. Multidrug resistance (MDR) was defined as resistance to at least three groups of antibiotics. MDR bacteria and MRSA, ESBL-producing

Enterobacteriaceae, vancomycin-resistant enterococci not fulfilling the MDR criteria were all defined as antimicrobial-resistant (AMR) bacteria and included in the statistical analysis of risk factors for mortality

Results In all, 9,268 cases of BSI were found. The overall 30-day all-cause mortality in the group of patients with BSI was $13 \%$. The incidence of BSI and associated 30-day all-cause mortality per 100,000 hospital admissions increased by $66 \%$ and $17 \%$ respectively during the nine-year study period. The most common species were Escherichia coli, Staphylococcus aureus, Klebsiella pneumoniae, Streptococcus pneumoniae and Enterococcus faecalis. Independent risk factors for 30day mortality were age (RR: 1.02 (CI: 1.02-1.03)) and 1, 2 or $\geq 3$ comorbidities RR: 2.06 (CI: 1.682.52), 2.79 (CI: 2.27-3.42) and 2.82 (CI: 2.31-3.45) respectively. Almost 3\% $(n=245)$ of all BSIs were caused by AMR bacteria increasing from 12 to 47 per 100,000 hospital admissions 2008-2016 $(\mathrm{p}=0.01)$, but this was not associated with a corresponding increase in mortality risk (RR: 0.89 (CI: 0.81-0.97)).

Conclusion Comorbidity was the predominant risk factor for 30-day all-cause mortality associated with BSI in this study. The burden of AMR was low and not associated with increased mortality. Patients with BSIs caused by AMR bacteria (MDR, MRSA, ESBL and VRE) were younger, had fewer comorbidities, and the 30-day all-cause mortality was lower in this group.

Keywords Multidrug resistance (MDR); antimicrobial resistance (AMR); ESBL-producing Enterobacteriaceae; MRSA; VRE; bloodstream infection; bacteremia; mortality; empiric antibiotic therapy; comorbidity. 


\subsubsection{Methods}

Design

Multicentre observational cohort study using prospectively recorded data.

\section{Objective}

To study the epidemiology of bloodstream infections focusing on risk factors for mortality and antimicrobial resistance in the Swedish setting.

\section{Exposure}

The exposure variables in this study required a blood culture taken between 2008 and 2016 in Östergötland, Sweden. A significant positive blood culture was required for antimicrobial resistance analysis and BSI analysis, and admission to hospital for an associated BSI was obligatory for analysis of BSI episodes. Multidrug resistance (MDR) was defined as nonsusceptibility to at least 1 agent from $\geq 3$ antimicrobial classes. Antimicrobial-resistant (AMR) bacteria were defined as MDR bacteria or ESBL-producing Enterobacteriaceae, MRSA, or vancomycin-resistant enterococci not fulfilling the MDR criteria.

\section{Outcome}

The primary outcome was to study incidence and impact of antimicrobial resistance bacteria (AMR bacteria) on 30-day mortality in a Swedish setting.

\section{Study population}

Altogether 98,363 blood cultures from adults ( $\geq 18$ years) were recorded. These resulted in 10,491 positive blood cultures and 9,268 episodes of BSI between 2008 and 2016 in Östergötland, Sweden. All patients included had a positive blood culture i.e., isolation of a microorganism (one or more bacterial or fungal isolates) from a set of blood cultures. BSI episode was defined as hospital admission with a significant positive blood culture. If a 
patient had more than one BSI episode per admission, only the first was included in the analysis involving comorbidity and mortality. A total of 9,587 microorganisms from 9,268 BSI episodes were analysed to investigate trend, incidence, and antimicrobial resistance for each pathogen. BSI episodes were divided between non-survivors (1,237 patients) and survivors $(8,031$ patients $)$ to study risk factors for 30-day mortality.

\section{Statistics and data analysis}

The incidence, BSI trend, and predominant pathogens were analysed by linear regression, presented as change in incidence with a 95\% CI. Chi-square and t-test were used for univariate analyses to determine risk factors for 30-day mortality. Multivariable regression analysis was used to calculate risk factors for incidence and 30-day mortality risk ratio with 95\% CI, adjusting for confounding factors. Patients with a negative blood culture were used as a reference group.

\subsubsection{Results}

Study II describes in-depth studies on risk factors for bloodstream infections and associated 30-day mortality. A clear association has previously been shown between antibiotic-resistant bacteria and mortality in BSI. However, we were unable to confirm this in Östergötland, where comorbidity was seen to be the dominating risk factor. Over the study period 20082016, the incidence of BSI continued to increase, with Gram-negative bacteria such as extended-spectrum $\beta$-lactamase-producing $E$. coli (ESBL) being the predominating pathogens. Despite this, a corresponding increase in mortality, as expected from previous observations, was not seen.

The overall 30-day all-cause mortality rate amongst patients with bloodstream infections was $13 \%$. The incidence of bloodstream infections and associated 30-day all-cause mortality per 100,000 hospital admissions increased by $66 \%$ and $17 \%$ respectively over the 9 -year study period. The most common species were Escherichia coli, Staphylococcus aureus, Klebsiella pneumoniae, Streptococcus pneumoniae, and Enterococcus faecalis. Antibiotic resistance rates increased over the study period, with significant increases in fluoroquinolone resistance 
from 3.7 to $7.7 \%(\mathrm{p}=0.01)$ and cephalosporin resistance from 2.5 to $5.2 \%(\mathrm{p}=0.03)$ amongst Enterobacteriaceae. The number of BSIs caused by E. coli resistant to ciprofloxacin increased from 9 to 43 (6.7-11\% per 100,000 hospital admissions, p=0.02), and by E. coli resistant to tobramycin from 2 to 19 BSI cases $(1.0-4.9 \%, \mathrm{p}=0.03)$. Significant increases in the number of BSIs with piperacillin-tazobactam-resistant organisms were observed among several gram-negative bacteria: Pseudomonas aeruginosa 0 to 5 (0-19.2\%), Klebsiella oxytoca 0-3 (0-13\%), and Enterobacter cloacae 0-6 BSI episodes (0-17.1\%). Almost 3\% $(n=245)$ of all BSIs were caused by AMR bacteria; an increase of 300\% from 12 to 47 per 100,000 hospital admissions 2008-2016 ( $\mathrm{p}=0.01$ ), but again, this was not associated with a corresponding increase in mortality risk (RR: 0.89 (CI: 0.81-0.97)). In conclusion, comorbidity, not antibiotic resistance, was the predominant risk factor for 30-day all-cause mortality associated with bloodstream infections in this study. 
5.3 STUDY III "Prehospital delay is an important risk factor for mortality in communityacquired bloodstream infection (CA-BSI): A matched case-control study"

Martin Holmbom ${ }^{1,2}$, Maria Andersson ${ }^{1}$, Sören Berg ${ }^{3}$, Dan Eklund ${ }^{1}$, Pernilla Sobczynski ${ }^{1}$, Daniel Wilhelms ${ }^{4}$, Anna Moberg ${ }^{5}$, Mats Fredrikson ${ }^{6}$, Åse Östholm Balkhed ${ }^{1 *}$, Håkan Hanberger ${ }^{1}$

Manuscript DOI: http://dx.doi.org/10.1136/bmjopen-2021-052582

Accepted for publication in BMJ Open

Copyright: () 2021 Holmbom et al.

${ }^{1}$ Division of Infectious Diseases, Department of Biomedical and Clinical Sciences, Faculty of Medicine and Health Sciences, Linköping University, Linköping, Sweden,

${ }^{2}$ Department of Urology and Department of Biomedical and Clinical Sciences, Linköping University, Linköping, Sweden,

${ }^{3}$ Unit for Cardiovascular Sciences, Faculty of Medicine and Health Sciences,

${ }^{4}$ Department of Emergency Medicine in Linköping, and Department of Biomedical and Clinical Sciences, Linköping University, Linköping, Sweden

${ }^{5}$ Department of Health, Medicine and Caring Sciences, Linkoping University, Linkoping, Sweden,

${ }^{6}$ Department of Biomedical and Clinical Sciences and Forum Östergötland, Faculty of Medicine and Health Sciences 


\section{Abstract}

Objectives The aim of this study was to identify prehospital and early hospital risk factors associated with 30-day mortality in patients with blood culture-confirmed community-acquired bloodstream infection (CA-BSI) in Sweden.

Methods A retrospective case-control study of 1,624 patients with CA-BSI (2015-2016), 195 nonsurvivors satisfying the inclusion criteria were matched 1:1 with 195 survivors for age, gender, and microorganism. All forms of contact with a healthcare provider for symptoms of infection within 7 days prior CA-BSI episode were registered. Logistic regression was used to analyse risk factors for 30-day all-cause mortality.

Results Of the 390 patients, 61\% (115 non-survivors and 121 survivors) sought prehospital contact. The median time from first prehospital contact till hospital admission was 13 hours (6-52) for nonsurvivors and 7 hours $(3-24)$ for survivors $(\mathrm{p}<0.01)$. Several risk factors for 30 -day all-cause mortality were identified: prehospital delay $\mathrm{OR}=1.26$ (CI: 1.07-1.47), $\mathrm{p}<0.01$; severity of illness (SOFA-score) $\mathrm{OR}=1.60$ (CI: 1.40-1.83), $\mathrm{p}<0.01$; comorbidity score (updated Charlson Index) $\mathrm{OR}=1.13$ (CI: 1.05-1.22), $\mathrm{p}<0.01$; and inadequate empirical antimicrobial therapy $\mathrm{OR}=3.92$ (CI: 1.64-9.33), $\mathrm{p}<0.01$. In a multivariable model, prehospital delay $>24$ hours from first contact remained an important risk factor for 30-day all-cause mortality due to CA-BSI OR=6.17 (CI: 2.1917.38), $\mathrm{p}<0.01$.

Conclusion Prehospital delay and inappropriate empirical antibiotic therapy were found to be important risk factors for 30-day all-cause mortality associated with CA-BSI. Increased awareness and earlier detection of bloodstream infection in prehospital and early hospital care is critical for rapid initiation of adequate management and antibiotic treatment. 


\subsubsection{Methods}

Design

Multicentre observational case-control study using prospectively recorded data.

\section{Objective}

To study prehospital and early hospital risk factors for 30-day mortality in patients with community-acquired bloodstream infection.

\section{Exposure}

The exposure variable in this study was community-acquired bloodstream infection in adults ( $\geq 18$ years), 2015-2016 in Östergötland, Sweden. To determine the impact of prehospital delay and early hospital care on 30-day mortality we matched non-survivors (case) with survivors (controls).

\section{Outcome}

Primary outcome was prehospital and early hospital risk factors for 30-day mortality.

\section{Study population}

A total of 1,624 culture-confirmed community-acquired BSIs in adults ( $\geq 18$ years) with a significant pathogen were included in the study. A total of 195 non-survivors (case) met the inclusion criteria and were matched with survivors 1:1 for age, gender, and microorganism. Data on all infection-related contacts with a healthcare provider within 7 days prior positive blood culture were collected and analysed. 


\section{Statistics and data analysis}

Quantitative variables were analysed using Student t-test and categorical variables using Chisquare test or Fisher exact test as appropriate. In other cases, Mann-Whitney U test or Kruskal Wallis test were used. A two-tailed $\mathrm{p}$ value $<0.05$ was considered statistically significant. Pairwise deletion was used to treat missing data. Imputation was not used. Univariate and multivariable analyses were performed with logistic regression.

\subsubsection{Results}

In Study III, we improved the study design and focused on factors underlying 30-day mortality 2015-2016. Data were extracted from patient records regarding pre-hospital and hospital care, clinical chemistry, antibiotic treatment, and microbiology (species identification and susceptibility patterns). Two cohorts were compared - those dying within 30 days (case, $\mathrm{n}=195$ ) and those surviving (controls, $\mathrm{n}=195$ ).

The purpose of this study was to investigate prehospital and hospital $(<24 \mathrm{~h})$ risk factors for 30-day mortality due to CA-BSI. The overall 30-day mortality rate of CA-BSI was $12.6 \%$ $(n=205)$. Almost $40 \%$ of the non-survivors died within 3 days after admission, increasing to $80 \%$ within 7 days. Of the total cohort, 236 patients sought prehospital care before being admitted to hospital. A significant difference was seen between non-survivors and survivors in time from first prehospital contact to hospital admission; 13 and 7 hours, respectively. There was a significant difference in time to admission depending on which healthcare facility was first contacted. Time to admission after contact with the region's telephone health advice service (1177) was shorter than when the patient contacted the local healthcare centre, physically or by phone ( $\mathrm{p}=<0.01$ respectively). Fever was the main reason for seeking prehospital care; $37 \%(88 / 236)$ in both groups.

Dysfunction of the respiratory, haemodynamic, or neurological systems on admission to hospital, was significantly more prominent in non-survivors than survivors. In-SOFA score (4.2 vs $2.3, \mathrm{p}=<0.01)$ and 24h SOFA score (6.8 vs $3.8, \mathrm{p}=<0.01)$, vital signs, and most laboratory test results were better in the survivor group. On admission, 75\% (119/158) of nonsurvivors and $52 \%(82 / 158)$ of survivors $(\mathrm{p}=<0.01)$ fulfilled the Sepsis 3 criteria. Within 24 
hours, $95 \%$ of non-survivors $(178 / 187)$ and $79 \%$ of survivors $(154 / 195)(\mathrm{p}=<0.01)$ fulfilled them.

The following risk factors for 30-day all-cause mortality were identified: prehospital delay (time from first infection-related contact with a healthcare facility to admission); severity of illness (SOFA-score and NEWS 2); comorbidity (updated Charlson score); and inadequate empirical antibiotic treatment. In the adjusted model, prehospital delay of 12-24 hours remained as an important risk factor for 30-day all-cause mortality associated with CA-BSI (OR 5.7, CI 2.20-14.74, $\mathrm{p}=<0.01$ ). 


\subsection{STUDY IV “Risk factors and outcome due to extended-spectrum $\beta$-lactamase-} producing uropathogenic Escherichia coli in community-onset bloodstream infections: a tenyear cohort study in Sweden"

Martin Holmbom ${ }^{1,2 *}$, Vidar Möller ${ }^{1 *}$, Loa Kristinsdottir ${ }^{1}$, Maud Nilsson ${ }^{3}$, Mamun-Ur Rashid ${ }^{4}$, Mats Fredriksson $^{5}$, Björn Berglund ${ }^{3}$, Åse Östholm Balkhed ${ }^{1}$.

\section{Submitted manuscript \\ Copyright: () 2021 Holmbom et al.}

\footnotetext{
${ }^{1}$ Division of Infectious Diseases, Department of Biomedical and Clinical Sciences, Faculty of Medicine and Health Sciences, Linköping University, Linköping, Sweden,

${ }^{2}$ Department of Urology and Department of Biomedical and Clinical Sciences, Linköping University, Linköping, Sweden,

${ }^{3}$ Department of Biomedical and Clinical Sciences, Linköping University, Linköping, Sweden.

${ }^{4}$ Department of Health, Medicine and Caring Sciences, Linkoping University, Linkoping, Sweden,

5 Department of Biomedical and Clinical Sciences and Forum Östergötland, Faculty of Medicine and Health Sciences.
} 


\section{Abstract}

Objective. To study clinical outcome and risk factors associated with extended-spectrum $\beta$ lactamase (ESBL)-producing uropathogenic Escherichia coli (UPEC) in community-onset bloodstream infections (CO-BSI).

Methods. This was a population-based cohort study including patients with pheno- and genotypematched ESBL-producing E. coli and non-ESBL- E. coli in urine and blood samples collected in 2009-2018 in southeast Sweden. Seventy-seven episodes of ESBL-UPEC satisfying the inclusion criteria were matched 1:1 with 77 non-ESBL-UPEC for age, gender, and year of culture.

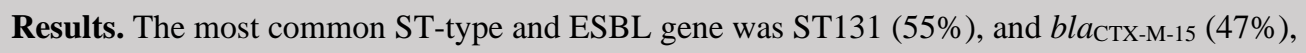
respectively. Risk factors for ESBL-UPEC were: previous genitourinary invasive procedure (RR 4.66; $p=0.005)$ or history of ESBL-producing Enterobacteriaceae (RR 12.14; $p=0.024)$. There was significant difference between ESBL-UPEC and non-ESBL-UPEC regarding time to microbiologically appropriate antibiotic therapy $(27: 15 \mathrm{~h}$ vs. $02: 14 \mathrm{~h} ; \mathrm{p}=<0.001)$ and hospital days ( 9 vs. $5 ; \mathrm{p}=<0.001$ ), but no difference in 30-day mortality (3\% vs. 3\%; $\mathrm{p}=>0.999$ ) or sepsis within 36 hours $(51 \%$ vs. $62 \%$; $=0.623)$ was observed.

Conclusion. Prolonged time to appropriate antibiotic therapy for ESBL-UPEC did not increase 30day mortality or the risk for sepsis within 36 hours. The predominant risk factors for ESBL-UPEC were: 1) history of ESBL-Ec infection; 2) history of genitourinary invasive procedure.

Keywords: Extended-spectrum $\beta$-lactamase (ESBL)-producing uropathogenic Escherichia coli (UPEC); community-onset bloodstream infections (CO-BSI); risk factors; clinical outcome.

Summary: Prolonged time to appropriate antibiotic therapy did not increase mortality or development of sepsis in community-onset bloodstream infections caused by extended spectrum $\beta$ lactamase producing uropathogenic Escherichia coli. 


\subsubsection{Methods}

Design

Multicentre observational cohort study using prospectively recorded data.

\section{Objective}

To study clinical outcome and risk factors associated with extended-spectrum $\beta$-lactamaseproducing (ESBL)-producing uropathogenic Escherichia coli (UPEC).

\section{Exposure}

The exposure variable in this study was blood and urine cultures taken between 2009 and 2018 in Östergötland, Sweden, showing ESBL-producing UPEC and non-ESBL UPEC in community-onset bloodstream infections (CO-BSI).

\section{Outcome}

The primary outcome was to study 30-day mortality and sepsis due to ESBL-producing UPEC. A secondary outcome was to study risk factors for ESBL-producing UPEC infection.

\section{Study population}

A total of 3,786 confirmed E. coli BSIs were obtained. Of these, 153 ESBL-producing E. coli BSIs were observed between 2009-2018 in Östergötland, Sweden. Of these, 77 met the inclusion criteria for ESBL-producing UPEC BSI and were matched with non-ESBL UPEC BSIs 1:1 for age, gender, and year of blood culture.

\section{Statistics and data analysis}

To analyse categorical variables, we used Fisher exact test or Chi-square test and quantitative variables were analysed using Student t-test. Univariate and multivariable analyses were 
performed with logistic regression. A two-tailed $\mathrm{p}$ value $<0.05$ was considered statistically significant.

\subsubsection{Results}

We had previously demonstrated an increase in gram-negative BSIs, particularly E. coli and ESBL-producing E. coli. Urinary tract infection is frequent in the community, and complicated urinary tract infection is a common cause of urosepsis in adults over the age of 65 [214]. Study IV, an observational cohort study, analysed clinical outcome and risk factors associated with 30-day mortality among patients with extended spectrum $\beta$-lactamaseproducing uropathogenic E. coli (ESBL UPEC) in bloodstream infection. In this study, a total of 77 ESBL UPEC infections were identified by genome assembly and bioinformatics analysis between 2009-2018 and 1:1 matched by gender, age, and year of blood culture to non-ESBL UPEC infections. The most common sequence types among ESBL-producing UPEC was ST131 (55\%), followed by ST38 (10\%) and ST405 (9\%). In the non-ESBL group there was a greater spread, and the most common STs were ST69 (15\%), ST73 (14\%) and ST95 (13\%). Comorbidity, severity of disease on admission to hospital, and initial treatment provided did not significantly differ between the groups. Univariate analysis provided several possible predisposing factors to the development of ESBL-producing UPEC: antibiotic treatment within the previous 3 months (66\% vs $36 \%)$; use of $3^{\text {rd }}$ generation cephalosporins within the previous 3 months (23\% vs 9\%); UTI within the previous 12 months (49\% vs $22 \%$ ); recurrent UTI (44\% vs $12 \%$ ); genitourinary tumour ( $27 \%$ vs $8 \%$ ); genito-urinary procedure/surgery within the previous 12 months (39\% vs $8 \%$ ); previous infection with ESBL-producing organism (26\% vs $1 \%$ ); and recent urinary catheterisation (26\% vs $9 \%$ ) all of which differed significantly between the ESBL-producing and non-ESBL-producing UPEC bacteraemia groups. Multivariate analysis showed that genitourinary procedure/surgery within 12 months prior to BSI (OR 4.66; $\mathrm{p}=0.005)$ and infection with ESBL-producing organism within 24 months prior to BSI (OR 12.14; $\mathrm{p}=0.024$ ) remained independent risk factors for ESBL-producing UPEC bloodstream infection.

Time to initiation of appropriate antibiotic treatment differed significantly between ESBLUPEC and non-ESBL UPEC BSIs ( $(27: 15 \mathrm{~h}$ vs $02: 14 \mathrm{~h} ; \mathrm{p}<=0.001)$ but there was no significant difference in mortality rate between patients in the ESBL UPEC $3 \%(2 / 77)$ and non-ESBL UPEC 3\% (2/77) groups. Furthermore, we did not see an increased risk for sepsis within 36 
hours in the ESBL UPEC compared to the non-ESBL UPEC group (51\% vs 62\%; $\mathrm{p}=0.623$ ) despite the delay in appropriate antibiotic treatment. Even when we compared the ESBL group regarding empirical appropriate $(n=22)$ vs. empirical non-appropriate $(n=55)$ antibiotic therapy no increased risk for sepsis or mortality was observed. 


\section{DISCUSSION}

\section{General}

The results presented in this dissertation answer many questions regarding the present status of BSI and antibiotic resistance in Östergötland, Sweden. However, new questions have been raised. In this chapter, future research and the methodological issues that need to be addressed will be discussed.

Several lessons in clinical practice can be learned from our results. There has been a surprisingly large increase in the incidence of BSI and associated mortality. The following factors have contributed to this are: 1) The number of vulnerable individuals in the community has increased (higher age and comorbidity); 2) Other population characteristics have changed; 3) Awareness of sepsis has increased and more blood cultures are taken; and 4) Needs for improved prehospital care. The prevalence of antibiotic resistance increased, but its impact on mortality was far less than comorbidity and severity of illness in this Swedish setting. From the patient perspective, BSI prevention should be aimed at improving healthcare in general, irrespective of antibiotic resistance. At the community level, however, the increasing burden of community-onset bloodstream infection does depend on increasing numbers of antibiotic resistant microorganisms. Indeed, from the economical and hospital perspective, the best way to reduce the total burden of BSI is not only prevention through identification of patients at risk, but also by reducing the prevalence of antibiotic resistance through lower antibiotic consumption and specific measures aimed at antibiotic-resistant bacteria. Since elderly patients with comorbidity and severe illness are those likely not to survive, strategies must be implemented to identify these patients and provide immediate and adequate care. Only then will the burden of this disease wane. 


\subsection{BLOODSTREAM INFECTION}

\subsubsection{Incidence}

The incidence of BSI has increased in most other population-based studies [5, 188, 215, 216], but the range is wide (76 to 215 BSIs per 100,000 persons per year) $[5,55,56,188,217,218]$. Since the incidence of BSI in Study I (Section 5.1) increased from 169 bloodstream infections/100,000 persons/year in 2000, to 266 BSIs/100,000 persons/year in 2013 (Figure 10 ), and we are above the upper range of those reported in other studies.

Figure 10. Incidence rate of bloodstream infections (BSIs, CO-BSIs and HA-BSIs), 2000-2013 per 100,000 persons and year

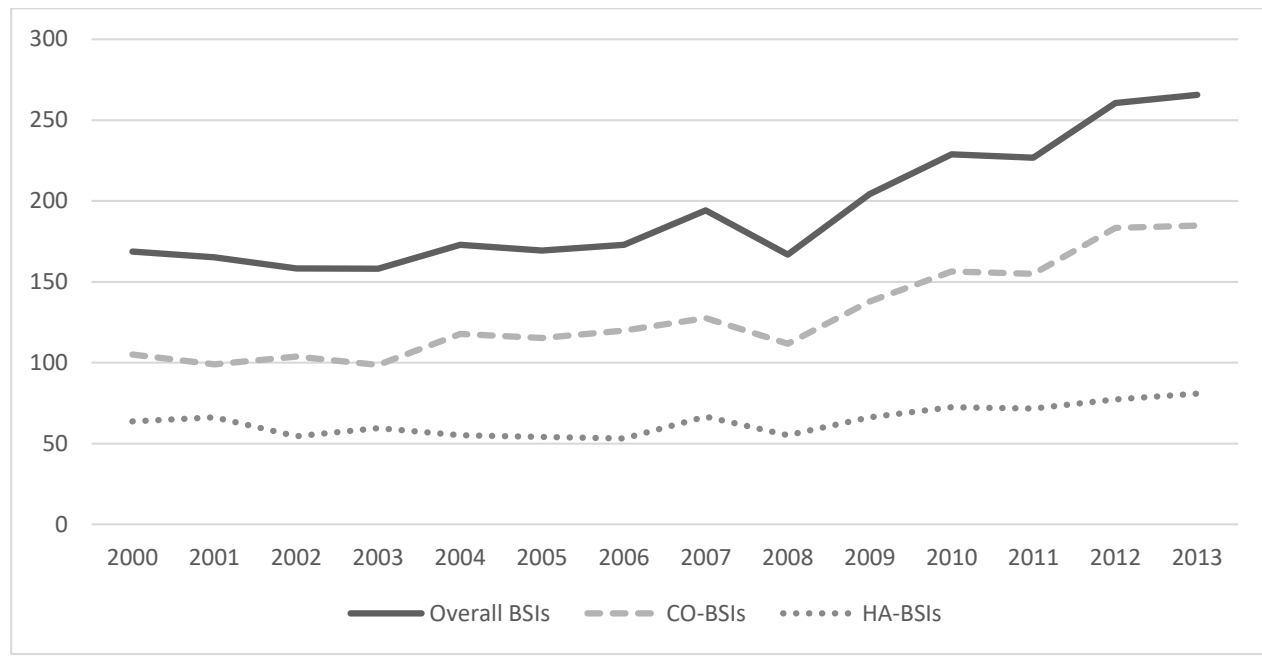

Fig 10. Positive blood culture: Defined as the isolation of microorganisms (one or more bacterial or fungal isolates) from a set of blood cultures taken on the same day. Non-significant pathogen: Microorganisms typically belonging to the skin microbiota (Coagulase-Negative Staphylococci, (CoNS), Micrococcus spp., Bacillus spp., Corynebacterium spp., and Propionibacterium spp.) were considered to be probable contaminants and excluded. An exception to this was CoNS isolated from blood cultures taken from at least two different puncture sites on the same occasion. Repeat isolate: Culture of same species with identical susceptibility pattern isolated during the same admission episode (from admission until hospital discharge). Repeat isolates were excluded. Episodes of BSI: An episode fulfilling the criterion "positive blood culture with a significant pathogen". New episode of BSI: Infection caused by a different bacterial or fungal pathogen $>3$ calendar days after the previous admission or by the same bacterial or fungal pathogen $>30$ calendar days after the previous admission. 
Figure 11. Incidence rate of bloodstream infections (BSIs, CO-BSIs and HA-BSIs), 20002016 per 100,000 hospital admission and year.

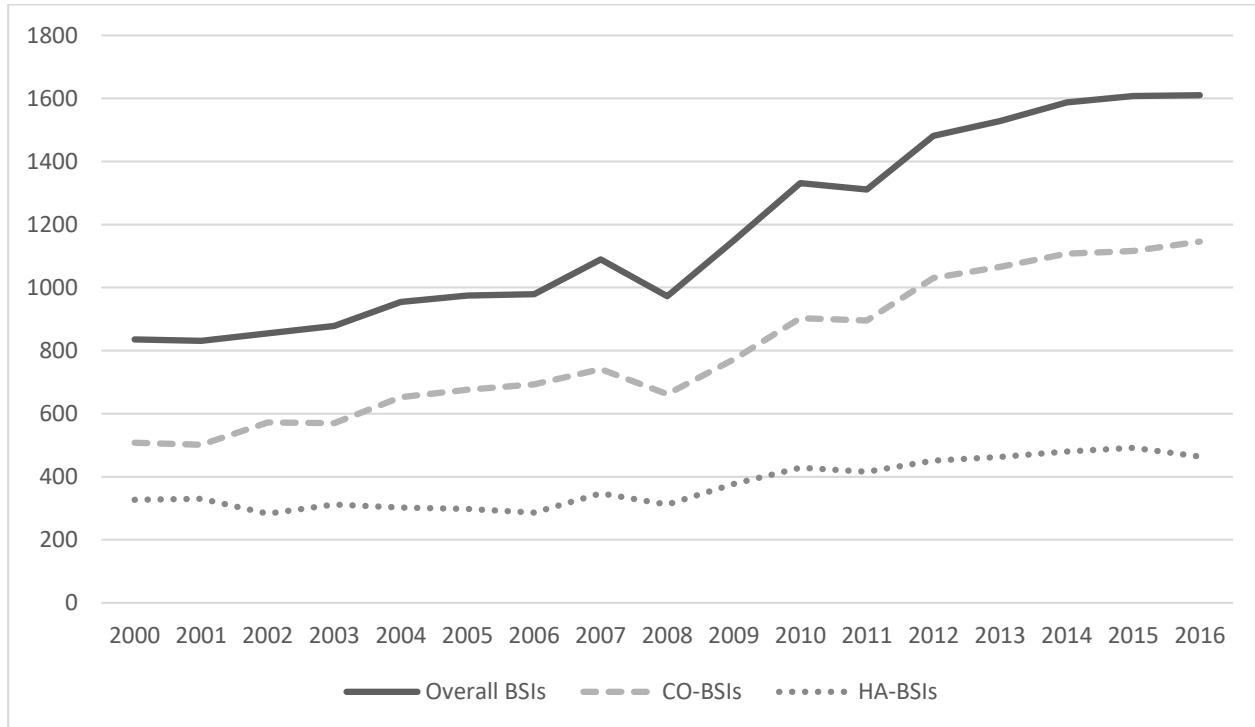

Fig 11. Positive blood culture: Defined as the isolation of microorganisms (one or more bacterial or fungal isolates) from a set of blood cultures obtained on the same day in an adult ( $\geq 18$ yrs). Only initial bacterial or yeast isolates were considered, thus repeat isolates of the same species with the same antibiogram (or change between $S$ and I or I and R) from the same patient were excluded. Nonsignificant pathogens: Microorganisms typically belonging to the skin microbiota: (coagulasenegative staphylococci, (CoNS); Micrococcus spp.; Bacillus spp.; Corynebacterium spp.; and Cutibacterium spp.), were considered probable contaminants and excluded. Repeat isolate: Culture of same species with identical resistance pattern isolated during the same admission episode (from admission until hospital discharge). Repeat isolates were excluded. BSI episode: An episode fulfilling the criterion "positive blood culture showing a significant pathogen". New BSI episode: Infection caused by a different bacterial or fungal pathogen $>3$ calendar days after the previous BSI episode or by the same bacterial or fungal pathogen $>30$ calendar days after the previous BSI episode.

The incidence of bloodstream infection increased in both our studies (Study I and Study II). The ratio between community-onset BSI and hospital-acquired BSI in Study I (Section 5.1) was surprising. The relatively larger increase in community-onset BSI may explained by difficulty in objectively deciding the true source of infection and variation in application of definitions [47]. There has also been a dramatic shift in healthcare delivery in recent years, where complex medical care such as haemodialysis and parenteral therapy is now provided in 
the community setting. As a result, patients in the community are exposed to infections that, by definition, were previously classed as hospital-associated/acquired. We were unable to separate these patients from patients with traditional community-onset BSI using data from the patient administration system, so we cannot comment on this possibility. This was also a limitation of the Danish BSI study by Nielsen et al, where $46 \%$ of BSIs were communityacquired, $31 \%$ were nosocomial (equivalent to hospital-acquired BSI in our study (33\%)), and $23 \%$ were healthcare-associated [219]. The last-named group only included patients discharged from a haematology, oncology, or nephrology clinic within 30 days prior to admission. Only $2 \%$ of patients registered as CO-BSI in the present study were admitted to a haematology or oncology department, but among the patients with HA-BSI, 19\% were treated on these wards, indicating that most BSIs amongst patients with cancer were registered as HA-BSI. However, the exact proportion of healthcare-associated but not hospital-acquired BSIs among those with community-onset BSI (CO-BSI) cannot be ascertained from our data. Patients with HA-BSI had a significantly longer hospital stay than those with CO-BSI. This may well be a consequence of the definitions used and agrees with other studies [55, 220222].

Furthermore, the number of HA-BSIs may be an underestimation since only the first BSI event was considered. If a patient admitted for a community-associated BSI suffered a second hospital-acquired BSI during the same admission, the latter would not have been included. However, since only $2 \%$ of patients had more than one BSI during the same admission, the impact on the results was minimal.

Another possible factor contributing to the increase in BSI was the increase in rate of blood cultures taken per patient admitted (from $8.2 \%$ to $15.4 \%$ per hospital admission). This was a consequence of the Surviving Sepsis campaign. However, the proportion of blood cultures that were positive only decreased from 12.9 to $11.3 \%$, indicating that no major change in strategy regarding blood culture taking took place during the study period.

An important factor in epidemiological observational studies is how contaminants are defined and managed. If coagulase-negative staphylococci were isolated from blood culture samples in our study, at least two different puncture sites taken on the same occasion were required for this to be classified as a BSI (usually central line-associated BSI (CLABSI)). In this study, $3.9 \%$ of all BSIs were caused by CoNS compared to $10 \%$ in the study by Skogberg et al where skin contaminants were included, and $10 \%$ in the study by Nielsen et al including skin 
contaminants if detected in $\geq$ two blood culture sets within 5 days [5, 219]. BSI studies not excluding skin contaminants should be judged with caution since this may have an impact on data including incidence, infectious agent, and mortality.

A limitation of this study is not knowing the exact time of admission and BSI samplings, plus the fact that two calendar days was the minimum time a patient could be hospitalised before being diagnosed with a HA-BSI (see Methods) which in practice could have been anything between 25 and 48 hours. The mean time that patients with HA-BSI had their blood culture taken was 6.3 days after admission, which suggests that this had no influence on how the BSI was classed. This is also supported by the fact that the corresponding mean time to first COBSI blood culture was 0.12 days after admission. Furthermore, the use of 2 or 3 calendar days is equivalent to the 48 hours definition of CO-BSI in the study performed by Laupland et al [223]. 


\subsubsection{Mortality}

The 30-day mortality rate increased over both study periods (Section 5.1 and 5.2). In Study I the overall increase was 44\%, with an average annual increase of $2.9 \%$ 2000-2013. In Study II (Section 5.2), an increase of 17\% was seen between 2008 and 2016 but reached a plateau between 2013 and 2016. The overall 30-day mortality rates in the two studies were similar (12.8\% and 13\%), agreeing with figures reported from Europe, North America, and Finland $[4,5,7]$.

Figure 12. 30-day mortality in BSI (overall BSI, CO-BSI and HA-BSI) per 100,000 hospital admission and year

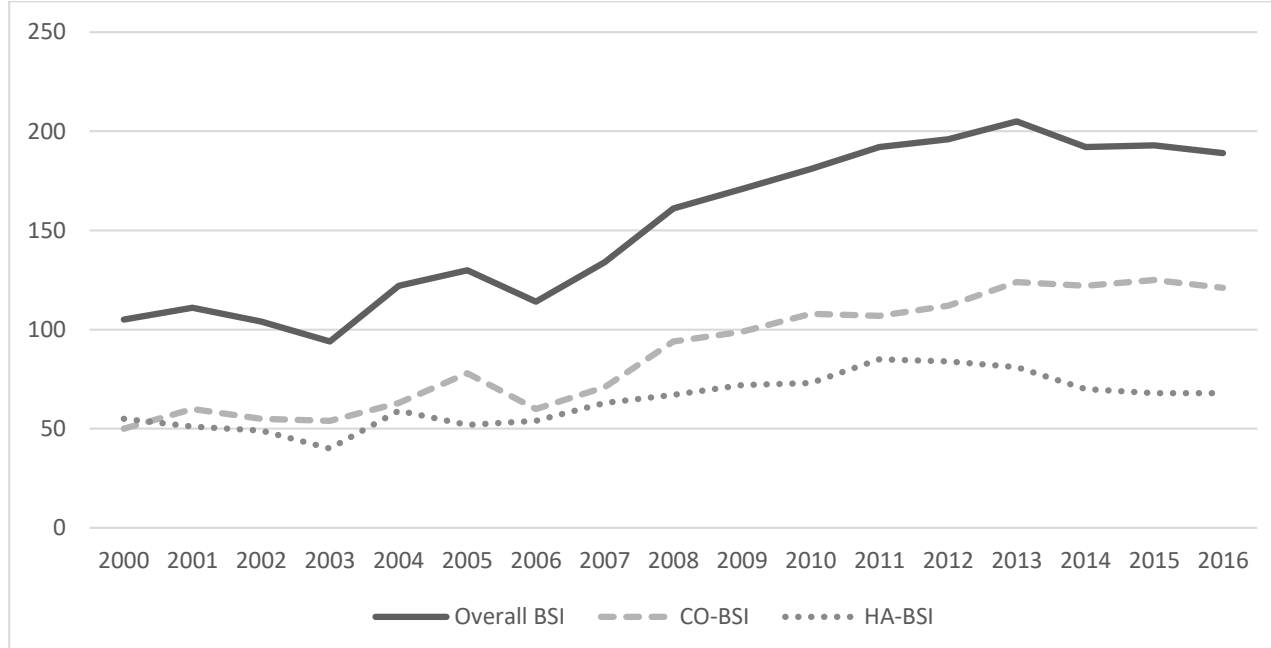

Fig 12. Positive blood culture: Defined as the isolation of microorganisms (one or more bacterial or fungal isolates) from a set of blood cultures obtained on the same day in an adult ( $\geq 18$ yrs). Only initial bacterial or yeast isolates were considered, thus repeat isolates of the same species with the same antibiogram (or change between $S$ and I or I and R) from the same patient were excluded. Nonsignificant pathogens: Microorganisms typically belonging to the skin microbiota: (coagulasenegative staphylococci, (CoNS); Micrococcus spp.; Bacillus spp.; Corynebacterium spp.; and Cutibacterium spp.), were considered probable contaminants and excluded. Repeat isolate: Culture of same species with identical resistance pattern isolated during the same admission episode (from admission until hospital discharge). Repeat isolates were excluded. BSI episode: An episode fulfilling the criterion "positive blood culture showing a significant pathogen". New BSI episode: Infection caused by a different bacterial or fungal pathogen $>3$ calendar days after the previous BSI episode or by the same bacterial or fungal pathogen $>30$ calendar days after the previous BSI episode. 
In Study II (Section 5.2), further analysis revealed a $98 \%$ increase in the number of patients with BSI plus two or more comorbidities over the study period. This increase in comorbidity reflects the increase in risk for fatal outcome. The dominant risk factor for 30-day all-cause mortality associated with bloodstream infections in Study I and Study II (Section 5.1 and 5.2) was comorbidity, which agrees with previous studies $[7,56,187]$.

Table 2. Risk factors for 30-day all-cause mortality in bloodstream infection (2000-2013).

\begin{tabular}{rrrr}
\cline { 2 - 4 } & Risk Ratio* $^{*}$ & 95 \% -Conf & p-value \\
\hline CO-BSI & 1.21 & $1.13-1.3$ & $<0.01$ \\
HA-BSI & 2.22 & $2.02-2.33$ & $<0.01$ \\
Age & 1.04 & $1.04-1.05$ & $<0.01$ \\
Female & 0.95 & $0.91-0.99$ & 0.02 \\
Year & 0.98 & $0.98-0.99$ & $<0.01$ \\
Comorbidity & & & $<0.01$ \\
1 & 1.56 & $1.48-1.65$ & $<0.01$ \\
\hline 2 & 1.89 & $1.79-2$ & \\
\hline
\end{tabular}

* Multivariate binomial regression analysis

Table 3. Risk factors for incidence and 30-day all-cause mortality in bloodstream infection (2008-2016).

BSI Incidence 30-day mortality

\begin{tabular}{rrrrr}
\hline Risk Ratio* & \multicolumn{2}{c}{ 95\% CI p-value } & Risk Ratio* $^{*}$ 95\% CI & p-value \\
\hline $1.01(1.01-1.01)$ & $<0.01$ & $1.02(1.02-1.03)$ & $<0.01$ \\
0.99 & $(0.95-1.03)$ & 0.58 & $1.05(0.94-1.17)$ & 0.39
\end{tabular}

Number of comorbidities

\begin{tabular}{lrrrr}
0 & 1 & & 1 & \\
1 & $1.25(1.18-1.32)$ & $<0.01$ & $2.06(1.68-2.52)$ & $<0.01$ \\
2 & $1.32(1.24-140)$ & $<0.01$ & $2.79(2.27-3.42)$ & $<0.01$ \\
$\geq 3$ & $1.58(1.50-1.67)$ & $<0.01$ & $2.82(2.31-3.45)$ & $<0.01$ \\
AMR BSI** & & & $0.89(0.81-0.97)$ & 0.01 \\
\hline
\end{tabular}

* Multivariate binomial regression analysis

** MDR bacteria and MRSA, ESBL, VRE) 
A major limitation is that individual patient data on site of infection, appropriate antibiotic treatment, and severity of disease were not available in our database. We were thus unable to assess any association between antibiotic use and risk for antibiotic resistant pathogens, or between specific empirical antibiotic regimens and outcome. Nor could we determine if delay in appropriate antibiotic treatment was a risk factor for mortality, as shown by Andersson et al [224] in a similar setting. Furthermore, other causes of mortality such as pulmonary embolus, respiratory failure, or myocardial infarction were registered as a comorbidity and not evaluated as a primary cause of death. Another limitation was that risk factor and mortality analyses were performed on the initial BSI event: if a patient admitted for a communityacquired BSI subsequently suffered a hospital-acquired BSI during the same admission, this was not included. However, since only $2 \%$ of patients had more than one BSI during the same admission, this limitation had minimal effect on the results.

Furthermore, since this is a population-based study without data from individual medical records, we did not know if the information received was correct and that adequate empirical treatment was given. The antibiotic resistance rate for major pathogens in Sweden is low $[175,190,225-227]$, and treatment failure due to infection with an antibiotic-resistant organism was probably uncommon in the present material, which explains why antibiotic resistance had little effect on mortality. 


\subsubsection{Comorbidity}

The number of patients with comorbidities increased significantly over the study period. Increase in comorbidity rate was a major factor behind the increase in mortality associated with BSI. There was no great change in patient age from year to year to explain this. Furthermore, being a retrospective study based on database information, changes in classification and reporting of diseases, and improvement in diagnostics during the study period could also have led to an apparent increase in the prevalence of comorbidity. In view of this, the significance of this variable must be interpreted with caution.

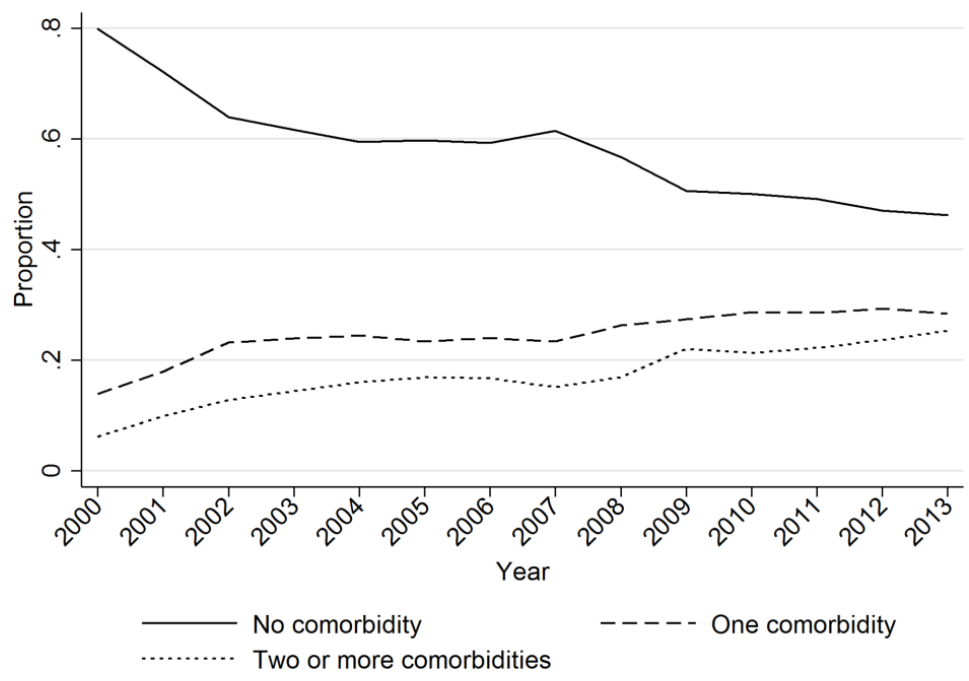

Fig 13. The proportions of comorbidity among patients with bloodstream infection. 


\subsubsection{Antimicrobial resistance}

In Study II (Section 5.2) we examined the pathogens involved and antimicrobial resistance as risk factors for mortality. BSI pathogens with antimicrobial resistance (AMR) increased from 12 to 47 per 100,000 hospital admissions, 2008-2016.

Figure 14. Antimicrobial resistance (AMR) per BSI-episode, 2008-2016

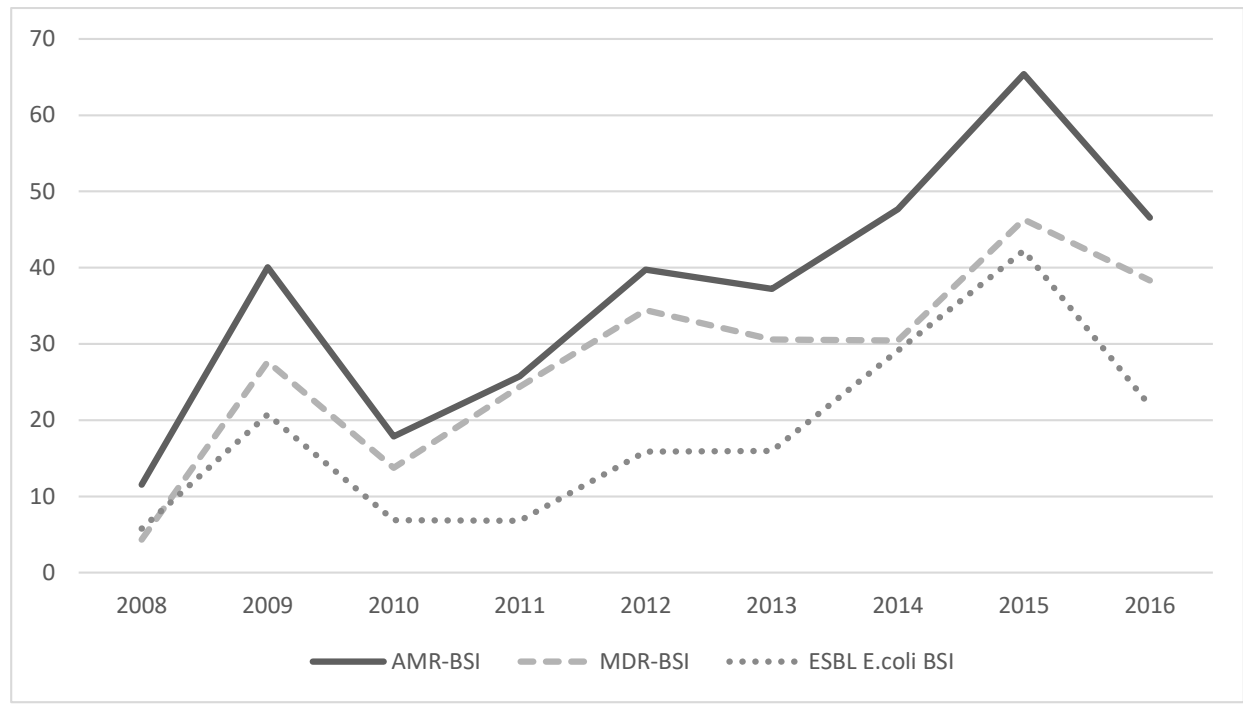

Fig 14. Antimicrobial Resistance (AMR): Bacteremia causes by MDR bacteria and MRSA, ESBLproducing Enterobacteriaceae, vancomycin-resistant enterococci not fulfilling the MDR criteria were defined as antimicrobial-resistant (AMR) bacteria. Multidrug resistance (MDR): Non-susceptibility to at least 1 agent in $\geq 3$ antimicrobial classes. Extended-spectrum $\boldsymbol{\beta}$-lactamase (ESBL) producing $\boldsymbol{E}$. coli: Isolates were defined as ESBL if the E. coli isolate demonstrated a positive phenotypic test indicating production of classic ESBLs, carbapenemases according to the definitions of the Swedish Public Health Agency and European Committee for Antimicrobial Susceptibility Testing (EUCAST) recommendations.

The 30-day mortality rate due to BSIs caused by AMR bacteria was 9.4\%. Ironically, 30-day mortality among patients with BSIs caused by antibiotic-resistant bacteria such as ESBLproducing E. coli, MRSA, and VRE without MDR, was lower than in patients with susceptible bacteria. In both studies, E. coli was the major cause of BSIs. In Study II (Section 5.2) we found an increase in BSI caused by $E$. coli resistant to cephalosporins, fluoroquinolones and aminoglycosides which concurs with global trends [8, 225, 228-230]. 
BSI caused by ESBL-producing Enterobacteriaceae increased during the study period, though the rates were low compared to many other European countries, but numbers are increasing [14]. The reason for the rapid increase in ESBL-producing Enterobacteriaceae is likely multifactorial, with travel and migration as major driving forces [231, 232]. Antibioticresistant bacteria caused only $2.6 \%$ of all BSIs. The restricted use of systemic antibiotics in Swedish primary healthcare and animals probably explains why we have a relatively low prevalence of AMR compared to other European countries. In the hospital setting, however, antibiotic consumption in Sweden is similar to other European countries [233, 234]. Other factors that could explain the low level of AMR in Sweden include high degree of food safety, infection prevention measures, improved hygiene, and meticulous sanitation. When designing this study, we decided to use the generally accepted definition of multidrug resistance (MDR) i.e., "non-susceptibility to at least 1 agent from $\geq 3$ antimicrobial classes" An exception to this was MRSA, which was not per se accepted as MDR. [235, 236]. However, application of this MDR definition in our study would exclude a significant number of MRSA and ESBLproducing Enterobacteriaceae not fulfilling the MDR criteria, thereby underestimating the frequency of AMR. Thus, we report both MDR and AMR without MDR (ESBL-producing Enterobacteriaceae, MRSA and vancomycin-resistant enterococci not fulfilling the MDR criteria). In this study, multivariable analyses showed a lower 30-day all-cause mortality among patients with BSI caused by AMR bacteria including ESBL-producing E. coli, MRSA and VRE without MDR, compared to those with susceptible bacteria [237], while other studies have reported the opposite[187, 238, 239]. Further studies are needed to explain the lower mortality rate found in this study. For instance, patients with a bloodstream infection caused by resistant bacteria were younger and had less comorbidity. It is possible that people in this age-group are more exposed to AMR because of frequent travel. Furthermore, patients with BSI due to a resistant pathogen may receive longer intravenous antibiotic therapy and spend more time in hospital, thereby reducing the chance of recurrent infection. The current lack of healthcare resources has led to a general reduction in admission times, possibly resulting in patients with sensitive bacteria being discharged prematurely. In Sweden, patients with resistant bacteria are usually treated by an infectious disease specialist. Infectious disease specialist consultations have been shown to improve outcome in S. aureus sepsis [240] and this may apply to treatment of BSI caused by other resistant species including ESBLproducing $E$. coli which was the most prevalent resistant pathogen found in this study. Improved care due to the involvement of a specialist may be one explanation for the better 
outcome and lower mortality rate among patients with antibiotic-resistant BSI [217, 237, 241, 242].

Similar to trends in the other Nordic countries, the use of piperacillin-tazobactam (PTZ) and amoxicillin-clavulanic acid has increased [243]. It is interesting to note a concurrent increase in PTZ resistance among Klebsiella oxytoca and Enterobacter cloacae as well as Pseudomonas aeruginosa, but the present study was not designed to show a causal relationship between consumption and emergence of resistance to PTZ. In other studies, however, degree of exposure to PTZ has paralleled the emergence of PTZ resistance among P. aeruginosa when cephalosporins have been replaced by PTZ [244]. This warrants further investigation since $P$. aeruginosa causes healthcare-associated infections that are difficult to treat.

\subsubsection{Antibiotic treatment}

As a part of the Swedish STRAMA antibiotic stewardship programme, several educational measures to reduce antibiotic use in the community have been implemented in Östergötland over the last 20 years [245]. The goal of this programme is to reduce the unnecessary use of antibiotics in the community. A national target of 250 dispensed prescriptions of antibiotics per 1,000 inhabitants per year was set in 2010, based on an estimation of possible overuse in other countries [246-248]. Between 2011 and 2014, the government introduced financial incentives for county authorities that reduced the consumption of antibiotics in their region. During the study period (Study 1, Section 5.1)), the number of antibiotics prescribed decreased by $24 \%$ to 322 dispensed prescriptions per 1,000 inhabitants per year, whilst the amount measured in defined daily doses (DDD) per 1,000 inhabitants per day (TIND) remained basically unchanged. In Study 2 (Section 5.2) dispensed to outpatients measured as DDD/TIND decreased by $-13 \%$. Antibiotic consumption of narrow- and broad-spectrum antibiotics in hospitals, measured as DDD per 1,000 hospital days, increased by approximately 50\% (2008-2016. Several factors could explain this: 1) BSIs per 100,000 hospital days increased by $108 \%$ and per 100,000 hospital admissions by $66 \%$, hence the increased use of antibiotics in hospitals; 2) the number of patients with multiple comorbidities increased, and since these patients are at greater risk for severe illness, they were probably prescribed more antibiotics [249]; and 3) modern guidelines recommend higher and more frequent doses of antibiotics which naturally leads to increased consumption as measured by 
DDD based on standard doses for the main indication [250-255]. This study was not designed to see if the decrease in antibiotic use in the community correlated with the increase in antibiotic consumption in hospital since we did not consider antibiotic use in individual patients.

DDDs/1,000 patient days is recommended when comparing antibiotic usage between hospitals. It is important to remember that the total antibiotic use defined as DDD is very much influenced by specialty mix within and between hospitals. Hospitals with specialist units such as intensive care are likely to have higher antibiotic use than a small district hospital. Furthermore, antibiotic use may be over- or underestimated since DDD does not account for alternative dosing schemes due to renal dysfunction, obesity etc. The use of three narrow-spectrum antibiotics rather than one broad-spectrum antibiotic will result in three times the DDD being used for the same infection. Doses of some agents such as penicillin may vary between countries and may not conform to WHO-defined DDD. Number of prescriptions per 1,000 inhabitants does not provide information on dose taken. DDDs per 1,000 patient days does not account for the case mix or infection rates in hospitals. DDDs per admission (or discharge) is useful where length of stay is short, and DDD per bed-day is more useful in units where length of stay is longer. 


\subsubsection{Prehospital delay}

The BSI database is used for "crash investigation" of all fatal cases of BSI, sepsis, and urosepsis, to find preventable risk factors for mortality associated with BSI, and thus improve our antibiotic stewardship programme.

In Study III (Section 5.3), we redefined the definition of CA-BSI to exclude patients who received intravenous treatment, advanced nursing care, parenteral nutrition, haemodialysis, or intravenous chemotherapy at home or in the community-setting within the previous 30 days. The study showed that prehospital delay has a major impact on all-cause 30-day mortality due to CA-BSI. Variation in delay may explain the surprisingly great variation in severity of disease on admission to hospital, with significantly higher In-SOFA score and sepsis rates among non-survivors. Although initial in-hospital treatment was comparable between the survivor and non-survivor groups, for some variables even better in the non-survivor group, this was not enough to compensate for prehospital delay.
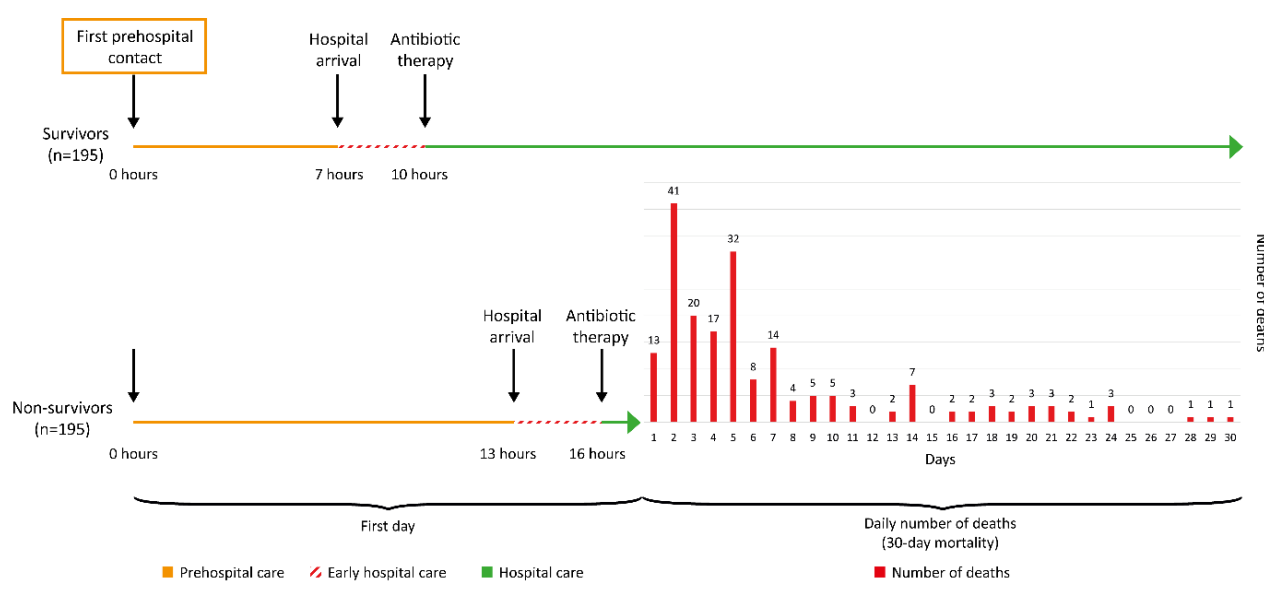

Fig 15. In total, the median time from first prehospital contact till hospital admission was 8 hours (427). This was significantly longer for non-survivors 13 hours (6-52) vs. 7 hours (3-24) for survivors, $p=0.01$. Almost $40 \%$ of the non-survivors died within 3 days after hospital admission, and $80 \%$ within 7 days.

Time to antibiotic treatment has been studied before, showing a clear association between delay and increased mortality [256]. However, few studies have addressed delay in antibiotic treatment prior to ambulance or ED, and the reasons for such. The implementation of 
strategies for early identification of sepsis in prehospital care is a difficult but essential part of our efforts to increase survival in sepsis, and several such strategies and screening tools have been used with varied success [257-259]. In this study, we looked at a subgroup of patients where there was delay between first infection-related contact with a healthcare facility and hospital admission. Gender, age, comorbidity, reason for contact, suspected focus of infection, severity of disease, and first prehospital contact facility were assessed. Of these, the type of prehospital contact facility was the main predictor of prehospital delay. Contact the telephone healthcare advice service (1177) led to shorter time to hospital admission than when the patient contacted the local healthcare centre. We can only speculate on the reason for this. The telephone healthcare advice service is manned by specially trained nurses who strictly follow algorithms for acute illness. As well as being more experienced in giving advice over the phone, they may also be more liberal in sending patients to the ED. Our study does not reflect true sepsis but CA-BSI and might therefore be even more heterogeneous. Even so, $75 \%$ of non-survivors and $52 \%$ of survivors had sepsis on arrival at the ED.

In summary, early prehospital identification of patients at risk for developing sepsis with its associated mortality is complicated [259]. This study confirmed that urgent attention to symptoms of infection in cancer patients is crucial, as reported previously. Otherwise, no other patient-specific factors were found that could be helpful in identifying patients with increased mortality risk. 


\subsubsection{Risk factors for ESBL UPEC-associated mortality and development of ESBL}

In Study IV (Section 5.4), a well-defined cohort of patients with extended spectrum $\beta$ lactamase (ESBL)-producing uropathogenic E. coli CO-BSI were studied. The aim was to identify risk factors for 30-day mortality. Our hypothesis was based on the results of Study II (Section 5.2), where we observed a lower mortality rate in the ESBL group compare to nonESBL E. coli group. In Study IV (Section 5.4), however, the 30-day mortality rate in the whole cohort was still low (almost 3\%) and no difference between ESBL UPEC and nonESBL UPEC BSI was observed. The most common ST-type and ESBL gene was ST131 (55\%) and blactX-M-15 (47\%), respectively.

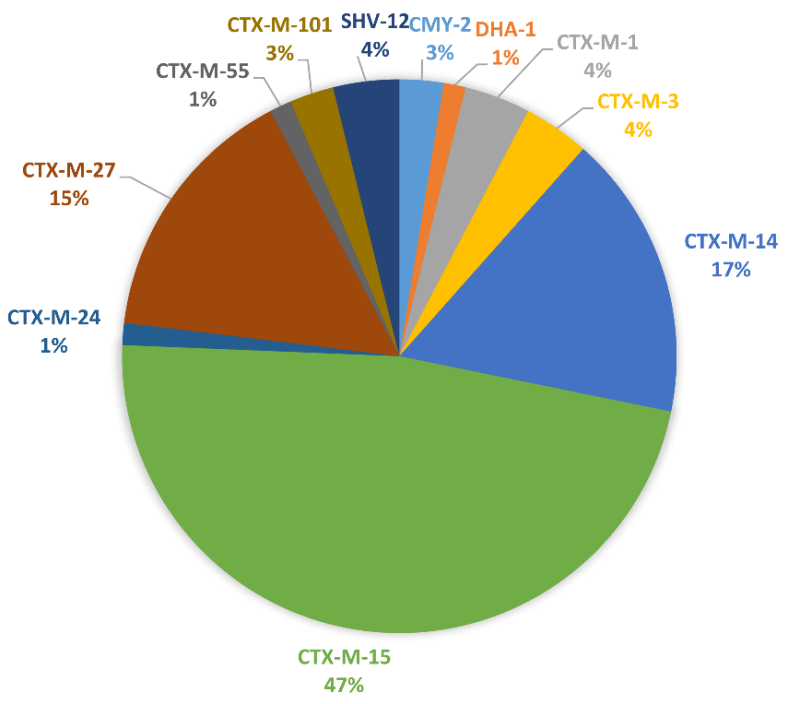

Fig 16. Distribution of ESBL genes in blood isolates of culture-confirmed communityonset-BSI with ESBL-Ec in blood with pheno- and genotypically matched urine isolates, UPEC $(n=77)$, taken 0-7 days prior the blood culture. Registered and treated in southeast of Sweden, 20092018 .

Several variables were investigated, but apart from the risk factors we found for ESBL BSI (i.e., antibiotics in past 3 months, recurrent UTI, genitourinary tumour, genitourinary procedure within the previous 12 months, ESBL-producing infection within the previous 24 months, and urinary catheterisation) demographic, clinical characteristics, severity of disease, and initial management were similar between the ESBL UPEC and non-ESBL UPEC groups. The only difference between the groups was time to appropriate antibiotic treatment, where the ESBL UPEC group showed significant delay. Surprisingly, this did not lead to increased 
mortality rate or development of sepsis (according to the sepsis-3 criteria) within 36 hours, and partly contradicts previous studies showing significant survival gains with early appropriate antibiotic treatment. A possible reason for this is that the bacterial load of the urinary tract is heavy, and early relief of obstruction and source control provide the main survival benefits. Other possible explanations are that the carriage of the resistance genes decreases the fitness of the E. coli strains, or that the sample size was too small.

Many previous studies have not separate nosocomial/hospital- and community-acquired infections in their analysis. This is unfortunate, since these two groups differ greatly. In two separate studies, risk factors for ESBL-producing E. coli bloodstream infection were studied. The first on nosocomial bloodstream infections and the second on community-acquired bloodstream infections [217, 260]. The same cases (ESBL-producing E. coli BSI) were compared with two control groups: non-ESBL E. coli BSI and all patients with suspected bloodstream infection. The authors describe somewhat different risk factors between the study-groups (nosocomial ESBL E. coli BSI vs. community-acquired ESBL E. coli BSI). The risk factor most strongly associated with ESBL-producing E. coli nosocomial BSI was history of previous use of 3GC [260]. In the second study on community-associated bloodstream infection, the following risk factors were associated with ESBL-producing E. coli (when compared to both control groups): "recent antimicrobial use, healthcare-associated bacteraemia, and presence of a urinary catheter" [217].

In recent years, several studies on risk factors for ESBL-producing pathogens in CO-BSI have been published. [178, 261-264]. The design of these studies varies. However, the risk factors associated with ESBL BSI in four of these studies were: 1) Healthcare-associated infection and/or admission from a long-term care facility, [178, 261, 262, 264]; 2) Recent or previous use of 3GC; 3) Use of/admitted with antibiotics [178, 262-264]; and 4) Severe illness on admission [262, 264]. 


\subsubsection{Predicting infection with ESBL-producing E. coli on admission to hospital}

Algorithms for predicting infection with ESBL-producing E. coli on hospital admission is an interesting way to optimise empirical antibiotic treatment. This is one of the most central reasons for studying risk factors for ESBL-producing E. coli. However, the source population in many of the studies described above differ greatly from a Swedish population, which may limit generalisability to Swedish healthcare.

In a Dutch study 2015, Rottier et al showed that basing antibiotic treatment decisions only on history of ESBL-producing Enterobacterales or previous antibiotic therapy leads to increase and unnecessary use of broad-spectrum antibiotics [265]. Further, they analysed the impact to give "broad-spectrum antibiotics (3GC + aminoglycoside, or carbapenem)" to all patients with suspected sepsis of unknown origin and with previous ESBL-producing Enterobacterales colonisation or cephalosporin/fluoroquinolone use. The authors concluded that this would lead to an overtreatment rate of $14 \%$ and appropriate therapy rate of $96.5 \%$. If ignoring a history of previous antibiotic use, overtreatment rate reduced to $4 \%$ and appropriate therapy rate to $95.8 \%$ [177].

Based on the results of Study IV (Section 5.4), further research should explore cephalosporin/fluoroquinolone treatment as a better broad-spectrum alternative prior to genitourinary procedures in the presence of ESBL-producing Enterobacterales colonisation. Furthermore, the fact that there was no increase in mortality or sepsis development due to delay in starting appropriate antibiotics, speaks in favour of a more restrictive approach with less broad-spectrum treatment. This, however, applies to urinary pathogenic E. coli only. Thus, it is possible that risk factors for infection with resistant bacteria differ depending on the focus of infection, with a greater need for broad-spectrum treatment in focuses outside the urinary tract. This should be the subject of further research.

Risk-scoring systems on admission to hospital to identify patients with BSIs caused by ESBLproducing Enterobacterales have been studied by, amongst others, Tumbarello et al. In Tumbarello's risk-scoring system, the following risk factors were evaluated (factors assigned 2 or 3 points): “1) Recent hospitalisation; 2) Admission from another healthcare facility; 3) Charlson comorbidity index $\geq 4$; 4) Previous treatment with $\beta$-lactams or fluoroquinolones; 5) History of urinary catheterisation; and 6 ) age $\geq 70$ years old". Results showed that: "a score $\geq 6$ 
gave a PPV of $82 \%$ and NPV of $81 \%$ for any infection caused by ESBL-producing bacteria". It must be pointed out that only $17 \%$ of cultures were blood samples.

\subsubsection{Empirical antibiotic therapy and differences in outcome to ESBL producing $E$. coli bloodstream infection}

Empiric treatment is given to treat a suspected infection before pathogen identification and resistance are known. If the pathogen is resistant, favourable outcome depends on the patient's immune response, and supportive therapy. In the case of a primary urinary tract infection (UTI) with secondary bacteraemia (as studied in Study IV, Section 5.4), a high antibiotic concentration in the urine may be sufficient despite resistance in vitro, and this in part may be the explanation for the low mortality rate seen in our study together with early source control. Differences in mortality outcome between studies could also be due to differences in primary focus of infection and the severity of the infections included. 


\section{SUMMARY OF THE MAIN FINDINGS}

\subsection{INTRODUCTION}

The aim of this thesis was to investigate the epidemiology and the clinical impact of bloodstream infections in the county of Östergötland, focusing on risk factors for BSIassociated mortality. This chapter summarises the results of the study and discusses the challenges that remain regarding community-onset BSI, a disease that generates a significant burden on the healthcare system. The incidence of bloodstream infection, in particular community-onset BSI, has increased in recent decades, resulting in increased mortality and greater burden on the healthcare system. The population is increasing, people live longer and have more comorbidity, and there is an increase in multi-resistant microorganisms such as ESBL-producing E. coli. All these factors make life difficult for the physician when making empirical treatment decisions.

The average age of many populations in the world, and thereby comorbidity, is increasing. Since the risk for BSI increases with old age, the burden of bloodstream infection is expected to increase, and healthcare systems must plan accordingly and enhance preventative and therapeutic interventions targeted at patients at highest risk.

\subsection{BLOODSTREAM SURVEILLANCE PROGRAMMES}

Sepsis following a bloodstream infection is a serious life-threatening condition $[185,266]$. Timely and appropriate antibiotic therapy is lifesaving [267]. The causes of bloodstream infection and the antibiotic susceptibility patterns of the organisms isolated vary with geographic location and time [185, 266]. Knowledge of locally important causes of bloodstream infection and patterns of antibiotic resistance of organisms involved is essential when designing empirical treatment strategies for patients with bloodstream infection and suspected sepsis. The sensitivity of blood cultures is low. This together with time from collection of the sample to detection of a pathogen means that initial management of seriously ill patients must be empirical. However, accumulated blood culture data from microbiology laboratories provide invaluable information on the local epidemiology of bloodstream infections. This provides a relevant basis when designing local empirical antibiotic treatment 
for sepsis, rather than following somewhat irrelevant recommendations in international guidelines that increase the risk for mismatch between pathogen and treatment.

Swedish infection surveillance systems have revealed the threat to public health that BSI poses. This has led to improvements in clinical care and has deepened our understanding of the epidemiology of regional bloodstream infections. By integrating bloodstream infections surveillance with clinical laboratory results, pathogen identification, antibiotic susceptibility profiles, and results of antibiotic therapy, we can monitor prevalence and trends in antibiotic resistance [268-270]. Furthermore, our attention has been drawn to the emergence of infectious diseases, such as the alarming increase in BSIs due to antibiotic-resistant (AMR) bacteria. The association between the increase in age and comorbidity in the population, and increased mortality due to BSI, is now well-recognised. In this way, BSI surveillance has contributed to regional healthcare policy decisions.

Public health officials must expect an increase in the burden of BSI, not only the cost of acute care but also of long-term care of bloodstream infection survivors who often suffer from functional disability and cognitive impairment [271].

BSI surveillance programmes are needed to promptly identify, characterise, and control the growing threat of bloodstream infections at its source, prevent further emergence of antibiotic resistance, and enhance global health security. Our unique surveillance database monitors the development of antibiotic resistance and burden of bloodstream infections on the healthcare system in Östergötland. Continuous transfer of data from the microbiology laboratory, including all positive cultures, has existed since 2000. Data have been assembled and matched with data from the patient-care administration system, the local pharmacy register, and the Swedish death register. In our experience, this process is sustainable at a local level. BSI surveillance systems should cover all healthcare facilities performing blood cultures. They should incorporate laboratory data, partly to ensure accurate measurement of the total burden of BSI disease, and partly to facilitate rapid detection and control of outbreaks at their source, thereby enhancing global health security. The increase in incidence of CO-BSI demonstrates the need for ongoing surveillance to improve clinical care and prevent further emergence of antibiotic resistance.

In 2016, the County Health Authority in Östergötland was granted access to the surveillance database, and its data were incorporated into a new sepsis alarm system to improve the 
management of sepsis in the county. This project is based on cooperation between the telephone healthcare advice service (1177), primary healthcare, and hospital emergency departments.

According to a recent study, public awareness of sepsis is low in Sweden [8] which may explain patient delay in contacting a healthcare facility. The higher incidence of BSI among men and individuals with comorbidity seen in this study concurs with previous studies [16, $55,272]$.

It is essential that the rate of BSI be reduced. Multitarget interventions in a "sepsis alarm" programme covering prehospital care, emergency units, and hospital care, were introduced in Sweden at the end of 2018. All patients are triaged for sepsis in the ambulance and at the emergency department using broad sepsis criteria including, but not limited to, the new qSOFA score [252]. Focused treatment and follow-up programmes using algorithms such as the surviving sepsis protocol are applied [4]. This enables early intensive treatment for those with confirmed sepsis and early de-escalation of treatment for those who are subsequently diagnosed with a non-sepsis ailment. The BSI register is a part of the "sepsis alarm" programme.

Since, the causal relationship between comorbidity and increased incidence of BSI is not clear, we suggest further studies to investigate this and other possible reasons for the increase in BSI and BSI-related mortality. Low public awareness of sepsis, late detection and treatment of sepsis in prehospital healthcare, restrictive antibiotic prescription, and increased frequency of infections caused by antibiotic-resistant bacteria, are all areas that must be looked into. 


\section{FUTURE PERSPECTIVES}

Finally, several studies have shown differences between countries and regions regarding BSI patterns and antibiotic resistance [7, 8, 26, 28, 43, 63, 91, 169, 187, 188, 190, 199, 273]. It is important to implement local surveillance programmes in hospitals to optimise infection control, monitor regional changes over time, follow trends, and develop local guidelines for the treatment of bloodstream infections (BSIs) [26, 28, 43, 169, 273]. The worldwide emergence (globally distributed) of clone ST131 has been studied in several molecular epidemiology studies, [166, 274-278]. ST131 clones are strongly associated with fluoroquinolone-resistant highly pathogenic H30 subclone and ESBL CTX-M-15 associated H30Rx and are highly pathogenic (virulent) [279-283]. The incidence of bloodstream infections caused by ESBL-producing E. coli is increasing in Sweden, we also know that urinary tract infection (UTI) is one of the most common diseases in both community and hospital settings. Studies comparing countries with high-, versus low-levels of ESBLproducing uropathogenic E. coli (UPEC) associated mortality, regarding virulence and resistance mechanisms/patterns, including changes in patient- and community-specific factors over time, are needed.

Microbial virulence and host response influences the severity of infection disease. The inflammatory response and cytokine storms are factors driving the development of sepsis. Therefore, both virulence factors and inflammatory mediators have emerged as the main potential targets in the development of future sepsis treatment. The pathogenesis of sepsis is complex and involves dysregulation of the immune response [69]. Several studies have shown that dysregulation and inflammatory response differs between patients and the mortality risk is associated with genetic predisposition. As was seen in Studies I and II (Section 5.1 and 5.2), it is well-known that patients with comorbidity, such as malignancy with immune suppression, have an increased risk for infection, sepsis, septic shock, and mortality. However, even patients without malignancy and immune suppression show important differences regarding their immune response.

A study from the UK in 2016 analysed peripheral blood leucocytes from patients admitted to ICU with sepsis or septic shock due to CA-pneumonia. Interestingly, heterogeneity in the immune response of the two subgroups of individuals was seen, with different immune responses and prognoses based on global genetic expression. There were two gene 
expression-based endotypes of sepsis patient response, termed "Sepsis Response Signatures 1 and 2 (SRS1 and SRS2)". The presence of SRS1 gene expression was associated with immunosuppression. Patients with SRS1 had an increased early mortality rate (14-days mortality) than those with SRS2 [284]. Later studies have observed four groups of endotypes based on gene expression [72].

Further studies have applied this theory, and a clinical trial (phase 1b) was published in 2019 on immunomodulatory therapy in individuals with SRS1 (immunosuppressed), regarding the safety of its use. Immunotherapy such as, the use of monoclonal antibodies, in this case blockprogrammed cell-death-ligand 1 (PD-L1) and programmed cell death protein-1 (PDP-1), are usually effective against cancer and could be effective in reducing immunosuppression. Under normal conditions, PD-L1 and PDP-1 are involved in the immune checkpoint pathway. Upregulation of this pathway is seen in dysregulated immunosuppression induced by sepsis, causing T-cell inhibition [199]. A concern of such therapies is overstimulation of the immune response (cytokine storm); however, this was not seen. Overall, this study gave promising results.

Bacterial virulence-related factors have been suggested as promising antivirulence targets for new adjuvant infection therapy [285, 286]. Targeting virulence factors offers several potential advantages including: "1. Low impact on host commensal flora; 2 . Less evolutionary pressure for development of resistance than traditional antibiotics; and 3. rapid inactivation of targets" [286]. Disadvantages: "1. A combination of therapies may be required for multiple virulence factors; 2. Empirical treatment is difficult because of species- or strain-specific virulence factors; 3. Rapid diagnostic methods are required; and 4. Some microbes might survive and cause damage when treatment is stopped" [286]. Treatments targeting bacterial virulence factors will probably not be as efficient as antibiotics, but an adjuvant effect may be achieved.

Studies such as Study IV (Section 5.4) take the first step in breaching this issue showing that type of bacteria per se and antibiotic treatment are not the only components that govern infection outcome and risk for sepsis and mortality. In Study IV (Section 5.4), a lower risk for sepsis and mortality was seen in patients with a urinary tract infection caused by ESBLEC leading to community-onset BSI. Immunosuppression and virulence factors may play a more important role in predicting the outcome, development, and management of sepsis than hitherto believed. Further studies are needed to investigate the importance of 
immunosuppression and blockade of virulence factors in bacteraemia and sepsis. However, because of inter-individual variation and the variety of bacterial virulence factors, tailored treatment will require new diagnostic tests to determine microbial virulence factors and immune response patterns if we are to design target therapy for the individual patient.

Sepsis is the third most common cause of death, but even so, much less research money is spent on sepsis compared to e.g., cancer. Large gaps still exist in our knowledge of sepsis management, one such gap is the immune response that is seen in sepsis.

During the pandemic, severely ill COVID-19 (SARS-CoV-2) patients have revealed similarities between COVID-19 and sepsis, and these can provide us with clues to future research. One such is the immune system's overreaction leading to widespread inflammation. Similarities are also seen in the laboratory picture e.g., DIC and rises in inflammation markers such as CRP, Ferritin, LD, and D-dimer that can increase considerably in patients with COVID-19. The immune system's components that are activated can be the same, such as an increase in the neutrophil count normally associated with bacterial infections. Most patients with severe COVID-19 infection develop organ failure, usually the lungs, but circulatory failure, kidney failure and liver effects are also seen. Just as in sepsis, multiple organ failure can occur in COVID-19 patients.

A problem with sepsis is that patients come to the emergency department in different stages of the disease, with different pathogens that originate from different loci in the body. COVID-19 is less complicated since all patients have the same virus and the overreaction of the immune system seen in some patients appears after a week - a pattern that is possible to follow. Just think if the process is similar in bacterial sepsis only, we do not have the tools to detect it. It is my hope that research into severe COVID-19 will increase our understanding of how the immune system is activated and that this is applied to sepsis research.

Apart from the acute phase of bacteraemia and sepsis, I would like to study long-term complications. The pandemic has seen great efforts to address the complications and aftercare of COVID-19, in particular long-term psychological and cognitive symptoms (concentration difficulties, anxiety, depression, and memory loss) that are also seen post-sepsis. In contrast to COVID-19, we have not appreciated the long-term complications of bacterial infections, in particular sepsis. Cognitive problems after sepsis have either not come to our attention or have not been followed up at all. 
In the future, we must be better at accurately identifying these patients and have a register that automatically compiles cases as soon as they are diagnosed in hospital, where, I believe, the number of cases missed is large. Furthermore, we must identify sepsis patients quicker as shown in Study 3 (Section 5.3), and perhaps the most important area of future research is better diagnostics. For instance, just think if we had a blood test that measures the immune response in sepsis so that we can tell which phase of the inflammatory process the patient is in. Were that so, we could seriously consider individualised treatment and not just blindly treat the patient with broad-spectrum antibiotics that also destroy the bowel flora. It would be much better to help the immune system take care of the infection instead, and suppress the inflammatory reaction that leads to sepsis, septic shock, and organ failure. Subsequently, this would lead to a lower risk for permanent damage or at least a reduction in the risk for longterm complications.

To improve the management of patients with bloodstream infection, sepsis and septic shock, the following strategies are suggested: 1 . Cost-effective local surveillance systems; 2. Strategies for early identification of bacteraemia; 3. Campaigns to raise awareness in the community and among healthcare workers of risk factors and signs and symptoms of bloodstream infection; 4 . New laboratory methods for targeting antibiotic treatment and designing individualised therapy as discussed above; 5. Long-term follow-up of recovered patients with sepsis or septic shock; 6. Digital medical registers, where data can easily be extracted; and finally 7. Algorithms that automatically compute risk scores, predict susceptibility patterns based on previous relevant cultures, and provide recommendations for empirical antibiotic treatment. Application of these strategies will certainly reduce morbidity and mortality associated with BSI and relieve its burden on society. 


\section{SAMMANFATTNING PÅ SVENSKA}

Infektioner i blodbanan och antibiotikaresistens ökar globalt och leder redan nu till att miljontals människor dör årligen och enligt World Health Organization (WHO) står blodförgiftning för ca $20 \%$ av den globala dödligheten vilket kan t.ex. jämföras med akut hjärtinfarkt, akut stroke och allvarliga trauman. Blodförgiftning kan uppstå när bakterier från en infektionshärd når blodbanan och kallas då för bakteriemi. Blodinfektioner undergrupperas ofta till samhällsförvärvade eller sjukhus/sjukvårdsrelaterade infektioner då det ofta rör sig om olika patientgrupper, bakterier och orsak till infektionen. Sverige har i relation till många andra länder varit förskonade med förhållandevis låg dödlighet i blodinfektioner och antibiotikaresistens. Dock i takt med en förändrad livsstil och en population med stigande ålder med fler underliggande sjukdomar och en förändrad sjukvård ökar både dödligheten och antibiotikaresistens i Sverige. Vid blodförgiftning är det viktigt att snabbt identifiera "alarmsymptom" för korrekt omhändertagande och effektiva behandlingsåtgärder. Att empiriskt skräddarsy effektiva åtgärder är svårt varför det är viktigt att känna till riskfaktorer för blodinfektioner, lokal antibiotikaresistensproblematik, och identifiera effektiva behandlingsåtgärder. Antibiotikaresistenta bakterier är ett ökat problem och i synnerhet hos tarmbakterier som kan bli mycket svåra att behandla. Förenklat kan man beskriva antibiotikaresistens som en evolutionär process där bakterien skyddar sig själv genom att utveckla resistensgener. Resistensgener kan överföras mellan bakterier som vidare kan orsaka infektion. Vid antibiotikaanvändning utsätts bakterier (även normal bakterieflora) för ett "selektions-/ evolutionärt tryck" vilket ger resistenta bakterier en överlevnadsfördel, varpå det kan öka i antal och därmed orsaka infektion. Antibiotikaresistenta bakterier är ett globalt hot mot folkhälsan.

Denna avhandling har till syfte att synliggöra en stor patientgrupp som drabbas av blodinfektioner. Blodinfektioner ökar globalt med hög dödlighet. Antibiotikaresistens är ett ökat hot mot folkhälsa och larmrapporter om skenande antibiotikaresistens sköljer över oss. Hur ser denna utveckling ut i Sverige och kan vi identifiera riskfaktorer för blodinfektion och dödlighet.

I Studie I vill vi fram för allt studera förekomst, dödlighet och utveckling av blodinfektioner i Östergötland för att kunna göra det behövs ett stort patientunderlag som sträcker sig över flera år. Vår studiedesign blev därför en populationsbaserad studie i form av en observation kohortstudie där samtliga blododlingar tagna mellan 2000 och 2013 analyserades och 
värderades utifrån kliniska data. Totalt analyserades 109,983 blododlingar som resulterade i 11,480 blodinfektioner och vi kunde då se att blodinfektionerna har ökat med 64\% och det var fram för allt de samhällsförvärvade infektionerna som ökade. Vi kunde även se att dödligheten har ökat (45\%) men även samsjukligheten i populationen. Resultatet understryker vikten av nationellt samordnat arbete för att motverka utvecklingen av ökat antal blodinfektioner och dödlighet samt utformning av övervakningsstrategier.

Målsättningen med Studie II var att undersöka resistensutveckling i Östergötland och relatera till dödlighet. Totalt analyserades 9,587 mikroorganismer mellan 2008-2016 där vi bland annat noterade en ökad resistensutveckling av kinolonresistens (3.7 till 7.7\%) och cefalosporinresistens (2.5 till 5.2\%) hos Enterobacteriaceae. Vidare undergrupperades blodinfektionerna till de infektioner som orsakades av en multiresistent bakterie, totalt 245 stycken $(2.6 \%)$. Totalt ökade dessa bakterier med 300\%. Trots fler infektioner orsakade av multiresistenta bakterier kunde vi inte se att det hade någon avgörande betydelse för dödligheten.

Det finns flera möjliga förklaringar till ökad mortalitet vid blodinfektioner, globalt är antibiotikaresistens en drivande faktor vilket vi inte kan se i våra studier, ändock ökar dödligheten och är på en hög nivå. I Studie III vill vi därför studera riskfaktorer kopplat till död vid samtidig blodinfektion, med fokus på den primära handläggningen både utanför och på sjukhus. Vilket undersöktes i en retrospektiv fall-kontroll studie med 195 fall (avlidna) matchade (1:1) avseende ålder, kön och mikroorganismer med 195 kontroller (överlevande). Resultatet visade på att många patienter har en infektionsrelaterad öppenvårdskontakt innan dom blir allvarligt sjuka och att den starkaste riskfaktorn för död var förlängd tid (>24 timmar) från öppenvårdskontakt till inläggning på sjukhus. Resultatet visar ökat behov av kunskap i allmänhet men även inom den medicinska professionen kring riskpatienter och symtom som bör föranleda ett snabbare omhändertagande.

I Studie I och Studie II beskrivs en ökning av både blodinfektioner och död, vi vet även att antibiotikaresistens och multiresistenta bakterier, fram för allt ESBL E. coli ökar. Dock kunde vi inte se att multiresistens per se leder till ökad dödlighet i en svensk population. E. coli är en gramnegativ bakterie som är den vanligaste förekommande bakterien vid blodinfektioner. E. coli är en primär urinvägspatogen varför vi i Studie IV vill studera ESBL E. coli med ursprung från urinvägarna. Både avseende förekomst av E. coli klon, resistensgener, riskfaktorer men även studera om det föreligger en ökad dödlighet vid ESBL E. coli infektion jämfört med känsliga E. coli. Huvudfyndet var låg dödlighet vid ESBL E. coli infektion (3\%). 
Majoriteten av patienterna i ESBL E. coli gruppen fick inadekvat antibiotika i nästan två dygn, dock kunde vi inte påvisa någon ökad dödlighet eller risk att utveckla allvarlig blodförgiftning med cirkulationspåverkan i denna grupp. Fyndet är intressant och öppnar upp för nya intressanta studier kring virulensfaktorer och immunologiska faktorer som styr det inflammatoriska svaret.

Implementering av kostnadseffektiva övervakningssystem med klinisk mikrobiologisk epidemiologi, tidig identifikation av blodinfektioner tillsammans med informationskampanjer till allmänheten och hälso- och sjukvårdspersonal avseende symptom och riskpatienter skulle leda till att vi kan reducera morbiditet och dödlighet vid blodinfektioner. Därutöver behövs nya diagnostiska verktyg både för att skräddarsy antibiotikabehandlingen men även för individualiserad behandling t.ex. genom att målinriktad behandling mot mikroorganismens virulensfaktorer. Vidare kan modernisering av journalsystemen med algoritmer för tidig identifikation av riskpatienter och generering av förslag till empirisk antibiotikabehandling utifrån antibiotikaresistens från tidigare odlingar men även utifrån aktuell resistenssituation lokalt förbättra handläggningen. Adderas därutöver nya immunologiska tester för att påvisa typ av immunologisk reaktion vid allvarlig blodinfektion kan individualiserad immunoterapi tillsammans med antibiotikabehandling ytterligare förbättra vården kring denna patientgrupp. 


\section{POPULAR SCIENCE SUMMARY}

Bloodstream infection (blood poisoning) and antibiotic resistance are increasing worldwide, and already cause the loss of millions of human lives each year. According to the World Health Organisation (WHO), bloodstream infections (BSIs) represent $20 \%$ of global mortality on a par with cardiac infarct, stroke, and major trauma. BSI may occur when bacteria from a focus of infection gain access to the circulation (bacteraemia). BSIs are usually divided into two subclasses: community- and hospital-onset infections, since disease this involves different patient groups, types of bacteria, and reasons for infection. Compared to other countries, Sweden has been fortunate in having a relatively low death rate from BSI and low antibiotic resistance. However, as our lifestyle changes, the age of the population increases with more disease as a result, and as the healthcare system responds, death from infection and antibiotic resistance are on the increase. It is important that we recognise "warning symptoms" if we are to manage BSIs correctly and initiate effective treatment. It is difficult to design individualised empirical treatment, so it is very important to be aware of risk factors for BSI and local resistance patterns, and to have an effective management programme.

Bacterial resistance to antibiotics is an increasing problem, especially in bowel organisms that can cause infections that are very difficult to treat. In short, antibiotic resistance arises as a result of evolutionary processes where bacteria protect themselves by developing resistance genes. These genes can be exchanged between similar organisms or transmitted to others that in turn cause resistant infection. The use of antibiotics leads to an evolutionary/selection process leading to resistance in bacteria, both normal and pathogenic, enabling resistant organisms to survive, thrive, and go on to cause infection. Antibiotic resistance is a threat to global health.

This thesis aims to increase our awareness of a large group of patients who suffer bloodstream infection. BSIs are increasing globally, and the death toll is high. Antibiotic resistance is an increasing threat to the health of the population, and we are inundated by alarming reports of resistance getting out of control. What is the situation in Sweden, and can we identify risk factors for BSI and mortality?

In Study I, our aim was to study the incidence and mortality of BSI in Östergötland. To be able to do this, a large patient population stretching over several years was required. The study design was thus population-based in the form of an observational cohort study where all 
blood culture results from 2000 to 2013 were analysed, and evaluated from clinical data. A total of 109,938 results were analysed resulting in 11,480 BSIs.

We saw that the incidence of BSI increased by $64 \%$ (mostly community-onset BSIs). We also saw that mortality increased by $45 \%$. These results illustrate the importance of nationwide cooperation to combat the increasing problem of BSI and its mortality, and the establishment of a nationwide BSI register.

The aim of Study II was to assess resistance development in Östergötland and its relationship to mortality. A total of 9,587 microorganisms were analysed between 2008 and 2016. We observed an increase in quinolone resistance (3.7-7.7\%) and cephalosporin resistance (2.5$5.2 \%$ ) amongst Enterobacteriaceae. We then looked at BSIs caused by multiresistant bacteria showing a total of 245 cases (2.6\%); an increase of $300 \%$. Despite this, we did not see an increased mortality in this group.

There are several possible explanations for the increase in BSI mortality of which antibiotic resistance is a predominant factor globally. We were unable to show this in our study, even so mortality is increasing and is currently at a high level. In Study III we therefore analysed risk factors associated with death during a community-acquired BSI, focusing on preliminary prehospital and hospital management. In a retrospective case-control study on 195 deaths matched 1:1 regarding age, gender, and microorganism, with 195 survivors (controls). Results showed that many patients had contacted the primary healthcare system because of infection before they became severely ill, and that the strongest affectable risk factor for death was delay ( $>24 \mathrm{~h}$ ) between primary healthcare visit and admission to hospital. This shows the need for increased awareness in society and amongst the medical profession of those patients at risk and symptoms that should raise the alarm, leading to more rapid treatment.

In Studies I and II we found an increase in both BSIs and mortality, we also saw an increase in antibiotic resistance and multiresistant bacteria, mainly ESBL-producing E. coli. On the other hand, we did not see any coupling between multiresistance and mortality in this Swedish population. E. coli is a gram-negative bacteria that causes most BSIs. Since E. coli is predominantly a urine tract pathogen, Study IV aimed to study BSIs caused by ESBLproducing $E$. coli originating from the urinary tract. We studied the prevalence of $E$. coli clones, resistance genes and risk factors, as well as any signs of increased mortality from ESBL-producing E. coli compared to sensitive E. coli. Our main finding was a surprisingly low mortality from ESBL-producing E. coli (3\%). Most patients in the ESBL-producing $E$. 
coli group received inadequate antibiotic treatment for at least $48 \mathrm{~h}$, but we did not see any sign of increased mortality or risk for serious sepsis with circulatory failure in this group. This finding is interesting and opens up for new studies on virulence factors and immunological factors that govern the immune response to BSI.

The implementation of cost-effective monitoring systems including clinical microbiological epidemiology and early identification of BSI, together with information campaigns aimed at the public as well as healthcare personnel regarding patients at risk and symptoms giving cause for alarm, should lead to a radical reduction in morbidity and mortality from BSI. This requires new diagnostic tools to individualise both antibiotic treatment and targeted management based on microorganism virulence factors. Modernisation of the medical journal system with algorithms aimed at early identification of risk patients and automated suggestions for empirical antibiotic treatment based on antibiotic resistance seen in previous cultures and local resistance patterns, would certainly improve management. Furthermore, new immunological tests showing the type of immunological reaction to a serious BSI will lead to individualised immunotherapy that, together with antibiotic treatment, will further improve patient care in this important group. 


\section{ACKNOWLEDGEMENTS}

"Om du vill gå snabbt, gå ensam. Om du vill gå långt, gå tillsammans"

Det absolut bästa med att skriva en avhandling är det fantastiska lagarbete som krävs. Tack till alla som har stöttat mig i detta arbete och ett särskilt tack till:

Först av allt vill jag tacka min huvudhandledare professor Håkan Hanberger, vän, kollega och ett fullständigt fenomenalt bollplank, både vad gäller forskningen men även livet $\mathrm{i}$ allmänhet. Vi har delat ups and downs, resor, livet och otaliga forskningsdiskussioner - en förutsättning för detta har varit vår gemensamma syn på att veckan har 7 dagar a 24 timmar.

Mats Fredriksson, bihandledare, vän, docent och statistikexpert. Med otrolig bredd och visdom guidat mig i statistikens märkliga värld. Du har alltid ställt upp för frågor i tid och otid. Medmänniska med hjärna och hjärta på rätta stället.

Åse Östholm Balkhed, bihandledare, vän och överläkare inom infektionsmedicin. Med oerhörd kunskap om infektionspanoramat har du guidat en simpel urolog med förlåtelse för alla tokiga idéer jag har haft genom åren. Du har även förgyllt våra möten med fika i alla dess former

Christian Giske, bihandledare, vän, professor och "akademisk-pelé”. I viktiga vägskäl har du alltid stöttat och med din visdom guidat rätt.

Lennart E Nilsson, bihandledare, vän och professor med oerhörd erfarenhet och kunskap. Du har stötta mig både inom mikrobiologins underbara värld, men även bjudit på många skratt och samtal.

Maria Andersson, Du har blivit en nära vän under dessa år - därutöver doktorand och specialistläkare infektionsmedicin. Vi har delat forskning och livet på ett underbart sätt. Vi har stött och blött artiklar och tillsammans fått till finfina saker.

Sören Berg, Vän, medförfattare och överläkare inom thoraxanestesi och thoraxintensivvård. Tack för din klokhet och pragmatiska hållning, med koncisa och kärnfulla råd och förmåga att aldrig se några problem. 
Vidar Möller, Vän, medförfattare och doktorand. I tid och otid har du med entusiasm, klokhet funnits där för diskussion och samtal om stort och smått.

Pete Cox, vän och språkgranskare. Du har med finess förbättrat allt du tagit i och alltid ställt upp. Du har med din positiva energi och peppande samtal bidragit på ett ovärderligt sätt.

Mamun Ur Rashid, Vän och medförfattare. Det har varit stor glädje för mig att få ta del av din resa som forskare och läkare.

Carina Claeson, Expert inom klinisk mikrobiologi. Tack för alla mer eller mindre akuta arbetsinsatser. Du har haft tålamod med mina sms/mail i tid och otid. Tack.

Filip Redéen, Svåger och vän. Tack för allt stöd i grafisk formgivning genom åren. Du är en klippa på alla sätt och vis.

Björn Berglund, Docent och medförfattare. Med klokhet och entusiasm har du lyft in nya perspektiv. Tack för kärnfulla diskussioner.

Reidar Källström, f.d., verksamhetschef urologiska kliniken. Idag centrumchef. Tack för hur du stöttade mig som nybliven läkare, både i att uppmuntra till forskning och chefskap men även hur du rent praktiskt hjälp till.

Åsa Petersson, Verksamhetschef urologiska kliniken. Tack för att du är du. Det är få förunnat att ha en chef som både kan driva och utveckla en klinik men samtidig prioritera de mjuka värdena. Tack för ditt stöd.

Oliver Gimm, Professor, kirurg och ämnesföreträdare inom kirurgi och urologi. Tack för all hjälp med logistik och disputationsansökan. Men även för din klokhet och goda råd.

Elvar Theodorsson, Professor och överläkare inom klinisk kemi, men fram för allt mentor och vän. Tack för ditt stöd, klokhet och visdom. Tack för hur du guidar mig rätt, vid för mig stora vägskäl. Stort tack!

Kollegor och vänner på Urologiska kliniken i Linköping och Norrköping - Firas Aljabery, Martin Alwin, Johannes Edström, Jon Forsberg, Georg Jancke, Elin Kalén, Theodoros Psarias, Aus Saudi, Jennifer Short, Per Skoglund, Johan Thorén, Anna-Eva Wiklund, Saleh Alahmad, Stina Christensen, Lisa Gasslander, Ali Haidar, Ylva Huge, Inge Hojgaard, Josefine Leirnes, Sigrid Ljunggren, Andreas Schneider. Tack för allt peppande stöd. 
Svärmor och Svärfar, Tack för att ni finns och allt stöd, ni betyder så mycket för mig och familjen.

Släkt och vänner, Stort tack för all support och glada hejarop. Ni är ovärderliga.

Mamma och Pappa, För att ni alltid, med villkorslös kärlek, stöttat mig och funnits där. Jag hade önskat att jag hade fått fira min disputationsdag tillsammans med er. Saknar er så enormt mycket. Älskar er.

Cecilia, min syster. Tack för att jag får dela livet med dig. Du är bäst ingen protest!

Matilda, Mitt livs kärlek och fantastisk mamma till våra barn. "Kärleken övervinner allt" William, Alma och Selma, Ni är det bästa som har hänt mig. Ni kommer alltid ha min villkorslösa kärlek. Ni är så värdefulla! Älskar Er Mest! 


\section{REFERENCES}

1. Laupland, K.B., Population-based epidemiology of intensive care: critical importance of ascertainment of residency status. Crit Care, 2004. 8(6): p. R431-6.

2. Steckelberg, J.M., et al., Influence of referral bias on the apparent clinical spectrum of infective endocarditis. Am J Med, 1990. 88(6): p. 582-8.

3. Laupland, K.B., Incidence of bloodstream infection: a review of population-based studies. Clin Microbiol Infect, 2013. 19(6): p. 492-500.

4. Goto, M. and M.N. Al-Hasan, Overall burden of bloodstream infection and nosocomial bloodstream infection in North America and Europe. Clin Microbiol Infect, 2013. 19(6): p. 501-9.

5. Skogberg, K., et al., Population-based burden of bloodstream infections in Finland. Clin Microbiol Infect, 2012. 18(6): p. E170-6.

6. Infectious Diseases Society of, A., et al., Combating antimicrobial resistance: policy recommendations to save lives. Clin Infect Dis, 2011. 52 Suppl 5: p. S397-428.

7. Holmbom, M., et al., 14-Year Survey in a Swedish County Reveals a Pronounced Increase in Bloodstream Infections (BSI). Comorbidity - An Independent Risk Factor for Both BSI and Mortality. PLoS One, 2016. 11(11): p. e0166527.

8. Buetti, N., et al., Incidence of bloodstream infections: a nationwide surveillance of acute care hospitals in Switzerland 2008-2014. BMJ Open, 2017. 7(3): p. e013665.

9. European Commission. A European one health action plan against antimicrobial resistance (AMR). 2017.

https://ec.europa.eu/health/amr/sites/amr/files/amr_action_plan_2017_en.pdf (accessed Feb 12, 2019).

10. WHO. Global Action Plan on Antimicrobial Resistance. Geneva: WHO; 2015. http://apps.who.int/iris/bitstream/handle/10665/193736/9789241509763_eng.pdf?seq uence $=1$ (accessed Feb 12, 2018).

11. Roberts, R.R., et al., Hospital and societal costs of antimicrobial-resistant infections in a Chicago teaching hospital: implications for antibiotic stewardship. Clin Infect Dis, 2009. 49(8): p. 1175-84.

12. Cerceo, E., et al., Multidrug-Resistant Gram-Negative Bacterial Infections in the Hospital Setting: Overview, Implications for Clinical Practice, and Emerging Treatment Options. Microb Drug Resist, 2016. 22(5): p. 412-31.

13. Larsson, D.G.J., et al., Critical knowledge gaps and research needs related to the environmental dimensions of antibiotic resistance. Environ Int, 2018. 117: p. 132-138.

14. European Centre for Disease Prevention and Control. Surveillance of antimicrobial resistance in Europe - Annual report of the European Antimicrobial Resistance Surveillance Network (EARS-Net) 2017. Stockholm: ECDC; 2018.

15. European Centre for Disease Prevention and Control. Antimicrobial consumption. In: ECDC. Annual

epidemiological report 2017. Stockholm: ECDC; 2018.

16. ATC/DDD Index. 2017. Oslo: World Health Organization Collaborating Centre for Drug Statistics Methodology; December 2016. Available from:

https://www.whocc.nolatc_ddd_index/.

17. World Health Organization: Antimicrobial resistance: Global report on surveillance. Geneva; 2014; Available from: http://www.who.int/drugresistance/documents/surveillancereport/en/.

18. Swedish work on containment of antibiotic resistance. 2014, The Public Health Agency of Sweden.; Available from: 
https://www.folkhalsomyndigheten.se/contentassets/dae82c7afd424a57b57ec8181879

3346/swedish-work-on-containment-of-antibiotic-resistance.pdf.

19. European Center for Disease Prenvention and Control. Surveillance Atlas of Infectious Diseases. 2020-10-28]; Available from:

https://atlas.ecdc.europa.eu/public/index.aspx.

20. Swedres-Svarm 2016. Consumption of antibiotics and occurrence of resistance in Sweden. Solna/Uppsala ISSN1650-6332.

21. Swedres-Svarm 2017. Consumption of antibiotics and occurrence of resistance in Sweden. Solna/Uppsala ISSN1650-6332.

22. Bien, J., O. Sokolova, and P. Bozko, Role of Uropathogenic Escherichia coli Virulence Factors in Development of Urinary Tract Infection and Kidney Damage. Int J Nephrol, 2012. 2012: p. 681473.

23. Terlizzi, M.E., G. Gribaudo, and M.E. Maffei, UroPathogenic Escherichia coli (UPEC) Infections: Virulence Factors, Bladder Responses, Antibiotic, and Nonantibiotic Antimicrobial Strategies. Front Microbiol, 2017. 8: p. 1566.

24. Nosocomial infection rates for interhospital comparison: limitations and possible solutions. A Report from the National Nosocomial Infections Surveillance (NNIS) System. Infection control and hospital epidemiology : the official journal of the Society of Hospital Epidemiologists of America, 1991. 12(10): p. 609-21.

25. Marra, A.R., et al., Nosocomial bloodstream infections in Brazilian hospitals: analysis of 2,563 cases from a prospective nationwide surveillance study. Journal of clinical microbiology, 2011. 49(5): p. 1866-71.

26. Russo, P.L., et al., Characteristics of national and statewide health care-associated infection surveillance programs: A qualitative study. Am J Infect Control, 2016. 44(12): p. 1505-1510.

27. de Kraker, M.E., A.J. Stewardson, and S. Harbarth, Will 10 Million People Die a Year due to Antimicrobial Resistance by 2050? PLoS Med, 2016. 13(11): p. e1002184.

28. Wernli, D., et al., Antimicrobial resistance: The complex challenge of measurement to inform policy and the public. PLoS Med, 2017. 14(8): p. e1002378.

29. Dellinger, R.P., et al., Surviving Sepsis Campaign: international guidelines for management of severe sepsis and septic shock, 2012. Intensive Care Med, 2013. 39(2): p. $165-228$.

30. Diekema, D.J., et al., Epidemiology and outcome of nosocomial and community-onset bloodstream infection. J Clin Microbiol, 2003. 41(8): p. 3655-60.

31. Bonilha, D.Q., et al., Prospective study of bacteremia rate after elective band ligation and sclerotherapy with cyanoacrylate for esophageal varices in patients with advanced liver disease. Arq Gastroenterol, 2011. 48(4): p. 248-51.

32. Chun, Y.J., et al., Prospective assessment of risk of bacteremia following colorectal stent placement. Dig Dis Sci, 2012. 57(4): p. 1045-9.

33. Duvall, N.B., et al., The comparative efficacy of $0.12 \%$ chlorhexidine and amoxicillin to reduce the incidence and magnitude of bacteremia during third molar extractions: a prospective, blind, randomized clinical trial. Oral Surg Oral Med Oral Pathol Oral Radiol, 2013. 115(6): p. 752-63.

34. Janssen, J., et al., Frequency of bacteremia after linear EUS of the upper GI tract with and without FNA. Gastrointest Endosc, 2004. 59(3): p. 339-44.

35. Konstantinou, E., et al., Difficult intubation provokes bacteremia. Surg Infect (Larchmt), 2008. 9(5): p. 521-4.

36. Levy, M.J., et al., Prospective study of bacteremia and complications With EUS FNA of rectal and perirectal lesions. Clin Gastroenterol Hepatol, 2007. 5(6): p. 684-9. 
37. Lockhart, P.B., et al., Bacteremia associated with toothbrushing and dental extraction. Circulation, 2008. 117(24): p. 3118-25.

38. Maharaj, B., Y. Coovadia, and A.C. Vayej, An investigation of the frequency of bacteraemia following dental extraction, tooth brushing and chewing. Cardiovasc $\mathrm{J}$ Afr, 2012. 23(6): p. 340-4.

39. Steinfort, D.P., D.F. Johnson, and L.B. Irving, Incidence of bacteraemia following endobronchial ultrasound-guided transbronchial needle aspiration. Eur Respir J, 2010. 36(1): p. 28-32.

40. Zani, E.L., O.A. Clark, and N. Rodrigues Netto, Jr., Antibiotic prophylaxis for transrectal prostate biopsy. Cochrane Database Syst Rev, 2011(5): p. CD006576.

41. Zhang, W., et al., Incidence and magnitude of bacteraemia caused by flossing and by scaling and root planing. J Clin Periodontol, 2013. 40(1): p. 41-52.

42. Garner, J.S., et al., CDC definitions for nosocomial infections, 1988. Am J Infect Control, 1988. 16(3): p. 128-40.

43. Marra, A.R., et al., Nosocomial bloodstream infections in Brazilian hospitals: analysis of 2,563 cases from a prospective nationwide surveillance study. J Clin Microbiol, 2011. 49(5): p. 1866-71.

44. Pittet, D., D. Tarara, and R.P. Wenzel, Nosocomial bloodstream infection in critically ill patients. Excess length of stay, extra costs, and attributable mortality. JAMA, 1994. 271(20): p. 1598-601.

45. Pittet, D. and R.P. Wenzel, Nosocomial bloodstream infections. Secular trends in rates, mortality, and contribution to total hospital deaths. Arch Intern Med, 1995. 155(11): p. 1177-84.

46. Orsi, G.B., L. Di Stefano, and N. Noah, Hospital-acquired, laboratory-confirmed bloodstream infection: increased hospital stay and direct costs. Infect Control Hosp Epidemiol, 2002. 23(4): p. 190-7.

47. Mayer, J., et al., Agreement in classifying bloodstream infections among multiple reviewers conducting surveillance. Clin Infect Dis, 2012. 55(3): p. 364-70.

48. De Bus, L., et al., Microbial etiology and antimicrobial resistance in healthcareassociated versus community-acquired and hospital-acquired bloodstream infection in a tertiary care hospital. Diagn Microbiol Infect Dis, 2013. 77(4): p. 341-5.

49. Friedman, N.D., et al., Health care--associated bloodstream infections in adults: a reason to change the accepted definition of community-acquired infections. Ann Intern Med, 2002. 137(10): p. 791-7.

50. Lenz, R., et al., The distinct category of healthcare associated bloodstream infections. BMC Infect Dis, 2012. 12: p. 85.

51. Laupland, K.B. and D.L. Church, Population-based epidemiology and microbiology of community-onset bloodstream infections. Clin Microbiol Rev, 2014. 27(4): p. 647-64.

52. Morin, C.A. and J.L. Hadler, Population-based incidence and characteristics of community-onset Staphylococcus aureus infections with bacteremia in 4 metropolitan Connecticut areas, 1998. J Infect Dis, 2001. 184(8): p. 1029-34.

53. Siegman-Igra, Y., et al., Reappraisal of community-acquired bacteremia: a proposal of a new classification for the spectrum of acquisition of bacteremia. Clin Infect Dis, 2002. 34(11): p. 1431-9.

54. Mehl, A., et al., Burden of bloodstream infection in an area of Mid-Norway 20022013: a prospective population-based observational study. BMC Infect Dis, 2017. 17(1): p. 205.

55. Sogaard, M., et al., Temporal changes in the incidence and 30-day mortality associated with bacteremia in hospitalized patients from 1992 through 2006: a population-based cohort study. Clin Infect Dis, 2011. 52(1): p. 61-9. 
56. Uslan, D.Z., et al., Age- and sex-associated trends in bloodstream infection: a population-based study in Olmsted County, Minnesota. Arch Intern Med, 2007. 167(8): p. 834-9.

57. Laupland, K.B., et al., Burden of community-onset bloodstream infection: a population-based assessment. Epidemiol Infect, 2007. 135(6): p. 1037-42.

58. Laupland, K.B., et al., Population-based laboratory assessment of the burden of community-onset bloodstream infection in Victoria, Canada. Epidemiol Infect, 2013. 141(1): p. 174-80.

59. Laupland, K.B., et al., Burden of community-onset bloodstream infections, Western Interior, British Columbia, Canada. Epidemiol Infect, 2016. 144(11): p. 2440-6.

60. Al-Hasan, M.N., J.E. Eckel-Passow, and L.M. Baddour, Impact of healthcareassociated acquisition on community-onset Gram-negative bloodstream infection: a population-based study: healthcare-associated Gram-negative BSI. Eur J Clin Microbiol Infect Dis, 2012. 31(6): p. 1163-71.

61. Evans, C.T., et al., Bloodstream infections and setting of onset in persons with spinal cord injury and disorder. Spinal Cord, 2009. 47(8): p. 610-5.

62. Kollef, M.H., et al., Epidemiology, microbiology and outcomes of healthcareassociated and community-acquired bacteremia: a multicenter cohort study. J Infect, 2011. 62(2): p. 130-5.

63. Son, J.S., et al., Bloodstream infections and clinical significance of healthcareassociated bacteremia: a multicenter surveillance study in Korean hospitals. J Korean Med Sci, 2010. 25(7): p. 992-8.

64. Valles, J., et al., Bloodstream infections in adults: importance of healthcareassociated infections. J Infect, 2008. 56(1): p. 27-34.

65. Gradel, K.O., et al., Classification of positive blood cultures: computer algorithms versus physicians' assessment--development of tools for surveillance of bloodstream infection prognosis using population-based laboratory databases. BMC Med Res Methodol, 2012. 12: p. 139.

66. Levy, M.M., et al., Outcomes of the Surviving Sepsis Campaign in intensive care units in the USA and Europe: a prospective cohort study. Lancet Infect Dis, 2012. 12(12): p. 919-24.

67. Wagenlehner, F.M., W. Weidner, and K.G. Naber, Optimal management of urosepsis from the urological perspective. Int J Antimicrob Agents, 2007. 30(5): p. 390-7.

68. Rhodes, A., et al., Surviving Sepsis Campaign: International Guidelines for Management of Sepsis and Septic Shock: 2016. Intensive Care Med, 2017. 43(3): p. 304-377.

69. Singer, M., et al., The Third International Consensus Definitions for Sepsis and Septic Shock (Sepsis-3). JAMA, 2016. 315(8): p. 801-10.

70. Hotchkiss, R.S., G. Monneret, and D. Payen, Sepsis-induced immunosuppression: from cellular dysfunctions to immunotherapy. Nat Rev Immunol, 2013. 13(12): p. 862-74.

71. Iskander, K.N., et al., Sepsis: multiple abnormalities, heterogeneous responses, and evolving understanding. Physiol Rev, 2013. 93(3): p. 1247-88.

72. Scicluna, B.P., et al., Classification of patients with sepsis according to blood genomic endotype: a prospective cohort study. Lancet Respir Med, 2017. 5(10): p. 816-826.

73. Tidswell, R., M. Inada-Kim, and M. Singer, Sepsis: the importance of an accurate final diagnosis. Lancet Respir Med, 2021. 9(1): p. 17-18.

74. Bonkat, G., et al., Management of Urosepsis in 2018. Eur Urol Focus, 2019. 5(1): p. 59. 
75. Hofmann, W., [Urosepsis and uroseptic shock]. Z Urol Nephrol, 1990. 83(6): p. 31724.

76. Levy, M.M., et al., 2001 SCCM/ESICM/ACCP/ATS/SIS International Sepsis Definitions Conference. Intensive Care Med, 2003. 29(4): p. 530-8.

77. Sorensen, S.M., H.C. Schonheyder, and H. Nielsen, The role of imaging of the urinary tract in patients with urosepsis. Int J Infect Dis, 2013. 17(5): p. e299-303.

78. Bonkat G., P.R., Bartoletti R., et. al.:, Guidelines on urological infections.2018. European Association of UrologyArnhem, The Netherlands.

79. Serniak, P.S., et al., [The diagnosis of urosepsis]. Urol Nefrol (Mosk), 1990(4): p. 913.

80. Wagenlehner, F.M., A. Pilatz, and W. Weidner, Urosepsis--from the view of the urologist. Int J Antimicrob Agents, 2011. 38 Suppl: p. 51-7.

81. Kumar, A., et al., Duration of hypotension before initiation of effective antimicrobial therapy is the critical determinant of survival in human septic shock. Crit Care Med, 2006. 34(6): p. 1589-96.

82. Wagenlehner, F.M., W. Weidner, and K.G. Naber, Pharmacokinetic characteristics of antimicrobials and optimal treatment of urosepsis. Clin Pharmacokinet, 2007. 46(4): p. 291-305.

83. Wagenlehner, F.M.E., et al., Urosepsis: Overview of the Diagnostic and Treatment Challenges. Microbiol Spectr, 2015. 3(5).

84. Bryant, J.K. and C.L. Strand, Reliability of blood cultures collected from intravascular catheter versus venipuncture. Am J Clin Pathol, 1987. 88(1): p. 113-6.

85. DesJardin, J.A., et al., Clinical utility of blood cultures drawn from indwelling central venous catheters in hospitalized patients with cancer. Ann Intern Med, 1999. 131(9): p. 641-7.

86. Everts, R.J., et al., Contamination of catheter-drawn blood cultures. J Clin Microbiol, 2001. 39(9): p. 3393-4.

87. Yu, D., et al., Single-Sampling Strategy vs. Multi-Sampling Strategy for Blood Cultures in Sepsis: A Prospective Non-inferiority Study. Front Microbiol, 2020. 11: p. 1639.

88. Isaacman, D.J. and R.B. Karasic, Lack of effect of changing needles on contamination of blood cultures. Pediatr Infect Dis J, 1990. 9(4): p. 274-8.

89. Leisure, M.K., et al., Changing the needle when inoculating blood cultures. A nobenefit and high-risk procedure. JAMA, 1990. 264(16): p. 2111-2.

90. Breiman, R.F., et al., Pneumococcal bacteremia in Charleston County, South Carolina. A decade later. Arch Intern Med, 1990. 150(7): p. 1401-5.

91. Skogberg, K., et al., Increase in bloodstream infections in Finland, 1995-2002. Epidemiol Infect, 2008. 136(1): p. 108-14.

92. Lamy, B., et al., How to Optimize the Use of Blood Cultures for the Diagnosis of Bloodstream Infections? A State-of-the Art. Front Microbiol, 2016. 7: p. 697.

93. Reimer, L.G., M.L. Wilson, and M.P. Weinstein, Update on detection of bacteremia and fungemia. Clin Microbiol Rev, 1997. 10(3): p. 444-65.

94. Wilson, M.L., M.P. Weinstein, and L.B. Reller, Automated blood culture systems. Clin Lab Med, 1994. 14(1): p. 149-69.

95. Cockerill, F.R., 3rd, et al., Optimal testing parameters for blood cultures. Clin Infect Dis, 2004. 38(12): p. 1724-30.

96. Lee, A., et al., Detection of bloodstream infections in adults: how many blood cultures are needed? J Clin Microbiol, 2007. 45(11): p. 3546-8.

97. Li, J., J.J. Plorde, and L.G. Carlson, Effects of volume and periodicity on blood cultures. J Clin Microbiol, 1994. 32(11): p. 2829-31. 
98. Cobos-Trigueros, N., et al., Acquisition of resistant microorganisms and infections in $H I V$-infected patients admitted to the ICU. Eur J Clin Microbiol Infect Dis, 2014. 33(4): p. 611-20.

99. Patel, R., et al., Optimized pathogen detection with 30-compared to 20-milliliter blood culture draws. J Clin Microbiol, 2011. 49(12): p. 4047-51.

100. Weinstein, M.P., et al., The clinical significance of positive blood cultures: $a$ comprehensive analysis of 500 episodes of bacteremia and fungemia in adults. II. Clinical observations, with special reference to factors influencing prognosis. Rev Infect Dis, 1983. 5(1): p. 54-70.

101. Cockerill, F.R., 3rd, et al., Clinical comparison of difco ESP, Wampole isolator, and Becton Dickinson Septi-Chek aerobic blood culturing systems. J Clin Microbiol, 1996. 34(1): p. 20-4.

102. Henry, N.K., et al., Microbiological and clinical evaluation of the isolator lysiscentrifugation blood culture tube. J Clin Microbiol, 1983. 17(5): p. 864-9.

103. Walker, R.C., et al., Lysis-centrifugation blood culture technique. Clinical impact in Staphylococcus aureus bacteremia. Arch Intern Med, 1986. 146(12): p. 2341-3.

104. Wilson, M.L., et al., Recovery of clinically important microorganisms from the BacT/Alert blood culture system does not require testing for seven days. Diagn Microbiol Infect Dis, 1993. 16(1): p. 31-4.

105. Zadroga, R., et al., Comparison of 2 blood culture media shows significant differences in bacterial recovery for patients on antimicrobial therapy. Clin Infect Dis, 2013. 56(6): p. 790-7.

106. Jorgensen, J.H., et al., Controlled clinical laboratory comparison of BACTEC plus aerobic/F resin medium with BacT/Alert aerobic FAN medium for detection of bacteremia and fungemia. J Clin Microbiol, 1997. 35(1): p. 53-8.

107. Pohlman, J.K., et al., Controlled clinical evaluation of BACTEC Plus Aerobic/F and BacT/Alert Aerobic FAN bottles for detection of bloodstream infections. J Clin Microbiol, 1995. 33(11): p. 2856-8.

108. Hall, K.K. and J.A. Lyman, Updated review of blood culture contamination. Clin Microbiol Rev, 2006. 19(4): p. 788-802.

109. Chu, V.H., et al., Emergence of coagulase-negative staphylococci as a cause of native valve endocarditis. Clin Infect Dis, 2008. 46(2): p. 232-42.

110. Weinstein, M.P., et al., The clinical significance of positive blood cultures: a comprehensive analysis of 500 episodes of bacteremia and fungemia in adults. I. Laboratory and epidemiologic observations. Rev Infect Dis, 1983. 5(1): p. 35-53.

111. Collazos-Blanco, A., et al., Estimation of missed bloodstream infections without the third blood culture set: a retrospective observational single-centre study. Clin Microbiol Infect, 2019. 25(4): p. 469-473.

112. Lin, H.H., et al., Evaluation of the blood volume effect on the diagnosis of bacteremia in automated blood culture systems. J Microbiol Immunol Infect, 2013. 46(1): p. 4852.

113. Beekmann, S.E., D.J. Diekema, and G.V. Doern, Determining the clinical significance of coagulase-negative staphylococci isolated from blood cultures. Infect Control Hosp Epidemiol, 2005. 26(6): p. 559-66.

114. Elzi, L., et al., How to discriminate contamination from bloodstream infection due to coagulase-negative staphylococci: a prospective study with 654 patients. Clin Microbiol Infect, 2012. 18(9): p. E355-61.

115. Favre, B., et al., Nosocomial bacteremia: clinical significance of a single blood culture positive for coagulase-negative staphylococci. Infect Control Hosp Epidemiol, 2005. 26(8): p. 697-702. 
116. Rahkonen, M., et al., True bacteremias caused by coagulase negative Staphylococcus are difficult to distinguish from blood culture contaminants. Eur J Clin Microbiol Infect Dis, 2012. 31(10): p. 2639-44.

117. Kassis, C., et al., Differentiating culture samples representing coagulase-negative staphylococcal bacteremia from those representing contamination by use of time-topositivity and quantitative blood culture methods. J Clin Microbiol, 2009. 47(10): p. 3255-60.

118. Bates, D.W., L. Goldman, and T.H. Lee, Contaminant blood cultures and resource utilization. The true consequences of false-positive results. JAMA, 1991. 265(3): p. 365-9.

119. Leal, J., et al., Development of a novel electronic surveillance system for monitoring of bloodstream infections. Infect Control Hosp Epidemiol, 2010. 31(7): p. 740-7.

120. Leal, J. and K.B. Laupland, Validity of electronic surveillance systems: a systematic review. J Hosp Infect, 2008. 69(3): p. 220-9.

121. Trick, W.E., et al., Computer algorithms to detect bloodstream infections. Emerg Infect Dis, 2004. 10(9): p. 1612-20.

122. Humphries, R.M., et al., The Continued Value of Disk Diffusion for Assessing Antimicrobial Susceptibility in Clinical Laboratories: Report from the Clinical and Laboratory Standards Institute Methods Development and Standardization Working Group. J Clin Microbiol, 2018. 56(8).

123. The European Committee on Antimicrobial Susceptibility Testing. Breakpoint tables for interpretation of MICs and zone diameters. Version 9.0, 2019. http://www.eucast.org.

124. Pulido, M.R., et al., Progress on the development of rapid methods for antimicrobial susceptibility testing. J Antimicrob Chemother, 2013. 68(12): p. 2710-7.

125. ISO, 20776-1:2006. Clinical laboratory testing and in vitro diagnostic test systems -

Susceptibility testing of infectious agents and evaluation of performance of

antimicrobial susceptibility test devices - Part 1: Reference method for testing the in

vitro activity of antimicrobial agents against rapidly growning aerobic bacteria

involved in infectious diseases. 2006.

126. Ellington, M.J., et al., The role of whole genome sequencing in antimicrobial susceptibility testing of bacteria: report from the EUCAST Subcommittee. Clin Microbiol Infect, 2017. 23(1): p. 2-22.

127. Idelevich, E.A. and K. Becker, How to accelerate antimicrobial susceptibility testing. Clin Microbiol Infect, 2019. 25(11): p. 1347-1355.

128. Ranjbar, R., et al., Typing methods used in the molecular epidemiology of microbial pathogens: a how-to guide. New Microbiol, 2014. 37(1): p. 1-15.

129. Sabat, A.J., et al., Overview of molecular typing methods for outbreak detection and epidemiological surveillance. Euro Surveill, 2013. 18(4): p. 20380.

130. Maiden, M.C., et al., Multilocus sequence typing: a portable approach to the identification of clones within populations of pathogenic microorganisms. Proc Natl Acad Sci U S A, 1998. 95(6): p. 3140-5.

131. Perez-Losada, M., et al., Pathogen typing in the genomics era: MLST and the future of molecular epidemiology. Infect Genet Evol, 2013. 16: p. 38-53.

132. Kwong, J.C., et al., Whole genome sequencing in clinical and public health microbiology. Pathology, 2015. 47(3): p. 199-210. 
133. National Human genome Research institute. DNA sequencing costs: Data. 2019 [cited 2021 May 22]; Available from: https://www.genome.gov/about-genomics/factsheets/DNA-Sequencing-Costs-Data.

134. Paterson, D.L., Restrictive antibiotic policies are appropriate in intensive care units. Crit Care Med, 2003. 31(1 Suppl): p. S25-8.

135. Singh, N. and V.L. Yu, Rational empiric antibiotic prescription in the ICU. Chest, 2000. 117(5): p. 1496-9.

136. WHO. WHO Model List of Essential Medicines, 20th List (March 2017). 2017. https://www.who.int/medicines/publications/essentialmedicines/20th_EML2017.pdf? $u a=1$.

137. Sharland, M., et al., Classifying antibiotics in the WHO Essential Medicines List for optimal use-be AWaRe. Lancet Infect Dis, 2018. 18(1): p. 18-20.

138. Klein, E.Y., et al., Assessment of WHO antibiotic consumption and access targets in 76 countries, 2000-15: an analysis of pharmaceutical sales data. Lancet Infect Dis, 2021. 21(1): p. 107-115.

139. Klein, E.Y., et al., Global increase and geographic convergence in antibiotic consumption between 2000 and 2015. Proc Natl Acad Sci U S A, 2018. 115(15): p. E3463-E3470.

140. Paul, M., et al., Systematic review and meta-analysis of the efficacy of appropriate empiric antibiotic therapy for sepsis. Antimicrob Agents Chemother, 2010. 54(11): p. 4851-63.

141. Tumbarello, M., et al., Predictors of mortality in patients with bloodstream infections caused by extended-spectrum-beta-lactamase-producing Enterobacteriaceae: importance of inadequate initial antimicrobial treatment. Antimicrob Agents Chemother, 2007. 51(6): p. 1987-94.

142. Frakking, F.N., et al., Appropriateness of empirical treatment and outcome in bacteremia caused by extended-spectrum-beta-lactamase-producing bacteria. Antimicrob Agents Chemother, 2013. 57(7): p. 3092-9.

143. Trecarichi, E.M., R. Cauda, and M. Tumbarello, Detecting risk and predicting patient mortality in patients with extended-spectrum beta-lactamase-producing Enterobacteriaceae bloodstream infections. Future Microbiol, 2012. 7(10): p. 117389.

144. Schwaber, M.J. and Y. Carmeli, Mortality and delay in effective therapy associated with extended-spectrum beta-lactamase production in Enterobacteriaceae bacteraemia: a systematic review and meta-analysis. J Antimicrob Chemother, 2007. 60(5): p. 913-20.

145. Schwaber, M.J., et al., Clinical and economic impact of bacteremia with extendedspectrum-beta-lactamase-producing Enterobacteriaceae. Antimicrob Agents Chemother, 2006. 50(4): p. 1257-62.

146. Tumbarello, M., et al., Costs of bloodstream infections caused by Escherichia coli and influence of extended-spectrum-beta-lactamase production and inadequate initial antibiotic therapy. Antimicrob Agents Chemother, 2010. 54(10): p. 4085-91.

147. Peirano, G. and J.D.D. Pitout, Extended-Spectrum beta-Lactamase-Producing Enterobacteriaceae: Update on Molecular Epidemiology and Treatment Options. Drugs, 2019. 79(14): p. 1529-1541.

148. Baquero, F. and T.M. Coque, Multilevel population genetics in antibiotic resistance. FEMS Microbiol Rev, 2011. 35(5): p. 705-6.

149. Mathers, A.J., G. Peirano, and J.D. Pitout, Escherichia coli ST131: The quintessential example of an international multiresistant high-risk clone. Adv Appl Microbiol, 2015. 90: p. 109-54. 
150. Mathers, A.J., G. Peirano, and J.D. Pitout, The role of epidemic resistance plasmids and international high-risk clones in the spread of multidrug-resistant

Enterobacteriaceae. Clin Microbiol Rev, 2015. 28(3): p. 565-91.

151. Adler, M., et al., Influence of acquired beta-lactamases on the evolution of spontaneous carbapenem resistance in Escherichia coli. J Antimicrob Chemother, 2013. 68(1): p. 51-9.

152. Allen, H.K., et al., Call of the wild: antibiotic resistance genes in natural environments. Nat Rev Microbiol, 2010. 8(4): p. 251-9.

153. Pages, J.M., C.E. James, and M. Winterhalter, The porin and the permeating antibiotic: a selective diffusion barrier in Gram-negative bacteria. Nat Rev Microbiol, 2008. 6(12): p. 893-903.

154. Bush, K. and P.A. Bradford, beta-Lactams and beta-Lactamase Inhibitors: An Overview. Cold Spring Harb Perspect Med, 2016. 6(8).

155. Bush, K., Past and Present Perspectives on beta-Lactamases. Antimicrob Agents Chemother, 2018. 62(10).

156. Paterson, D.L. and R.A. Bonomo, Extended-spectrum beta-lactamases: a clinical update. Clin Microbiol Rev, 2005. 18(4): p. 657-86.

157. Giske, C.G., et al., Redefining extended-spectrum beta-lactamases: balancing science and clinical need. J Antimicrob Chemother, 2009. 63(1): p. 1-4.

158. Nicolas-Chanoine, M.H., X. Bertrand, and J.Y. Madec, Escherichia coli ST131, an intriguing clonal group. Clin Microbiol Rev, 2014. 27(3): p. 543-74.

159. Banerjee, R. and J.R. Johnson, A new clone sweeps clean: the enigmatic emergence of Escherichia coli sequence type 131. Antimicrob Agents Chemother, 2014. 58(9): p. 4997-5004.

160. Pitout, J.D. and R. DeVinney, Escherichia coli ST131: a multidrug-resistant clone primed for global domination. F1000Res, 2017. 6.

161. Woodford, N., J.F. Turton, and D.M. Livermore, Multiresistant Gram-negative bacteria: the role of high-risk clones in the dissemination of antibiotic resistance. FEMS Microbiol Rev, 2011. 35(5): p. 736-55.

162. Tabah, A., et al., Characteristics and determinants of outcome of hospital-acquired bloodstream infections in intensive care units: the EUROBACT International Cohort Study. Intensive Care Med, 2012. 38(12): p. 1930-45.

163. Timsit, J.F. and K.B. Laupland, Update on bloodstream infections in ICUs. Curr Opin Crit Care, 2012. 18(5): p. 479-86.

164. Chuang, Y.Y. and Y.C. Huang, Molecular epidemiology of community-associated meticillin-resistant Staphylococcus aureus in Asia. Lancet Infect Dis, 2013. 13(8): p. 698-708.

165. David, M.Z. and R.S. Daum, Community-associated methicillin-resistant Staphylococcus aureus: epidemiology and clinical consequences of an emerging epidemic. Clin Microbiol Rev, 2010. 23(3): p. 616-87.

166. Peirano, G., et al., Molecular epidemiology over an 11-year period (2000 to 2010) of extended-spectrum beta-lactamase-producing Escherichia coli causing bacteremia in a centralized Canadian region. J Clin Microbiol, 2012. 50(2): p. 294-9.

167. Pitout, J.D. and K.B. Laupland, Extended-spectrum beta-lactamase-producing Enterobacteriaceae: an emerging public-health concern. Lancet Infect Dis, 2008. 8(3): p. 159-66.

168. Pitout, J.D., et al., Population-based laboratory surveillance for Escherichia coliproducing extended-spectrum beta-lactamases: importance of community isolates with blaCTX-M genes. Clin Infect Dis, 2004. 38(12): p. 1736-41. 
169. de Kraker, M.E., et al., The changing epidemiology of bacteraemias in Europe: trends from the European Antimicrobial Resistance Surveillance System. Clin Microbiol Infect, 2013. 19(9): p. 860-8.

170. Ho, P.L., et al., Extended-spectrum-beta-lactamase-positive Escherichia coli mainly adds to, rather than replaces, extended-spectrum-beta-lactamase-negative E. coli in causing bacteraemia in Hong Kong, 2000-10. J Antimicrob Chemother, 2012. 67(3): p. $778-80$.

171. Kang, C.I., et al., Epidemiology and risk factors of community onset infections caused by extended-spectrum beta-lactamase-producing Escherichia coli strains. J Clin Microbiol, 2012. 50(2): p. 312-7.

172. Kanoksil, M., et al., Epidemiology, microbiology and mortality associated with community-acquired bacteremia in northeast Thailand: a multicenter surveillance study. PLoS One, 2013. 8(1): p. e54714.

173. Lowe, C.F., et al., Efficacy of admission screening for extended-spectrum betalactamase producing Enterobacteriaceae. PLoS One, 2013. 8(4): p. e62678.

174. Williamson, D.A., et al., Population-based incidence and comparative demographics of community-associated and healthcare-associated Escherichia coli bloodstream infection in Auckland, New Zealand, 2005-2011. BMC Infect Dis, 2013. 13: p. 385.

175. SWEDRES. A report on Swedish Sales of antibiotics and occurrence of antibiotic resistance in Sweden 2019. Available:

https://www.folkhalsomyndigheten.se/contentassets/fb80663bc7c94d678be785e33609 17d1/swedres-svarm-2019.pdf.

176. Van Aken, S., et al., Risk factors, outcome and impact of empirical antimicrobial treatment in extended-spectrum beta-lactamase-producing Escherichia coli bacteraemia. Scand J Infect Dis, 2014. 46(11): p. 753-62.

177. Froding, I., et al., Prediction of bloodstream infection caused by extended-spectrum beta-lactamase-producing Enterobacterales in patients with suspected communityonset sepsis. Int J Antimicrob Agents, 2019. 53(6): p. 820-829.

178. Quan, J., et al., High prevalence of ESBL-producing Escherichia coli and Klebsiella pneumoniae in community-onset bloodstream infections in China. J Antimicrob Chemother, 2017. 72(1): p. 273-280.

179. Swedres-Svarm 2019. Sales of antibiotics and occurrence of resistance in Sweden. Solna/Uppsala ISSN1650-6332.

180. The Center for Disease Dynamics Economics \& Policy ResistanceMap: Antibiotic resistance. 2019 [cited 2021 May 3]; Available from: https://resistancemap.cddep.org.

181. Laupland, K.B., Defining the epidemiology of bloodstream infections: the 'gold standard' of population-based assessment. Epidemiol Infect, 2013. 141(10): p. 214957.

182. Schuchat, A., et al., Active bacterial core surveillance of the emerging infections program network. Emerg Infect Dis, 2001. 7(1): p. 92-9.

183. Rempel, O.R. and K.B. Laupland, Surveillance for antimicrobial resistant organisms: potential sources and magnitude of bias. Epidemiol Infect, 2009. 137(12): p. 1665-73.

184. Filice, G.A., et al., Bacteremia in Charleston County, South Carolina. Am J Epidemiol, 1986. 123(1): p. 128-36.

185. Deen, J., et al., Community-acquired bacterial bloodstream infections in developing countries in south and southeast Asia: a systematic review. Lancet Infect Dis, 2012. 12(6): p. 480-7. 
186. Einsiedel, L.J. and R.J. Woodman, Two nations: racial disparities in bloodstream infections recorded at Alice Springs Hospital, central Australia, 2001-2005. Med J Aust, 2010. 192(10): p. 567-71.

187. Hattori, H., et al., Epidemiology and risk factors for mortality in bloodstream infections: A single-center retrospective study in Japan. Am J Infect Control, 2018. 46(12): p. e75-e79.

188. Madsen, K.M., et al., Secular trends in incidence and mortality of bacteraemia in a Danish county 1981-1994. APMIS, 1999. 107(3): p. 346-52.

189. Thriemer, K., et al., The burden of invasive bacterial infections in Pemba, Zanzibar. PLoS One, 2012. 7(2): p. e30350.

190. Holmbom, M., et al., Low incidence of antibiotic-resistant bacteria in south-east Sweden: An epidemiologic study on 9268 cases of bloodstream infection. PLoS One, 2020. 15(3): p. e0230501.

191. Dagasso, G., et al., Risk factors associated with bloodstream infections in end-stage renal disease patients: a population-based study. Infect Dis (Lond), 2018. 50(11-12): p. 831-836.

192. Isendahl, J., et al., Risk factors for community-onset bloodstream infection with extended-spectrum beta-lactamase-producing Enterobacteriaceae: national population-based case-control study. Clin Microbiol Infect, 2019. 25(11): p. 14081414.

193. Paulsen, J., et al., Associations of obesity and lifestyle with the risk and mortality of bloodstream infection in a general population: a 15-year follow-up of 64027 individuals in the HUNT Study. Int J Epidemiol, 2017. 46(5): p. 1573-1581.

194. Thomsen, R.W., et al., Impact of diabetes and poor glycaemic control on risk of bacteraemia with haemolytic streptococci groups A, B, and G. J Infect, 2011. 63(1): p. 8-16.

195. Thulstrup, A.M., et al., Population-based study of the risk and short-term prognosis for bacteremia in patients with liver cirrhosis. Clin Infect Dis, 2000. 31(6): p. 135761.

196. Charlson, M.E., et al., A new method of classifying prognostic comorbidity in longitudinal studies: development and validation. J Chronic Dis, 1987. 40(5): p. 37383.

197. Mohus, R.M., et al., Association of iron status with the risk of bloodstream infections: results from the prospective population-based HUNT Study in Norway. Intensive Care Med, 2018. 44(8): p. 1276-1283.

198. Skov Dalgaard, L., et al., Risk and Prognosis of Bloodstream Infections among Patients on Chronic Hemodialysis: A Population-Based Cohort Study. PLoS One, 2015. 10(4): p. e0124547.

199. Sogaard, M., et al., Blood culture status and mortality among patients with suspected community-acquired bacteremia: a population-based cohort study. BMC Infect Dis, 2011. 11: p. 139.

200. Laupland, K.B., T. Ross, and D.B. Gregson, Staphylococcus aureus bloodstream infections: risk factors, outcomes, and the influence of methicillin resistance in Calgary, Canada, 2000-2006. J Infect Dis, 2008. 198(3): p. 336-43.

201. Thomsen, R.W., et al., Diabetes mellitus as a risk and prognostic factor for community-acquired bacteremia due to enterobacteria: a 10-year, population-based study among adults. Clin Infect Dis, 2005. 40(4): p. 628-31.

202. Inghammar, M., et al., Increased incidence of invasive bacterial disease in chronic obstructive pulmonary disease compared to the general population--a population based cohort study. BMC Infect Dis, 2014. 14: p. 163. 
203. Laupland, K.B., et al., Population-based risk factors for community-onset bloodstream infections. Eur J Clin Microbiol Infect Dis, 2020. 39(4): p. 753-758.

204. McGregor, J.C., et al., A systematic review of the methods used to assess the association between appropriate antibiotic therapy and mortality in bacteremic patients. Clin Infect Dis, 2007. 45(3): p. 329-37.

205. Christensen, J.S., et al., Bacteremia with Streptococcus pneumoniae: sepsis and other risk factors for 30-day mortality--a hospital-based cohort study. Eur J Clin Microbiol Infect Dis, 2012. 31(10): p. 2719-25.

206. Madsen, K.M., et al., Can hospital discharge diagnosis be used for surveillance of bacteremia? A data quality study of a Danish hospital discharge registry. Infect Control Hosp Epidemiol, 1998. 19(3): p. 175-80.

207. Helweg-Larsen, K., The Danish Register of Causes of Death. Scand J Public Health, 2011. 39(7 Suppl): p. 26-9.

208. Huttunen, R., et al., Obesity and smoking are factors associated with poor prognosis in patients with bacteraemia. BMC Infect Dis, 2007. 7: p. 13.

209. Koch, K., et al., Effect of socioeconomic status on mortality after bacteremia in working-age patients. A Danish population-based cohort study. PLoS One, 2013. 8(7): p. e70082.

210. Harris, A.D., et al., Methodological principles of case-control studies that analyzed risk factors for antibiotic resistance: a systematic review. Clin Infect Dis, 2001. 32(7): p. 1055-61.

211. Schechner, V., et al., Epidemiological interpretation of studies examining the effect of antibiotic usage on resistance. Clin Microbiol Rev, 2013. 26(2): p. 289-307.

212. Mansournia, M.A., N.P. Jewell, and S. Greenland, Case-control matching: effects, misconceptions, and recommendations. Eur J Epidemiol, 2018. 33(1): p. 5-14.

213. Hosmer, D., S. Lemeshow, and R. Sturdivant, Applied logistic regression. Third ed. Wiley Series in probability and statistics. 2013, Hoboken, New Jersey: Wiley.

214. Kalra, O.P. and A. Raizada, Approach to a patient with urosepsis. J Glob Infect Dis, 2009. 1(1): p. 57-63.

215. Rodriguez-Creixems, M., et al., Bloodstream infections: evolution and trends in the microbiology workload, incidence, and etiology, 1985-2006. Medicine (Baltimore), 2008. 87(4): p. 234-249.

216. Tsertsvadze, A., P. Royle, and N. McCarthy, Community-onset sepsis and its public health burden: protocol of a systematic review. Syst Rev, 2015. 4: p. 119.

217. Rodriguez-Bano, J., et al., Community-onset bacteremia due to extended-spectrum beta-lactamase-producing Escherichia coli: risk factors and prognosis. Clin Infect Dis, 2010. 50(1): p. 40-8.

218. Sjoberg, L. and H. Fredlund, Survey of blood culture isolates in an area of Sweden from 1980 to 1986. Eur J Clin Microbiol Infect Dis, 1988. 7(4): p. 501-4.

219. Nielsen, S.L., et al., The daily risk of bacteremia during hospitalization and associated 30-day mortality evaluated in relation to the traditional classification of bacteremia. Am J Infect Control, 2016. 44(2): p. 167-72.

220. Kaye, K.S., et al., Effect of nosocomial bloodstream infections on mortality, length of stay, and hospital costs in older adults. J Am Geriatr Soc, 2014. 62(2): p. 306-11.

221. Vrijens, F., et al., Hospital-acquired, laboratory-confirmed bloodstream infections: linking national surveillance data to clinical and financial hospital data to estimate increased length of stay and healthcare costs. J Hosp Infect, 2010. 75(3): p. 158-62.

222. ECDC, S.R., Point prevalence survey of healthcare-associated infections and antimicrobial use in European acute care hospitals 2011-2012, 
http://ecdc.europa.eu/en/publications/Publications/healthcare-associated-infectionsantimicrobial-use-PPS.pdf. Accessed [2015-10-12] 2013.

223. Laupland, K.B., D.B. Gregson, and D.L. Church, Validity of calendar day-based definitions for community-onset bloodstream infections. BMC Res Notes, 2015. 8: p. 123.

224. Andersson, M., et al., Delay of appropriate antibiotic treatment is associated with high mortality in patients with community-onset sepsis in a Swedish setting. Eur J Clin Microbiol Infect Dis, 2019.

225. Surveillance of antimicrobial resistance in Europe. Stockholm: European Centre for Disease Prevention and Control, 2016.

226. Swedres-Svarm 2017. Consumption of antibiotics and occurrence of resistance in Sweden. Solna/Uppsala ISSN1650-6332. .

227. Hanberger, H., et al., Antibiotic consumption and antibiotic stewardship in Swedish hospitals. Ups J Med Sci, 2014. 119(2): p. 154-61.

228. Allocati, N., et al., Escherichia coli in Europe: an overview. Int J Environ Res Public Health, 2013. 10(12): p. 6235-54.

229. Ny, S., et al., Community carriage of ESBL-producing Escherichia coli is associated with strains of low pathogenicity: a Swedish nationwide study. J Antimicrob Chemother, 2017. 72(2): p. 582-588.

230. van der Mee-Marquet, N.L., et al., Marked increase in incidence for bloodstream infections due to Escherichia coli, a side effect of previous antibiotic therapy in the elderly. Front Microbiol, 2015. 6: p. 646.

231. Doi, Y., A. Iovleva, and R.A. Bonomo, The ecology of extended-spectrum betalactamases (ESBLs) in the developed world. J Travel Med, 2017. 24(suppl_1): p. S44S51.

232. Huizinga, P., et al., Extended-spectrum beta-lactamase producing Enterobacteriaceae (ESBL-E) isolated from bean sprouts in the Netherlands. PLoS One, 2018. 13(8): p. e0203338.

233. European Centre for Disease Prevention and Control (ECDC), Summary of the latest data on antibiotic consumption in the European Union, ESAC-Net surveillance data November 2017, Available from:

https://ecdc.europa.eu/sites/portal/files/documents/Final_2017_EAAD_ESACNet_Summary-edited\%20-\%20FINALwith\%20erratum.pdf.

234. Bengtsson, B. and C. Greko, Antibiotic resistance--consequences for animal health, welfare, and food production. Ups J Med Sci, 2014. 119(2): p. 96-102.

235. Falagas, M.E., P.K. Koletsi, and I.A. Bliziotis, The diversity of definitions of multidrug-resistant (MDR) and pandrug-resistant (PDR) Acinetobacter baumannii and Pseudomonas aeruginosa. J Med Microbiol, 2006. 55(Pt 12): p. 1619-29.

236. Magiorakos, A.P., et al., Multidrug-resistant, extensively drug-resistant and pandrugresistant bacteria: an international expert proposal for interim standard definitions for acquired resistance. Clin Microbiol Infect, 2012. 18(3): p. 268-81.

237. Lim, C.J., et al., Community-onset bloodstream infection with multidrug-resistant organisms: a matched case-control study. BMC Infect Dis, 2014. 14: p. 126.

238. Blot, S., et al., Nosocomial bacteremia caused by antibiotic-resistant gram-negative bacteria in critically ill patients: clinical outcome and length of hospitalization. Clin Infect Dis, 2002. 34(12): p. 1600-6.

239. Lambert, M.L., et al., Clinical outcomes of health-care-associated infections and antimicrobial resistance in patients admitted to European intensive-care units: a cohort study. Lancet Infect Dis, 2011. 11(1): p. 30-8. 
240. Bai, A.D., et al., Impact of Infectious Disease Consultation on Quality of Care, Mortality, and Length of Stay in Staphylococcus aureus Bacteremia: Results From a Large Multicenter Cohort Study. Clin Infect Dis, 2015. 60(10): p. 1451-61.

241. Cassini, A., et al., Attributable deaths and disability-adjusted life-years caused by infections with antibiotic-resistant bacteria in the EU and the European Economic Area in 2015: a population-level modelling analysis. Lancet Infect Dis, 2019. 19(1): p. 56-66.

242. Melzer, M. and I. Petersen, Mortality following bacteraemic infection caused by extended spectrum beta-lactamase (ESBL) producing E. coli compared to non-ESBL producing E. coli. J Infect, 2007. 55(3): p. 254-9.

243. Möller et al, Evaluation of antibiotic consumption, resistance and treatment guidelines in Nordic Hospitals, Poster NSCMID, Reykjavik Aug 19, 2018.

244. Knudsen, J.D., S.E. Andersen, and G. Bispebjerg Intervention, A multidisciplinary intervention to reduce infections of ESBL-and AmpC-producing, gram-negative bacteria at a University Hospital. PLoS One, 2014. 9(1): p. e86457.

245. Swedish Strama antibiotic stewardship programme. Available; https://www.folkhalsomyndigheten.se/the-public-health-agency-ofsweden/communicable-disease-control/antibiotics-and-antimicrobialresistance/swedish-work-on-containment-of-antibiotic-resistancel Accessed 2021-0310.

246. Neumark, T., et al., Trends in number of consultations and antibiotic prescriptions for respiratory tract infections between 1999 and 2005 in primary healthcare in Kalmar County, Southern Sweden. Scand J Prim Health Care, 2009. 27(1): p. 18-24.

247. Neumark, T., L. Brudin, and S. Molstad, Use of rapid diagnostic tests and choice of antibiotics in respiratory tract infections in primary healthcare--a 6-y follow-up study. Scand J Infect Dis, 2010. 42(2): p. 90-6.

248. Läkartidningen. <vid vanliga infektioner att ge eller inte ge antibiotika.pdf>. 2009. Available:

file:///C:/Users/5F5Z/AppData/Local/Microsoft/Windows/INetCache/IE/ICNJOL15/LK T0947s3162_3166.pdf. Accessed 2021-03-07. .

249. Wood, F., S. Simpson, and C.C. Butler, Socially responsible antibiotic choices in primary care: a qualitative study of GPs' decisions to prescribe broad-spectrum and fluroquinolone antibiotics. Fam Pract, 2007. 24(5): p. 427-34.

250. Joukhadar, C., et al., Impaired target site penetration of beta-lactams may account for therapeutic failure in patients with septic shock. Crit Care Med, 2001. 29(2): p. 38591.

251. Kumar, A., An alternate pathophysiologic paradigm of sepsis and septic shock: implications for optimizing antimicrobial therapy. Virulence, 2014. 5(1): p. 80-97.

252. Lindberg, O., L. De Geer, and M.S. Chew, Nonadherence to antibiotic guidelines in patients admitted to ICU with sepsis is associated with increased mortality: A registry-based, retrospective cohort study. Eur J Anaesthesiol, 2020. 37(2): p. 113120.

253. Roberts, J.A., et al., DALI: defining antibiotic levels in intensive care unit patients: are current beta-lactam antibiotic doses sufficient for critically ill patients? Clin Infect Dis, 2014. 58(8): p. 1072-83.

254. Thallinger, C., et al., Effect of severity of sepsis on tissue concentrations of linezolid. $\mathrm{J}$ Antimicrob Chemother, 2008. 61(1): p. 173-6.

255. Swedish-Association-of-Infectious-Diseases, Vårdprogram: Sepsis och septisk chocktidig identifiering och initial handläggning, Available 2021-03-7, from: 
https://infektion.net/wp-content/uploads/2018/06/revision-sepsis-och-septisk-chock-

180626.pdf. .

256. Whiles, B.B., A.S. Deis, and S.Q. Simpson, Increased Time to Initial Antimicrobial Administration Is Associated With Progression to Septic Shock in Severe Sepsis Patients. Crit Care Med, 2017. 45(4): p. 623-629.

257. Smyth, M.A., S.J. Brace-McDonnell, and G.D. Perkins, Identification of adults with sepsis in the prehospital environment: a systematic review. BMJ Open, 2016. 6(8): p. $\mathrm{e} 011218$.

258. Lane, D.J., et al., Screening strategies to identify sepsis in the prehospital setting: a validation study. CMAJ, 2020. 192(10): p. E230-E239.

259. Lane, D., et al., Prehospital management and identification of sepsis by emergency medical services: a systematic review. Emerg Med J, 2016. 33(6): p. 408-13.

260. Rodriguez-Bano, J., et al., Risk factors and prognosis of nosocomial bloodstream infections caused by extended-spectrum-beta-lactamase-producing Escherichia coli. $\mathrm{J}$ Clin Microbiol, 2010. 48(5): p. 1726-31.

261. Ben-Ami, R., et al., Influx of extended-spectrum beta-lactamase-producing enterobacteriaceae into the hospital. Clin Infect Dis, 2006. 42(7): p. 925-34.

262. Marchaim, D., et al., National multicenter study of predictors and outcomes of bacteremia upon hospital admission caused by Enterobacteriaceae producing extended-spectrum beta-lactamases. Antimicrob Agents Chemother, 2010. 54(12): p. 5099-104.

263. Park, S.H., et al., Emergence of extended-spectrum beta-lactamase-producing escherichia coli as a cause of community-onset bacteremia in South Korea: risk factors and clinical outcomes. Microb Drug Resist, 2011. 17(4): p. 537-44.

264. Park, Y.S., et al., Risk factors and molecular epidemiology of community-onset extended-spectrum beta-lactamase-producing Escherichia coli bacteremia. Yonsei Med J, 2014. 55(2): p. 467-75.

265. Rottier, W.C., et al., Predictive value of prior colonization and antibiotic use for thirdgeneration cephalosporin-resistant enterobacteriaceae bacteremia in patients with sepsis. Clin Infect Dis, 2015. 60(11): p. 1622-30.

266. Reddy, E.A., A.V. Shaw, and J.A. Crump, Community-acquired bloodstream infections in Africa: a systematic review and meta-analysis. Lancet Infect Dis, 2010. 10(6): p. 417-32.

267. Leibovici, L., et al., The benefit of appropriate empirical antibiotic treatment in patients with bloodstream infection. J Intern Med, 1998. 244(5): p. 379-86.

268. Jaganath, D., et al., Staphylococcus aureus Bacteremia Incidence and Methicillin Resistance in Rural Thailand, 2006-2014. Am J Trop Med Hyg, 2018. 99(1): p. 155163.

269. Sawatwong, P., et al., High Burden of Extended-Spectrum beta-Lactamase-Producing Escherichia coli and Klebsiella pneumoniae Bacteremia in Older Adults: A SevenYear Study in Two Rural Thai Provinces. Am J Trop Med Hyg, 2019. 100(4): p. 943951.

270. Whistler, T., et al., Epidemiology and antimicrobial resistance of invasive nontyphoidal Salmonellosis in rural Thailand from 2006-2014. PLoS Neg1 Trop Dis, 2018. 12(8): p. e0006718.

271. Iwashyna, T.J., et al., Long-term cognitive impairment and functional disability among survivors of severe sepsis. JAMA, 2010. 304(16): p. 1787-94.

272. Nielsen, S.L., et al., Decreasing incidence rates of bacteremia: a 9-year populationbased study. J Infect, 2014. 69(1): p. 51-9. 
273. Nosocomial infection rates for interhospital comparison: limitations and possible solutions. A Report from the National Nosocomial Infections Surveillance (NNIS) System. Infect Control Hosp Epidemiol, 1991. 12(10): p. 609-21.

274. Freeman, J.T., et al., Bloodstream infection with extended-spectrum beta-lactamaseproducing Enterobacteriaceae at a tertiary care hospital in New Zealand: risk factors and outcomes. Int J Infect Dis, 2012. 16(5): p. e371-4.

275. Karfunkel, D., et al., The emergence and dissemination of CTX-M-producing Escherichia coli sequence type 131 causing community-onset bacteremia in Israel. Eur J Clin Microbiol Infect Dis, 2013. 32(4): p. 513-21.

276. Laupland, K.B., et al., Community-onset extended-spectrum beta-lactamase (ESBL) producing Escherichia coli: importance of international travel. J Infect, 2008. 57(6): p. 441-8.

277. van der Bij, A.K. and J.D. Pitout, The role of international travel in the worldwide spread of multiresistant Enterobacteriaceae. J Antimicrob Chemother, 2012. 67(9): p. 2090-100.

278. Walsh, T.R., et al., Dissemination of NDM-1 positive bacteria in the New Delhi environment and its implications for human health: an environmental point prevalence study. Lancet Infect Dis, 2011. 11(5): p. 355-62.

279. Adams-Sapper, S., et al., Clonal composition and community clustering of drugsusceptible and -resistant Escherichia coli isolates from bloodstream infections. Antimicrob Agents Chemother, 2013. 57(1): p. 490-7.

280. Banerjee, R., et al., The clonal distribution and diversity of extraintestinal Escherichia coli isolates vary according to patient characteristics. Antimicrob Agents Chemother, 2013. 57(12): p. 5912-7.

281. Colpan, A., et al., Escherichia coli sequence type 131 (ST131) subclone H30 as an emergent multidrug-resistant pathogen among US veterans. Clin Infect Dis, 2013. 57(9): p. 1256-65.

282. Johnson, J.R., et al., Abrupt emergence of a single dominant multidrug-resistant strain of Escherichia coli. J Infect Dis, 2013. 207(6): p. 919-28.

283. Price, L.B., et al., The epidemic of extended-spectrum-beta-lactamase-producing Escherichia coli ST131 is driven by a single highly pathogenic subclone, H30-Rx. mBio, 2013. 4(6): p. e00377-13.

284. Davenport, E.E., et al., Genomic landscape of the individual host response and outcomes in sepsis: a prospective cohort study. Lancet Respir Med, 2016. 4(4): p. 25971.

285. Clatworthy, A.E., E. Pierson, and D.T. Hung, Targeting virulence: a new paradigm for antimicrobial therapy. Nat Chem Biol, 2007. 3(9): p. 541-8.

286. Dickey, S.W., G.Y.C. Cheung, and M. Otto, Different drugs for bad bugs: antivirulence strategies in the age of antibiotic resistance. Nat Rev Drug Discov, 2017. 16(7): p. 457-471. 


\section{Papers}

The papers associated with this thesis have been removed for copyright reasons. For more details about these see:

http://urn.kb.se/resolve?urn=urn:nbn:se:liu:diva-181406 


\section{FACULTY OF MEDICINE AND HEALTH SCIENCES}

Linköping University Medical Dissertation No. 1794, 2021

Department of Biomedical and Clinical Sciences

Linköping University

SE-581 83 Linköping, Sweden

www.liu.se 